\title{
The Epistemic Contract of Bisexual Erasure
}

\author{
Kenji Yoshino*
}

In this article, Professor Kenji Yoshino seeks to explain why the category of bisexuality has been erased in contemporary American political and legal discourse. He first argues that the invisibility of bisexuality relative to homosexuality does not reflect the incidences of those orientations in the population. Defining bisexuality as the possession of more than incidental desire for both sexes, Yoshino shows that the major sexuality studies demonstrate that the incidence of bisexuality is in fact greater than or comparable to the incidence of homosexuality. Yoshino explains the erasure of bisexuality by positing that both self-identified heterosexuals and self-identified homosexuals have overlapping interests in the erasure of bisexuality that lead them into an "epistemic contract" of bisexual erasure. These interests include: (1) the stabilization of exclusive sexual orientation categories; (2) the retention of sex as an important diacritical axis; and (3) the protection of norms of monogamy. Noting that such contracts tend to become visible only when they are challenged, Yoshino describes how bisexuals have increasingly contested their own erasure. Finally, Yoshino examines the effects of bisexual invisibility and visibility in the legal realm, focusing on the sexual harassment jurisprudence of recent decades.

* Associate Professor, Yale Law School. I thank Akhil Amar, Ian Ayres, Jennifer Gerarda Brown, Ariela Dubler, Bill Eskridge, Oren Izenberg, Robert Post, Bill Rubenstein, Vicki Schultz, Reva Siegel, and Amanda Tyler. I am also grateful to participants in workshops at Columbia Law School, Fordham Law School, and Yale Law School, as well as students in my Theorizing Sexuality seminar at Yale and Larry Lessig's Advanced Constitutional Law seminar at Harvard. Rick Baker, Romana Mancini, Ravenna Michalsen, Zachary Potter, Rose Saxe, and Eric Sonnenschein supplied excellent research assistance. 


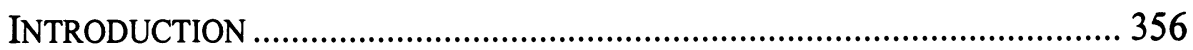

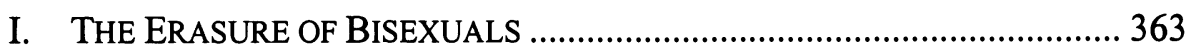

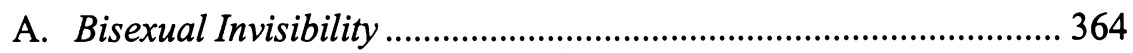

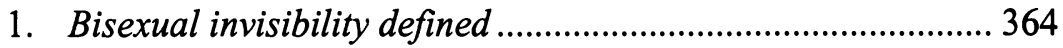

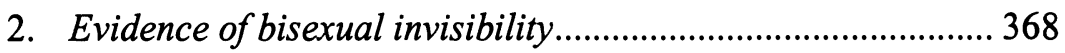

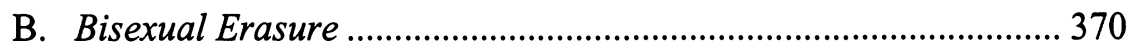

1. Bisexuality defined ................................................................. 370

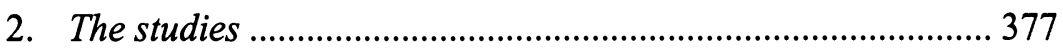

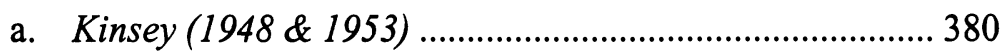

b. Masters and Johnson (1979) ........................................... 382

c. Janus and Janus (1993)..................................................... 383

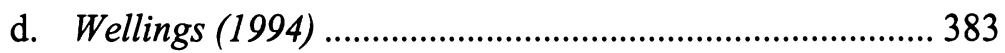

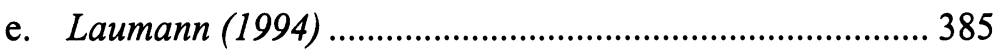

f. Critiques of the studies ....................................................... 386

C. Bisexual Erasure as a Cause of Bisexual Invisibility ..................... 388

II. THE EPISTEMIC CONTRACT OF BISEXUAL ERASURE ............................ 388

A. Different Explanations …………………………....................... 389

B. The Epistemic Contract Defined .................................................. 391

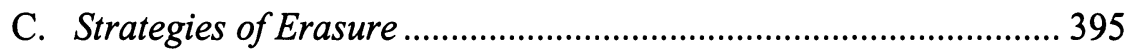

1. Straight deployments of the strategies ........................................ 395

2. Gay deployments of the strategies ............................................ 397

D. The Epistemic Contract as a Cause of Bisexual Erasure ............... 399

III. MonoseXUAL INVESTMENTS IN THE EPISTEMIC CONTRACT .............. 399

A. Stabilization of Sexual Orientation ................................................ 400

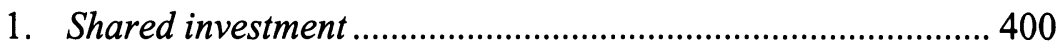

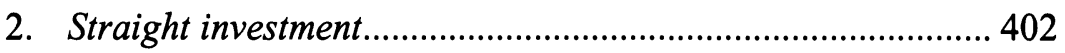

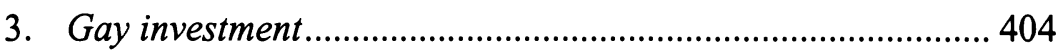

B. Bisexuality Destabilizes the Primacy of Sex ................................... 410

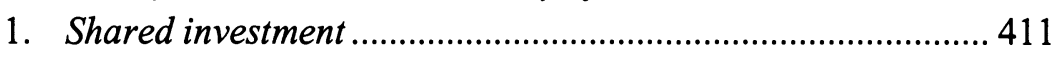

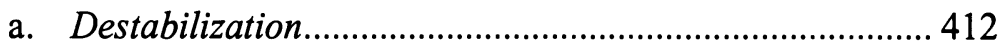

b. The tension between public and private
treatments of sex

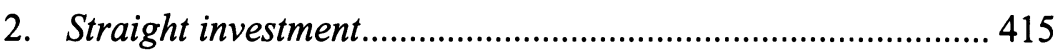

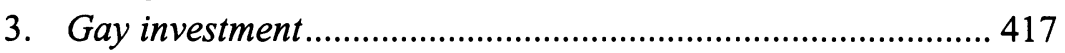


C. Bisexuality Destabilizes Norms of Monogamy ..............................420

1. Shared investment ................................................................... 421

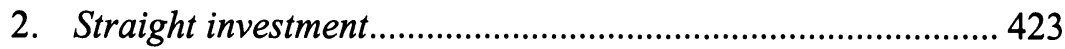

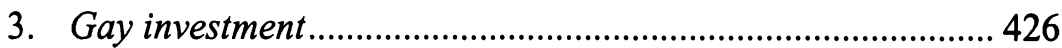

D. Overlapping Monosexual Investments as a Cause

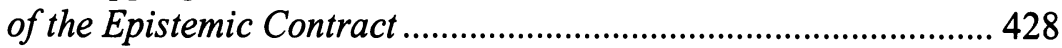

IV. SELF-IDENTIFIED BISEXUALS AND THE EPISTEMIC CONTRACT ........... 429

A. Bisexual Capitulation to the Epistemic Contract ...........................430

B. Bisexual Resistance to the Epistemic Contract .............................. 431

C. The Dissolution of the Epistemic Contract ...................................... 434

V. BISEXUALITY AND SEXUAL HARASSMENT LAW ..................................... 434

A. A Summary of the Development of the Sexual Harassment Jurisprudence.

B. Bisexual Visibility-The Recognition and Closing of the Bisexual Harassment Exemption.

1. The recognition of the bisexual harassment exemptionbisexual visibility

2. (Incoherently) closing the bisexual harassment exemption-bisexual invisibility

3. (Coherently) closing the bisexual harassment exemption - bisexual visibility (again)

C. Recognizing and Closing the Horseplay Exemption

1. Understanding horseplaythe homosocial and the homoerotic

2. Recognizing the horseplay exemptionbisexual invisibility

3. Closing the horseplay exemptionbisexual visibility

D. Sexual Harassment at a Crossroads................................................. 454

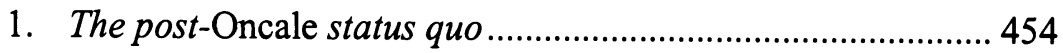

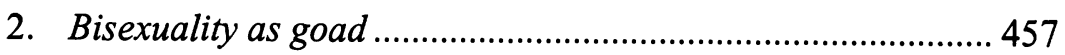

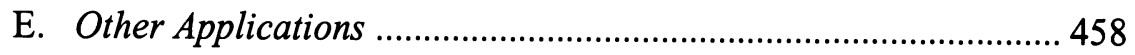

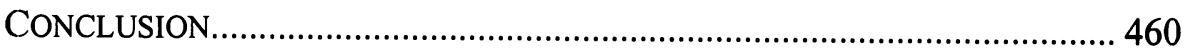




\section{INTRODUCTION}

Teaching a seminar on Sexual Orientation and the Law, I faced an old inconsistency so frontally that it became difficult to avoid giving it sustained attention. I began the course in what appears to be a common way, ${ }^{1}$ by posing basic questions about sexual orientation. I asked why contemporary American society ${ }^{2}$ organizes people according to their sexualities; ${ }^{3}$ why we do so on the basis of sexual orientation in particular; 4 and why, when classifying by sexual orientation, we insist on doing so with the binary system of heterosexual and homosexual.5 In discussing the last question, I adduced the

1. A leading casebook on sexual orientation and the law, for example, begins with such an introductory unit. See WILlIAM B. RUBENSTEIN, CASES AND MATERIALS ON SEXUAL ORIENTATION AND THE LAW 1-40 (2d ed. 1997) (presenting background materials discussing sexual classifications).

2. These temporal and geographical restrictions apply to this entire analysis. These restrictions partially recognize that the concept of orientation is culturally specific. See note 77 infra and accompanying text (describing Latin bisexuality). That recognition, however, will unfortunately be incomplete, insofar as it ignores variations within modern American society based on, for example, culture, race, and class. See, e.g., Will Roscoe, How to Become a Beardache: Toward a Unified Analysis of Gender Diversity, in THIRD SEX, THIRD GENDER: BEYOND SEXUAL DIMORPHISM IN CULTURE AND HISTORY 329, 330-49 (Gilbert Herdt ed., 1994) (describing the Native American berdache, an identity based on gender atypicality that cuts across the orientation categories considered here, as an identity that is more socially salient in many Native American societies than those orientation categories).

3. Resistance to the classification of persons according to their sexualities can be seen in that usage of the word "queer" which refers to individuals who fall outside of the realm of the "normal," either because of their sexuality or for some other reason. See Michael Warner, Introduction to FEAR OF A QUEER PlaNET: QUEER POLITICS AND SOCIAL THEORY vii, xxvi-xxviii (Michael Warner ed., 1993). This usage's "aggressive impulse of generalization," id. at xxvi, resists the reification of sexuality as an axis of demarcation by recasting the conflict between sexual deviance and sexual normalcy as one between social deviance and social normalcy.

4. Resistance to the classification of persons according to their sexual orientations can be found in Eve Sedgwick's provocative list of alternative classifications. See EVE KOSOFSKY SEDGWICK, EPISTEMOLOGY OF THE CLOSET 25-26 (1990). Sedgwick notes that even if we set out to distinguish between people based on their sexualities, many other axes besides sex of object choice are available. See id. at 25 . For example, "[s]exuality makes up a large share of the selfperceived identity of some people, a small share of others"; "[s]ome people spend a lot of time thinking about sex, others little"; and "[s]ome people like to have a lot of sex, others little or none." Id. Indeed, Sedgwick contends that the rise of sex of object choice as the critical axis of definition was a contingent and puzzling historical development out of an era in which such other axes had analogous diacritical force. See id. at 8-9.

5. Resistance to the classification of persons according to a binary system of sexual orientation can be found in Alfred Kinsey's classic statement:

Males do not represent two discrete populations, heterosexual and homosexual. The world is not to be divided into sheep and goats. Not all things are black nor all things white. It is a fundamental of taxonomy that nature rarely deals with discrete categories. Only the human mind invents categories and tries to force facts into separated pigeon-holes. The living world is a continuum in each and every one of its aspects. The sooner we learn this concerning human sexual behavior the sooner we shall reach a sound understanding of the realities of sex.

AlfRed C. Kinsey, WARdell B. Pomeroy \& Clyde E. MARTIN, SEXUAl BehaVior IN the HumAN MALE 639 (1948) [hereinafter KINSEY ET AL., MALE]. 
view-powerful in modern American culture from at least the publication of the Kinsey studies ${ }^{6}$ onward - that sexual orientation arrays itself along a continuum from exclusive heterosexuality to exclusive homosexuality. ${ }^{7}$ I noted that this view encouraged us to think of the straight/gay binary as defining the ends of a continuum that could be stretched, accordion-like, to accommodate ever finer gradations of cross-sex and same-sex desire. This meant recognizing a group - often called bisexuals - on the intermediate stretch of the continuum, as well as the possibility of a group-sometimes called asexuals-not represented on the continuum at all. ${ }^{8}$ Indeed, I argued

6. Alfred C. Kinsey, Wardell B. Pomeroy, Clyde E. Martin \& PaUl Gebhard, SEXUAL BEHAVIOR IN THE HUMAN FEMALE (1953) [hereinafter KINSEY ET AL., FEMALE]; KINSEY ET AL., MALE, supra note 5.

7. See Carol Queen, Sexual Diversity and Bisexual Identity, in BISEXUAL POLITICS: THEORIES, QUERIES, \& VISIONS 151, 152 (Naomi Tucker ed., 1995) (noting the importance of the Kinsey continuum).

8. It is with some regret that I have decided not to attempt a systematic discussion of asexuals in this article, especially since asexuals are, if anything, more likely than bisexuals to be erased in sexuality discourse. To concede that there are two forms of desire-cross-sex and same-sex desire-is to recognize the analytic possibility of at least four kinds of persons. These include: (1) those who harbor cross-sex but not same-sex desire; (2) those who harbor same-sex but not crosssex desire; (3) those who harbor both forms of desire; and (4) those who harbor neither form of desire. Yet even those who acknowledge that orientation arrays itself on a continuum spanning the first three categories often ignore the fact that the continuum fails to represent the fourth. This is somewhat surprising, as the number of individuals in this category is not insignificant. See Naomi Mezey, Dismantling the Wall: Bisexuality and the Possibilities of Sexual Identity Classification Based on Acts, 10 BERKELEY WOMEN's L.J. 98, 106-07 (1995) (citing the Kinsey report and noting that the number of asexuals is "not negligible"). Kinsey, for example, found that asexuals included 14 to 19 percent of unmarried women between the ages of twenty and thirty-five. See KINSEY ET AL., FEMALE, supra note 6, at 499.

My regret is made keen by the convergences between bisexual and asexual erasure, most notably the refusal by both self-identified straights and self-identified gays to acknowledge either category. Thus asexuals, like bisexuals, are prone to being accused of duplicity or false consciousness, or, more specifically, of being closeted gays. See JEFFREY S. NEVID, LOIS FICHNER-RATHUS \& SPENCER A. RATHUS, HUMAN SEXUALITY IN A WORLD OF DIVERSITY 302 (1995) (describing asexuals as a subset of homosexuals). See generally AlAN P. BELl \& MARTIN S. WEINBERG, HOMOSEXUALITIES: A STUDY OF DIVERSITY AMONG MEN AND WOMEN (1978) (discussing asexuals throughout as subsets of male and female homosexuals).

The decision to defer a discussion of asexuals for another day, however, is supported by the undertheorized divergences between bisexuality and asexuality, which suggest that the two topics deserve separate analysis. While both doubled and absent desire appear to threaten straights and gays, they do so in quite different ways. To take one crude cut at that difference, consider the disparate ways in which the time-honored conflation of sexuality and sin ramifies across bisexuality and asexuality. If this conflation leads some to view bisexuals as particularly culpable because of their "promiscuous" desire for both sexes, see notes 353-393 infra and accompanying text, it leads some of the same people to view asexuals as particularly pure. See Lucinda J. Peach, From Spiritual Descriptions to Legal Prescriptions: Religious Imagery of Woman as "Fetal Container" in the Law, 10 J.L. \& RELIGION 73, 76 (1994) (noting that the two templates of the feminine in the Christian tradition are Eve and Mary, and that Mary, in contrast to Eve, is portrayed as pure, celibate, and asexual). But while such purity is often ascribed to celibacy, see, e.g., Gabrielle Brown, The Celibate Life Is Fulfilling, in HUMAN SEXUALITY 393, 395 (Bruno Leone et al. eds., 1985) (noting that celibacy "can be thought of as the desire for something more eternal, more permanent"), it is not obvious whether that ascription applies equally to the subset of celibates who are asexual. Celibacy 
that sexual orientation classifications that only used the two "monosexual" terms 9 "heterosexual" and "homosexual" were unstable and naive.

As soon as the introductory unit was over, however, the inconsistency occurred. I found myself and the class falling back into the very "unstable" usages I had worked hard to retire-specifically the usages of the words "heterosexual" and "homosexual" as mutually exclusive, cumulatively exhaustive terms. 10 While we sometimes rallied by using the word "queer" instead of "gay," 11 or by adding the rider "or bisexual" to "gay,"12 these efforts were token and fitful. In the face of legal discussions ${ }^{13}$ and academic commentary 14 that were relentless in reifying the straight/gay binary, it was difficult to hold the bisexual steadily visible, even as a spectral possibility. And while this failure to resist what I had criticized as a distortion was striking in a class that sought to treat the issue of sexual orientation with sophistication, it was simultaneously all too recognizable as an inconsistency that riddles more quotidian discourse. Many who would not deny that bisexuals exist when the subject of bisexuality arises can nonetheless revert to the straight/gay dichotomy when the topic shifts. 15 I myself can speak at length about bisexuals at one moment and then, in the next, field a question

may be pure because it constitutes a conquest of the baser desires of the body, see id.; if so, the celibate asexual's claim to purity is attenuated because his licentious desire is not overcome, but rather absent. And even if described as pure, the absence of desire may be viewed as a disquieting purity, insofar as our hedonic pleasure in others is viewed by some as a generative, fecundating, and humanizing force even (or perhaps especially) when sublimated. See Leon R. Kass, The Wisdom of Repugnance: Why We Should Ban the Cloning of Humans, 32 VAL. U. L. REV. 679, 691-92 (1998) ("Sexual desire ... is thus sublimated into erotic longing for wholeness . ..."). Thus, while bisexuality and asexuality may in some senses be viewed as simple opposites (oversexed v. undersexed), they share negative connotations. But these connotations, in turn, are differently negative.

9. Technically, "monosexuality" denotes the state of possessing one of the two traditional "sexes" (male or female), as opposed to having one of the two traditional "orientations" (heterosexual or homosexual). See 9 OXFORD ENGLISH DicTIONARY 1029, (2d ed. 1989) [hereinafter OED]. In this article, however, I follow the rising practice of using the term in the latter sense. See, e.g., RUTH COLKER, Hybrid: BiseXUALS, MUlTiRACIAls, AND OTHER Misfits UNDER AMERICAN LAW 16 (1996) [hereinafter COLKER, HYBRID]. sive).

10. See Mezey, supra note 8 , at 98 (describing the categories as exclusive and comprehen-

11. See MARJorie Garber, Vice Versa: BISEXUALITY AND THE EROTICISM OF EVERYDAY LIFE 62-66 (1995) (discussing "queer" as a means of including bisexuals within a coalition movement of sexual minorities).

12. See Liz A. Highleyman, Identity and Ideas: Strategies for Bisexuals, in BISEXUAL POLITICS, supra note 7, at 73, 83-86 (describing the "lesbigay" strategy of naming bisexuals alongside lesbians and gay men). ing text.

13. See, e.g., notes 48-52 infra and accompanying text; notes 503-534 infra and accompany-

14. See, e.g., notes 60-62 infra and accompanying text.

15. See Christopher James, Denying Complexity: The Dismissal and Appropriation of Bisexuality in Queer, Lesbian, and Gay Theory, in QUEER STUDIES: A LESBIAN, GAY, BISEXUAL, AND TRANSGENDER ANTHOLOGY 217, 226 (Brett Beemyn \& Mickey Eliason eds., 1996). 
such as "Is $X$ straight or gay?" without instinctively feeling as if an important possibility - the bisexual possibility - has been elided.

What is happening here? Why is bisexuality so invisible? If we interpret that invisibility as the product of erasure, why does that erasure occur? Why is bisexuality now becoming sufficiently visible that commentators have begun to theorize its invisibility as the result of erasure? How might contemporary sexual orientation politics and law look different if this trend toward visibility continues? This article will occupy itself with these questions.

Framing the questions in this way itself raises definitional issues. One of the difficult things about writing about sexuality is that there are too many distortions to correct at once. Some of these distortions must be accepted, although never without the fear that they will infect the result. I address two such distortions at the outset.

The first is a qualification of the definition of "bisexual." In asking why bisexuals are invisible and/or erased, I assume that there is a category of individuals who can usefully be denominated as bisexuals. I provisionally define that category below. ${ }^{16}$ I emphasize, however, that I do not present the category of bisexuals (or heterosexuals, homosexuals, or asexuals) as a natural kind awaiting detection. While individuals harboring both cross-sex and same-sex desire clearly exist, it does not necessarily follow that such individuals should be classified together as a group. Strictly speaking, then, the real question is not why bisexuals are erased: one cannot erase something that does not have material existence outside of one's writing it, and which one has never written. Rather the question is why we have divided the world of orientation into categories that tend to suppress the existence of bisexual desire.

Even bearing this in mind, however, I find it difficult to discuss that suppression without isolating the various constituencies that have interests in effectuating or resisting it. While socially constructed, the constituencies of heterosexual, homosexual, bisexual, and asexual have political and material consequence. Underscoring their contingency takes nothing away from their social importance or heuristic utility. I therefore self-consciously retain the terms.

The second issue is the definition of "sex." To possess "bi"-sexual desire implies the existence of two sexes-male and female. While bisexuality is sometimes seen as eroding the salience of the sex binary, ${ }^{17}$ it thus nominally reifies the premise that there are only two sexes. That premise has been contested on the grounds that a significant portion of the population is intersexed at birth, with genitalia that do not conform to the two conventional sex

16. See text accompanying notes 71-109 infra.

17. See text accompanying notes 314-352 infra. 
categories.18 Yet a man who is attracted to women and intersexed individuals, but not to men, is not considered a bisexual, because the intersexed do not count as a sex for these purposes. ${ }^{19}$ Bisexuality also suggests that these two sexes are defined biologically rather than culturally. ${ }^{20}$ This is the classic division made between anatomical sex and social gender. ${ }^{21}$ Thus a lesbian who is attracted to both "butch" and "femme" women will fail the classical definition of a bisexual, because even though she is attracted to two individuals who might be said to have different "genders," both of them are of the same "sex."

I will again leave both these premises-that there are two sexes (male and female) and that anatomical sex can be coherently distinguished from social gender-unchallenged for the purposes of this analysis. I wish to recognize these premises, however, as deeply contestable ones, and to gesture briefly toward the costs of leaving them unassailed. First, the intersexed occupy a place between the two conventionally ordained sexes (male and female) that the bisexual occupies between the two conventionally ordained orientations. Making bisexuality visible on the grounds that intermediate categories deserve social attention while letting intersexuality remain invisible thus creates an ironic asymmetry. More importantly, the elision of intersexuality represents a missed opportunity to interrogate orientation. For just as bisexuality challenges our conceptions of sex,22 so too might intersexuality be used to challenge our conceptions of orientation. To see this, think of the man who is attracted more to intersexed individuals than to either men or to women. ${ }^{23}$ What is this man's orientation? What if he is attracted only to the intersexed? Is the bisexual, who is sometimes understood to be "pansexual," also understood to be attracted to the intersexed?

More familiarly, the distinction between sex and gender has been under increasing fire in contemporary queer theory, such that its use requires de-

18. See SUZANNE J. KESSLER, LeSSONS FROM THE INTERSEXED 135 n.4 (1998) (noting estimate that the "frequency of intersexuality may be as high as 2 percent of live births").

19. See id. at 5 (arguing that the popular fascination with intersexed individuals may stem in part from the fact that one's heterosexual or homosexual status is not called into question by attraction to an intersexed person).

20. See, e.g., Martin S. Weinberg, Colin J. Williams \& Douglas W. Pryor, Dual ATTRACTION: UNDERSTANDING BIXSEXUALITY 4 (1994) (defining bisexuality according to sex rather than gender).

21. See Biddy Martin, Sexualities Without Genders and Other Queer Utopias, 24.2-3 DiACRITICS 104, 104 (1994).

22. See text accompanying notes $314-352$ infra.

23. There is a notable amount of pornography that depicts intersexed individuals, leading one to believe that some consumers may be particularly attracted to the intersexed. See KESSLER, supra note 18 , at $160 \mathrm{n} .82$ ("The attraction to intersexed bodies is far more common than what would be revealed in counting partners of the intersexed, as is evident in the abundant pornography available featuring actors with vaginas and standard-sized penises ...."). 
fense. ${ }^{24}$ The defense is purely pragmatic - bisexuals are simply not currently understood as people who are attracted to both genders, as opposed to sexes. While not attempted here, however, that extension should be theorized. This is because it is clearly true that people have gender orientations as well as sexual orientations - one can be attracted not to all men, but only to butch men, or not to all women, but only to femme women. Why are certain people attracted to both kinds of gender performance within one sex, while others limit themselves to people who perform their gender only in one way? The answer is doubtless linked to the ways in which they perceive and appreciate "biological" sex. Indeed, it is the strength of this link that has led theorists like Judith Butler to posit that there is no pre-discursive biological substrate of sex that can be distinguished from gender. ${ }^{25} \mathrm{Be}$ that as it may, this article leaves the work of theorizing the gender orientatation-bi- or otherwise-for another day.

That said, I can now assail the question of why bisexuals are invisible and/or erased in contemporary American culture. In Part I, I demonstrate that bisexuality is invisible relative to homosexuality and that this invisibility is better explained by bisexual erasure than by bisexual nonexistence. After defining bisexual invisibility, I show that bisexuals (under any plausible definition of bisexuality) are much less socially and politically visible than homosexuals. I acknowledge, however, that this discrepancy in visibility does not necessarily betoken bisexual erasure, as it could simply mean that there are fewer bisexuals than homosexuals in the population. Because determining the merit of this position requires a more precise definition of "bisexuality," I generate and defend a provisional definition of bisexuality as the ability to feel more than incidental sexual desire for both sexes. Using this definition, I look at what the major sexuality studies say about the incidence of bisexuality and homosexuality in the population. Two things are surprising about such an investigation. First, to my knowledge, no one has previously made such a systematic comparison. Second, when such an investigation is actually made, it reveals that each of the major sexuality studies demonstrates that the number of bisexuals is greater than or comparable to the number of homosexuals. This suggests that bisexual invisibility is not a reflection of the fact that there are fewer bisexuals than there are homosexuals in the population, but is rather a product of social erasure.

Having demonstrated erasure in Part I, I seek to explain it in Part II. I suggest that erasure occurs because the two dominant sexual orientation groups-self-identified straights and self-identified gays-have shared in-

24. See, e.g., JUdith BUTLER, GENDER TROUBLE: FEMINISM AND THE SUBVERSION OF IDENTITY 7 (1990) (describing the claim, central to her work, that "this construct called 'sex' is as culturally constructed as gender; indeed, perhaps it was always already gender, with the consequence that the distinction between sex and gender turns out to be no distinction at all").

25. See id. 
vestments in that erasure. It is as if these two groups, despite their other virulent disagreements, have agreed that bisexuals will be made invisible. I call this the epistemic contract of bisexual erasure. To support the existence of such a contract, I adduce evidence that self-identified straights and selfidentified gays both deploy the same three strategies of bisexual erasure: class erasure, individual erasure, and delegitimation.

In Part III, I describe the investments that both self-identified straights and self-identified gays have in bisexual erasure. These are: (1) an interest in stabilizing sexual orientation; (2) an interest in retaining sex as a dominant metric of differentiation; and (3) an interest in defending norms of monogamy. I disaggregate each interest into its three components: (1) the component shared by both straights and gays; (2) the component held only by straights; and (3) the component held only by gays.

The first investment monosexuals have in bisexual erasure is an interest in stabilizing sexual orientation. The component of that interest shared by both straights and gays is an interest in knowing one's place in the social order: both straights and gays value this knowledge because it relieves them of the anxiety of identity interrogation. Straights have a more specific interest in ensuring the stability of heterosexuality because that identity is privileged. Less intuitively, gays also have a specific interest in guarding the stability of homosexuality, insofar as they view that stability as the predicate for the "immutability defense" or for effective political mobilization. Bisexuality threatens all of these interests because it precludes both straights and gays from "proving" that they are either straight or gay. This is because straights (for example) can only prove that they are straight by adducing evidence of cross-sex desire. (They cannot adduce evidence of the absence of same-sex desire, as it is impossible to prove a negative.) But this means that straights can never definitively prove that they are straight in a world in which bisexuals exist, as the individual who adduces cross-sex desire could be either straight or bisexual, and there is no definitive way to arbitrate between those two possibilities. Bisexuality is thus threatening to all monosexuals because it makes it impossible to prove a monosexual identity.

The second interest monosexuals have in bisexual erasure is an interest in retaining the importance of sex as a distinguishing trait in society. Straights and gays have a shared investment in this because to be straight or to be gay is to discriminate erotically on the basis of sex. Straights have a specific interest in preserving the importance of sex because sex norms are currently read through a heterosexual matrix: to be a man or a woman in contemporary American society is in part defined by one's sexual attractiveness to the opposite sex. Gays also have a particular interest in sex distinctions, as homosexuality is often viewed as a way to engage in complete sex separatism - that is, as a means of creating single-sex communities that are bonded together erotically as well as socially and politically. Bisexuality 
endangers all of these interests because it posits a world in which sex need not (or should not) matter as much as monosexuals want it to matter. Indeed, bisexuals and asexuals are the only sexual orientation groups that have at least the capacity not to discriminate on the basis of sex in any aspect of their lives.

The final interest that monosexuals have in bisexual erasure is an interest in defending norms of monogamy. Both straights and gays share this interest, as the dominant ethic of contemporary American society favors dyadic relationships. Straights may have a particular interest in this insofar as the form of nonmonogamy associated with bisexuals has been connected to HIV infection, with bisexual "promiscuity" acting as a bridge (phantasmatically if not actually) between the "infected" gay population and the "uninfected" straight population. Gays may have a particular interest in monogamy insofar as they seek to assimilate into "mainstream" society. Bisexuality threatens all of these interests because bisexuals are often perceived to be "intrinsically" nonmonogamous.

Thus, along at least three different axes, both gays and straights have distinct but overlapping interests that are threatened by the concept of bisexuality. It is thus unsurprising that both of these sexual orientation groups collude in bisexual erasure.

In Part IV, I examine how self-identified bisexuals both capitulate to and resist the epistemic contract. I first show how the contract retards the degree to which individuals can articulate a bisexual identity. I then turn to the ways in which individuals articulating such an identity have begun to dissolve the contract. I hypothesize that this visibility will only increase over time, and I endorse this trend.

In Part V, I look at how bisexual invisibility and visibility affect practical outcomes in the legal realm. Taking the case of same-sex sexual harassment, I note that bisexuals have remained largely invisible in that jurisprudence, although they are more visible in this doctrinal area than in others. I then ask how that jurisprudence might be transformed if bisexuals were rendered more visible.

\section{THE ERASURE OF BISEXUALS}

That bisexuals are being erased will appear self-evident to many. Yet numerous conversations I have had on the subject of bisexuality have called into question the nature of the proposition (e.g., under what definition of bisexuality is erasure occurring?), if not its veracity (e.g., under a particular definition, are bisexuals really being erased?). Answering these questions is useful, not only to assuage the doubts of skeptics, but also to ensure that nonskeptics are talking about the same thing when they agree that bisexuals are being erased. I therefore treat bisexual erasure as a controversial proposition 
that must be proven rather than assumed. That proposition consists of two claims: first, that bisexuals are invisible; second, that this invisibility stems not from nonexistence, but rather from erasure.

\section{A. Bisexual Invisibility}

To show that bisexuals are invisible, I must specify and defend a definition of bisexual invisibility (as opposed to a definition of bisexuality), 26 and then produce evidence that bisexuals are invisible under this definition. Defining bisexual invisibility is somewhat difficult, as bisexuality exists at the intersection of many different kinds of social invisibility. Even when narrowly defined, however, bisexual invisibility is easy to prove.

\section{Bisexual invisibility defined.}

There are at least three causes of bisexual invisibility, and it will be useful to speak of each as creating a different kind of invisibility. ${ }^{27}$ The three invisibilities can be seen as nested within each other: the first affects straights, gays and bisexuals; the second affects only gays and bisexuals; and the third affects only bisexuals. In this article, I focus on the last kind of invisibility.

The first kind of invisibility arises from a general urge to keep all sexualities invisible, which leads to the invisibility not only of bisexuals, but also of homosexuals, and even of heterosexuals. As David Halperin has noted, sexuality discourse has always been haunted by "the ancient and persistent specter of sexual despecification." 28 Despite recent efforts to demys-

26. It may seem strange that I define "bisexual invisibility" before defining "bisexuality." See notes 71-109 infra and accompanying text. The order arises from the fact that I believe that bisexuals are invisible under any definition of bisexuality, such that I need not specify the definition of bisexuality in demonstrating bisexual invisibility.

27. In contrast to the way I have used the words in previous work, "invisibility" and "visibility" in this article refer to social rather than corporeal (in)visibility. See Kenji Yoshino, Assimilationist Bias in Equal Protection: The Visibility Presumption and the Case of "Don't Ask, Don't Tell," 108 YALE L.J. 485, 497-98 \& n.44 (1998) (using the word "invisibility" throughout to refer to "corporeal invisibility"). Corporeal visibility refers to "the perceptibility of traits such as skin color that manifest themselves on the physical body in a relatively permanent and recognizable way." Id. at 497. Social visibility, in contrast, "designates the perceptibility of nonphysical traits." Id. Social visibility includes "'declarative visibility,' which arises when a corporeally invisible trait is made visible through speech," id. at 497 n.44; "[p]olitical visibility, [which] 'arises when a person claims group membership as a central and constitutive feature of her identity,"' id. (quoting Kathryn Abrams, The Supreme Court, Visibility, and the "Politics of Presence," 50 VAND. L. REV. 411, 414 (1997)); and "programmatic visibility," which "'arises from group members' efforts to connect their group-based identities with a particular political interest or program," id. (quoting Abrams, supra, at 414). For the most part, the term "visibility" in this article will refer to the subset of social visibility that is political visibility.

28. David M. Halperin, SAINT Foucault: TOWARDS A Gay Hagiography 65 (1995). 
tify sex, "the erotic still arouses acute moral anxiety and confusion." 29 Thus it is still true that, as Richard Posner has noted, "[a]nyone in our society who wants to write about sex ... had better explain what the source of his interest in the subject is." ${ }^{30}$ In the law, squeamishness about sexuality causes even heterosexual sexual subjects to be shrouded in euphemism. For instance, a number of state statutes criminalizing sodomy denote heterosexual as well as homosexual sodomy no more specifically than as a "crime against nature." 31 As one legal encyclopedia puts it, the terms of these statutes "reflect the legislators' reluctance to set out in detail the elements of sodomy because of its loathsome nature." 32 That these chronically vague provisions ${ }^{33}$ have been upheld against void-for-vagueness challenges ${ }^{34}$ suggests that the judiciary shares the legislative squeamishness about sexuality. Judicial reticence about naming deviant heterosexual sexual practices can also be seen in the contexts of obscenity regulation ${ }^{35}$ and sexual harassment. ${ }^{36}$

29. JeFFrey WeEkS, SEXUALITY 1 (1986); see also JeFFrEy WEEKS, SEXUALITY AND ITS DiscontentS: MEANINGS, MYTHS \& MODERN SEXUALITIES 44 (1985) ("Sexuality is a fertile source of moral panic, arousing intimate questions about personal identity, and touching on crucial social boundaries.... This is what makes sex a particular site of ethical and political concern-and of fear and loathing.").

30. RICHARD A. POSNER, SEX AND REASON 1 (1992).

31. See, e.g., ARIZ. REV. STAT. § 13-1411 (1999) ("A person who knowingly and without force commits the infamous crime against nature with an adult is guilty of a class 3 misdemeanor."); IDAHO CODE § 18-6605 (1999) ("Every person who is guilty of the infamous crime against nature, committed with mankind or with any animal, is punishable by imprisonment in the state prison not less than five years."); MASS. GEN. LAWS ANN. ch. 272, § 34 (West 1992) ("Whoever commits the abominable and detestable crime against nature, either with mankind or with a beast, shall be punished by imprisonment in the state prison for not more than twenty years."); MICH. COMP. LAWS ANN. § 750.158 (West 1999) ("Any person who shall commit the abominable and detestable crime against nature either with mankind or with any animal shall be guilty of a felony ...."); MISS. CODE ANN. § 97-29-59 (1998) ("Every person who shall be convicted of the detestable and abominable crime against nature committed with mankind or with a beast, shall be punished by imprisonment in the penitentiary for a term of not more than ten years."); N.C. GEN. STAT. \& 14-177 (1999) ("If any person shall commit the crime against nature, with mankind or beast, he shall be punished as a Class I felon."); OKLA. STAT. ANN. tit. 21, § 886 (West 1999) ("Any person who is guilty of the detestable and abominable crime against nature, committed with mankind or with a beast, shall be guilty of a felony."). Unlike other "crime against nature" statutes, none of the above statutes goes on to define what constitutes a "crime against nature."

32. 70A AM. JUR. 2D Sodomy § 3 (1987) (authored by Lonnie E. Griffith, Jr.).

33. For a discussion of the vagueness of these statutes, see RUTHANN ROBSON, LESBIAN (OUT)LAW: SURVIVAL UNDER THE RULE OF LAW 47-57 (1992).

34. See, e.g., Rose v. Locke, 423 U.S. 48 (1975) (per curiam) (upholding Tennessee "crime against nature" statute against vagueness challenge); Wainwright v. Stone, 414 U.S. 21 (1973) (per curiam) (same for Florida statute); Hogan v. State, 441 P.2d 620 (Nev. 1968) (same for Nevada statute); Warner v. State, 489 P.2d 526 (Okla. Crim. App. 1971) (same for Oklahoma statute).

35. See A Book Named "John Cleland's Memoirs of a Woman of Pleasure" v. Massachusetts, 383 U.S. 413, 441 (1966) (Clark, J., dissenting) (noting that "quotations from typical episodes [of an allegedly obscene book] would so debase our Reports that I will not follow that course").

36. See Oncale v. Sundowner Offshore Servs., Inc., 523 U.S. 75, 77 (1998) (omitting graphic facts in sexual harassment case in the "interest of both brevity and dignity"). 
The second kind of invisibility relates specifically to same-sex desire. It can be seen in the treatment of same-sex desire as unspeakable. As Eve Sedgwick notes, the nonmedical terms for same-sex desire in the Christian tradition included "'that sin which should be neither named nor committed,' the 'detestable and abominable sin, amongst Christians not to be named,' ... 'things fearful to name,' ... [and] 'the love that dare not speak its name ...."' 37 In the law, the code of silence about same-sex desire can be seen in so-called "no promo homo" statutes, ${ }^{38}$ which prohibit public education likely to promote homosexuality. ${ }^{39}$ It can also be seen in the military's current "don't ask, don't tell" policy, in which articulations of same-sex desire are chilled.40 Unlike the first kind of invisibility, this invisibility does not pertain to cross-sex desire. Thus, heterosexuality may be promoted under the "no promo homo" statutes, ${ }^{41}$ and articulated under "don't ask, don't tell." 42 In both cases, however, bisexuals are made as invisible as homosexuals. This is because "unspeakable" same-sex desire is also a component of bisexuality. Despite their name, the "no promo homo" statutes also prohibit the promotion of bisexuality, either by explicitly encompassing bisexu-

37. SEDGWICK, supra note 4, at 202-03 (footnotes omitted).

38. See, $e \rightarrow$ Nan D. Hunter, Identity, Speech, and Equality, 79 VA. L. REV. 1695, 1702-06 (1993) (describing the genesis of these statutes).

39. See, e.g., ARIZ. REV. STAT. § 15-716(c) (1998) ("No district shall include in its course of study instruction which: (1) Promotes a homosexual life-style. (2) Portrays homosexuality as a positive alternative life-style. (3) Suggests that some methods of sex are safe methods of homosexual sex."); CONN. GEN. STATE. § 46a-81r (1997) ("Nothing in [the enumerated sections] shall be deemed or construed ... to authorize the promotion of homosexuality or bisexuality in education institutions ...."); LA. REV. STAT. ANN. §17-281(A)(3) (West 1999) ("No sex education course offered in the public schools of the state shall utilize any sexually explicit materials depicting male or female homosexual activity."); MINN. STAT. $§ 363.021$ (1999) ("Nothing in this chapter shall be construed to ... authorize or permit the promotion of homosexuality or bisexuality in education institutions or require the teaching in education institutions of homosexuality or bisexuality as an acceptable lifestyle ....”); TeX. Health \& SAFETy CODE ANN. § 85.007(b) (West 1992) ("The materials in the education programs intended for persons younger than 18 years of age must ... state that homosexual conduct is not an acceptable lifestyle ....").

40. See 10 U.S.C. $\S 654$ (b)(2) (1998) (noting that, in the absence of further findings, a member stating "that he or she is a homosexual or bisexual" will be separated from the armed forces). Because I allude repeatedly to the policy in this article, I briefly describe it here. The policy immediately predating "don't ask, don't tell" contained a categorical exclusion of homosexuals, noting that "[h]omosexuality [was] incompatible with military service." 32 C.F.R. pt. 41 app. A (1998) ("Enlisted Administrative Separations: Standards and Procedures"). After winning his first presidential election, then President-elect Bill Clinton maintained that he would lift the ban on gays in the military and permit gays to serve openly. See JANET E. HALLEY, DON'T: A READ-ER'S GUIDE TO THE MILITARY'S ANTI-GAY POLICY 20 (1999). This engendered massive resistance on the part of the military establishment. See id. at 21 . The current policy, colloquially known as "don't ask, don't tell," was framed as a compromise. See William N. Eskridge, Jr. \& Philip P. Frickey, The Supreme Court, 1993 Term-Foreword: Law as Equilibrium, 108 HARV. L. REV. 27, 92 (1994). Under this policy, gays can serve in the military, but they may not serve openly without risking separation. See 10 U.S.C. $\S 654$ (b)(2) (1998).

41. See note 39 supra.

42. See note 40 supra. 
ality within their interdictions or by prohibiting homosexual acts. ${ }^{43}$ And the "don't ask, don't tell" policy explicitly muzzles bisexuals as well as homosexuals-the "statements" portion of the statute asserts that the presumption of homosexual conduct is triggered if "the member has stated that he or she is a homosexual or bisexual." 44

The final kind of invisibility pertains only to bisexuality. Bisexual invisibility manifests itself in the studied omission of bisexuality in discussions of sexual orientation. One example among many 45 is an anthology of essays on sexual orientation entitled Homosexuality/Heterosexuality. 46 This elision carries over into the law, where discussions of sexual orientation almost invariably privilege the straight/gay binary. One example among many 47 is the recent Supreme Court opinion in Romer v. Evans. ${ }^{48}$ In that case, the Court found that Amendment 2 of Colorado's state constitution violated the federal Equal Protection Clause. Amendment 2 stated that there would be "No Protected Status Based on Homosexual, Lesbian or Bisexual Orientation." 49 The Amendment thus took the class of bisexuals seriously, probably because the municipal ordinances it overrode explicitly protected bisexuals. 50 The Court, however, subsumed bisexuals into the homosexual category, noting that it would refer to the "named class" protected by the ordinances "as homosexual persons or gays and lesbians." 51 Thus, the only references to bisexuals in the opinion occur in the quoted language of the ordinances and Amendment 2; when the Court speaks for itself, it speaks solely about homosexual persons. 52

Because I wish to consider how bisexuals qua bisexuals are being erased, I focus on the third kind of invisibility. Thus, bisexual invisibility is defined for the purposes of this article as that social invisibility that affects only bisexuals. In order to determine how significant that invisibility is, I must isolate its effects from the effects of the other kinds of invisibility. I can accomplish this isolation by comparing the relative visibility of bisexuality and

43. See note 39 supra.

44. 10 U.S.C. $\S 654(b)(2)$ (1998) (emphasis added).

45. For other examples, see notes 54-70 infra and accompanying text.

46. HOMOSEXUALITY/HETEROSEXUALITY: CONCEPTS OF SEXUAL ORIENTATION (David P. McWhirter, Stephanie A. Sanders \& June Machover Reinisch eds., 1990).

47. For other examples, see text accompanying notes 503-534 infra.

48. 517 U.S. 620 (1996).

49. Id. at 624 (quoting CoLo. ConST., art. II $\S 306$ (1992)).

50. See id. (citing DEN. REV. MUN. CODE, art. IV, $\S \S 28-91$ to 28-116 (1991); ASPEN MUN. CODE § 13-98 (1977); BOULDER REV. CODE §§ 12-1-1 to 12-1-11 (1987)).

51. Id.

52. This does not indicate that the Court was intending to exclude bisexuals from its protections, but rather that the Court permitted the homosexual category to absorb bisexuals. Yet this absorption, of course, is itself an example of bisexual invisibility. 
homosexuality. ${ }^{53}$ To demonstrate that bisexuality is invisible under my definition, I must demonstrate that bisexuality is less socially visible than homosexuality.

\section{Evidence of bisexual invisibility.}

Such a demonstration is easily made. On-line searches for the words "homosexuality" and "bisexuality" in mainstream newspapers, newsmagazines, and academic abstracts reveal a striking discrepancy in the incidence of the two terms. In the period from January 1, 1990 to November 30, 1999, the Los Angeles Times had 2790 documents mentioning "homosexuality" and 121 documents mentioning "bisexuality";54 USA Today had 1768 documents mentioning "homosexuality" and twenty-nine documents mentioning "bisexuality";55 and The Wall Street Journal had 396 documents mentioning "homosexuality" and nine documents mentioning "bisexuality." 56 In the same time period, Time magazine had 240 documents mentioning "homosexuality" and fifteen documents mentioning "bisexuality"; 57 U.S. News and World Report had 120 documents mentioning "homosexuality" and three documents mentioning "bisexuality";58 and The New Republic had 144 documents mentioning "homosexuality" and three documents mentioning "bisexuality." 59 While I expected much less of a discrepancy in moving from popular to academic sources, this proved not to be the case. In the same time period, the Social Sciences Abstract Database on Wilson Web had 1122 documents mentioning "homosexuality" and eighty-seven documents mentioning "bisexuality";60 the General Sciences Abstracts had 221 documents mentioning "homosexuality" and six documents mentioning "bisexuality"; 61 the Humanities Abstracts had 962 documents mentioning "homosexuality" and twenty-six documents mentioning "bisexuality." 62

The discrepancy between the relative visibility of homosexuality and bisexuality can be described sociologically as well as statistically. Robin Ochs

53. A comparison of bisexuality and heterosexuality would not isolate this kind of invisibility because bisexuality could be more invisible than heterosexuality due to the second kind of invisibility.

54. Search of WESTLAW, ALLNEWS Library, LAT File (Mar. 22, 1999).

55. Search of WESTLAW, ALLNEWS Library, USATD File (Mar. 22, 1999).

56. Search of WESTLAW, ALLNEWS Library, WSJ File (Mar. 22, 1999).

57. Search of WESTLAW, ALLNEWS Library, TIMEMAG File (Mar. 22, 1999).

58. Search of WESTLAW, ALLNEWS Library, USNWR File (Mar. 22, 1999).

59. Search of WESTLAW, ALLNEWS Library, NEWREPUB File (Mar. 22, 1999).

60. Search of General Science Abstracts Database, Wilson Web (Mar. 18, 1999) <http:// wilsonweb2.hwwilson.com/cgi-bin/auto_login.cgi>.

61. Search of General Science Abstracts Database, Wilson Web (Mar. 18, 1999) <http:// wilsonweb2.hwwilson.com/cgi-bin/auto_login.cgi>.

62. Search of Humanities Abstracts Database, Wilson Web (Mar. 18, 1999) <http:// wilsonweb2.hwwilson.com/cgi-bin/auto_login.cgi>. 
has argued that bisexuals are invisible not only relative to straights, but also relative to gays. ${ }^{63}$ She points out that while we sometimes suspend the general presumption that all individuals are straight, the presumption that replaces it is that all individuals within that context are gay.64 Thus, "[i]n most families, for example, members are presumed to be heterosexual; conversely, at a women's bar all the women present are presumed lesbians." 65 There are few contexts, however, in which an individual is presumed bisexual. In a similar vein, Marjorie Garber has observed that bisexuals have few recognizable symbols of their identity6--the pink and blue "biangle" is one of the few symbols specifically denoting bisexuality 67 and is much less culturally visible than the gay symbols ${ }^{68}$ of the pink triangle ${ }^{69}$ or the rainbow. ${ }^{70}$ Thus, even when the heterosexual presumption that all individuals are straight is suspended, it is replaced by the monosexual presumption that all individuals are straight or gay.

It is understandable that the heterosexual presumption has received more theoretical attention than the monosexual presumption. The erosion of the presumption that all individuals are heterosexual was obviously necessary to identify the fallback presumption that all individuals are heterosexual or homosexual. The evidence above demonstrates, however, that the monosexual presumption is powerful, and urgently requires such attention.

I will therefore take it to be relatively uncontroversial that bisexuals, howsoever defined, are less socially visible than homosexuals in contemporary American culture. What remains to be explored is the cause of this invisibility.

63. See Robin Ochs, Biphobia: It Goes More than Two Ways, in BISEXUALITY: THE Psychology AND Politics OF AN INVISIBLE MINORITY 217, 225 (Beth A. Firestein ed., 1996) [hereinafter INVISIBLE MINORITY].

64. See id.

65. Id.

66. See GARBER, supra note 11 , at 25 .

67. See id. (noting that "lavender and blue 'biangles' seem to go unrecognized").

68. It is true that these "gay" symbols have been appropriated for multiple other purposes. See id. ("Pink triangles ... have been taken over as "the province of every liberal-leaning Clinton supporter."'). But the inaugural gay meanings of these symbols still remain intact and widely understood.

69. See, e.g., Gays Revise Nazi Symbol, S.F. CHRON., June 29, 1992, at D5 (noting high visibility of pink triangles during Gay Pride Month); Deb Price, Concentration Camps' Pink Triangle Recalled at Holocaust Museum, STAR TRIB., May 5, 1993, at 3E (noting that "[t]he pink triangle is sported around the world ... as a sign of gay pride").

70. See, e.g., Thomas J. Brady, How Some Gays Choose to Show the Colors, PHILA. INQUIRER, Nov. 19, 1997, at D1 (noting rising popularity of rainbow as symbol of homosexuality); Deb Price, Rainbow Flag is Symbol of a United Gay People, STAR TRIB., Apr. 19, 1995, at 4E (describing utility of rainbow symbol in recognizing homosexuals). 


\section{B. Bisexual Erasure}

In discussing this project with peers, I was struck by how many of them agreed that bisexuals were invisible relative to homosexuals without believing that bisexuals were being erased. In their view, the scant visibility of bisexuals relative to homosexuals did not signify their "erasure," but rather accurately reflected their smaller relative numbers. Call this the "relative nonexistence thesis." The merit of this position depends on the numbers of bisexuals and homosexuals in the population. Those numbers in turn depend on the definitions of "bisexual" and "homosexual." I thus provide and defend a provisional definition of "bisexuality" (and, by doing so, provide and defend definitions of "homosexuality" and "heterosexuality"). I then apply this definition to a number of major sexuality studies to compare the relative incidences of bisexuality and homosexuality.

\section{Bisexuality defined.}

I discuss the definition of bisexuality with some care because the validity of my thesis depends up on this definition. Whether bisexual invisibility denotes bisexual erasure turns on how expansively or narrowly bisexuality is defined. To adopt whatever definition of bisexuality undergirds the conventional wisdom that " [e]veryone is bisexual," "71 for example, is to demonstrate bisexual erasure at the moment of definition. Similarly, to adopt whatever definition of bisexuality undergirds the countervailing conventional wisdom that "'[t]here is no such thing as bisexuality,"'72 is simultaneously to demonstrate bisexual nonerasure.

Neither definition is particularly satisfactory. The universalizing definition of bisexuality maximizes the number of persons erased, but only by dropping the threshold of bisexual ascription so low as arguably to empty the term of diacritical force. 73 The eradicating definition of bisexuality mini-

71. GARBER, supra note 11 , at 16 (quoting conventional wisdom); see also PAULA C. RUST, BiseXuality and the Challenge to Lesbian Politics: SEX, LOYALTY, aNd REVOlution 1 (1995) [hereinafter RUST, CHALLENGE] (quoting view that "[e]veryone is inherently bisexual").

72. GARBER, supra note 11 , at 16 (quoting conventional wisdom); see also RUST, CHALLENGE, supra note 71, at 1 (quoting view that bisexuality "does not exist").

73. This can be seen in the intuitive distance between the statement "Everyone is bisexual" and the statement "I am bisexual"- that is, in the ability of individuals to say the former without conceding the latter. At the level of formal logic, this makes no sense. If I am part of "everyone," and "everyone is bisexual," then I, too, must be bisexual. At the level of praxis, however, it is intelligible because the word "bisexual" in the first sentence is seen to have a sufficiently dilute significance (precisely because it is spread so thinly across the mass of humanity) as to have no consequence. In the second sentence, the word "bisexual" is seen to have a sufficiently potent significance (precisely because it refers to some, but not others, in the human population) as to have serious ramifications. Put in Sedgwickian terms, this is the difference between a universalizing discourse of bisexuality (in which bisexuality is a latent trait in all of us) and a minoritizing discourse of bisexuality (in which bisexuality is a trait that some, but not others, possess). See SEDGWICK, 
mizes the number of persons erased but only by raising the threshold of definition to dizzying heights. ${ }^{74}$ Eliminating these two endpoints, however, still leaves a vast spectrum of choice.

In staking out a definitional position, two issues must be defensibly resolved. The first is the axis or axes along which sexual orientation will be defined. The second is how expansively or narrowly to define a particular sexual orientation along the chosen axis or axes.

There are three axes along which sexual orientation is conventionally defined: desire, conduct, and self-identification. ${ }^{75}$ Definitions can rely on a single axis, or on a combination of the axes. ${ }^{76}$ The number of bisexuals will vary dramatically according to the permutation used. Consider, for example, this taxonomy of bisexualities constructed by a study using a pure conductbased definition:

[1] "Defense Bisexuality" (defending against homosexuality in societies where it is stigmatized), [2] "Latin Bisexuality" (the insertive role in certain "Mediterranean cultures" is not regarded as homosexual, so that men who participate in same-sex encounters may consider themselves nonetheless heterosexual), [3] "Ritual Bisexuality" (as with the Sambia of Papua-New Guinea, in which younger males fellate older men in order to ingest their "masculinizing" semen, a practice that is part of a rite of initiation, may continue for years, and is apparently replaced by exclusive heterosexuality after marriage), [4] "Married Bisexuality," [5] "Secondary Homosexuality" (more frequently called "situational bisexuality"- sex with same-sex partners in prisons or other single-sex institutions, in public parks or toilets, or for money), [6] "Equal Interest in Male and Female Partners" (so-called true bisexuality), [7] "Experimental Bisexuality," and [8] "Technical Bisexuality" (with partners who may be dressed as members of the other sex, or have had some form of gender reassignment: transsexuals or members of a "third sex" in some cultures). ${ }^{77}$

supra note 4, at 1 (using these terms in discussing the definitions of homosexuality and heterosexuality).

74. Indeed, there is a way in which the two positions converge in their extremity. $C f$. GARBER, supra note 11, at 105 (noting that bisexual invisibility can be "produced as a startling byproduct of omnipresence"). For if "everyone is bisexual" then the definition of bisexuality must be so anemic as to leave open the possibility that "no one is bisexual" in a less anemic sense. Conversely, if "no one is bisexual" then the definition of bisexuality must be so robust as to leave open the possibility that "everyone is bisexual" in some less robust sense. See Michael du Plessis, Blatantly Bisexual; or, Unthinking Queer Theory, in REPRESENTING BISEXUALITIES 19, 30 (Donald E. Hall \& Maria Pramaggiore eds., 1996) (noting that "[i]f everyone is bisexual, 'bisexuality' can no longer be a specific or pertinent feature").

75. See Edward O. Laumann, John H. Gagnon, Robert T. Michael \& Stuart Michaels, The Social Organization of Sexuality: SeXual Practices in the United STATES 290 (1994) [hereinafter LAUMANN ET AL.] (noting that "homosexuality" can refer to "same-gender behavior, desire, self-definition, or identification or some combination of these elements").

76. See id.

77. GARBER, supra note 11 , at 30 (numbering added). 
This array appears so vertiginously diverse that it might fairly be asked whether these individuals should all be characterized by the same term. ${ }^{78}$ In actuality, however, this array gives an oversimplified picture of bisexuality, insofar as it only uses one axis of definition.

For if a different axis were used, many of the individuals who fall into many of the above categories would not be characterized as bisexuals, and vice versa. Thus, if we relied on desire alone, no "defense bisexuals" would be considered bisexual, given that they only profess cross-sex desire to mitigate the stigma of possessing same-sex desire. ${ }^{79}$ Some "ritual bisexuals" and "situational bisexuals" might also fall out of the desire-based category. This is because these individuals could be engaged in same-sex conduct for reasons other than sexual desire (such as initiation into adult status in the case of the ritual bisexual ${ }^{80}$ or financial remuneration in the case of the situationally bisexual sex worker ${ }^{81}$ ). At the same time, however, we might expect many individuals who would not be characterized as bisexuals under a conductbased definition to be included under a desire-based definition. This would encompass all individuals who nursed unacted same-sex desires.

Similarly, if we defined bisexuality according to self-identification alone, "defense bisexuality" would probably be the only category that was not seriously diminished. "Latin bisexuals" engage in sexual conduct with both men and women but self-identify as heterosexual rather than as bisexual. ${ }^{82}$ And a significant portion of the men who engage in extramarital same-sex conduct, ${ }^{83}$ or who view their same-sex conduct as "experimental" 84 or "situational,"85 are likely to self-identify as straight.

Because the populations captured by the different axes are so different, the choice of axis (or combination of axes) is crucial. The choice cannot be made acontextually, but will depend on the purpose for which the definition is used. For example, the study that generated the taxonomy described above used a conduct-based definition because its purpose was to examine the role

78. Cf. id. at 31 (speculating about the usefulness of using the single term "bisexuality" to describe a similarly diverse array of activities and fantasies).

79. See Ronald C. Fox, Bisexuality in Perspective: A Review of Theory and Research, in INVISIBLE MINORITY, supra note 63, at 3, 22-23.

80. See id. at 23.

81. See Fritz KleIN, The BiseXUAl Option 19 (1978) ("Male prostitutes who allow themselves to be fellated for money often do not consider this a homosexual act, or consider themselves bisexual.").

82. See Fox, supra note 79, at 23.

83. See John J. Brownfain, A Study of the Married Bisexual Male: Paradox and Resolution, in BISEXUALITIES: THEORY AND RESEARCH 173, 173 (Fritz Klein \& Timothy J. Wolf eds., 1985) (noting evidence that "individuals who choose to live within a conventional marriage while simultaneously having significant love-sex relations with members of their own sex .... are not rare, only rarely identified").

84. See KLEIN, supra note 81, at 18.

85. See id. 
of bisexuality in the transmission of the Human Immunodeficiency Virus ("HIV"). ${ }^{86}$ This definition makes obvious sense because HIV is spread through sexual conduct rather than through desire or self-identification. ${ }^{87}$ However, neither this nor any other axis of definition will be valid across all contexts.

So which axis or combination of axes is best suited for our purposes? I believe that the answer is a pure desire-based definition. This may seem self-serving as the desire-based definition is likely to yield more bisexuals than a conduct-based or self-identification-based definition, 88 thereby making the claim of erasure easier to sustain.

But the purely desire-based definition of bisexuality can be defended against this criticism. One can frame that defense by (1) asking who is bisexual under a desire-based definition who would not be bisexual under a conduct-based or self-identification-based definition, and then (2) asking whether it is fair to call those individuals bisexual for the purposes of determining erasure. The analogy to homosexuality is useful. For when we ask those questions about homosexuality, the answers are that the desire-based definition includes those who have unacted same-sex desires and that it is clearly defensible to call those individuals homosexual. I assume that these individuals do not act out their desires through conduct or self-identification because of the stigma of homosexuality, and I assume that the inability to convert desire to conduct or self-identification is consequential to that individual (at least insofar as the desire is more than incidental). ${ }^{89}$ I would call the individual who possesses unexpressed same-sex desire a closeted homosexual rather than a heterosexual. Indeed, I would view the exclusion of such individuals from the definition of homosexuals for the purposes of demonstrating erasure to be ironic, as it would permit erasure to control that definition, to let erasure erase itself. And I would not expect much resistance to these analytic moves.

I believe that these moves will be much more strongly resisted when applied to bisexuality, but that they are nonetheless valid. The desire-based definition will include individuals who desire both sexes but who do not express that dual desire either through conduct or through speech. The resistance arises when this suppression is characterized as consequential. It is harder to argue that bisexuals are giving up an important aspect of their

86. See GARBER, supra note 11 , at 30 .

87. See Joseph P. Stokes, Kittiwut Taywaditep, Peter Vanable \& Daniel J. McKirnan, Bisexual Men, Sexual Behavior, and HIV/AIDS, in INVISIBLE MINORITY, supra note 63, at 149, 150-51.

88. See, e.g., COLKER, HYBRID, supra note 9, at 15 (noting that "[o]nly about 1 percent of the adult population identifies as bisexual," but that "nearly 4 percent acknowledge that they are attracted to people of both sexes") (citing Trip Gabriel, A New Generation Seems Ready to Give Bisexuality a Place in the Spectrum, N.Y. TIMES, June 12, 1995, at C10).

89. I discuss the restriction that the desire be more than incidental below. See notes 99-108 infra and accompanying text. 
identity since they are not being denied all satisfactory interpersonal sexual expression (as a homosexual in the same position arguably is) but merely sexual expression with one sex.90 In fact, the stereotype of bisexuals as "greedy" or "promiscuous" implies that bisexuals are asking for more than their due, such that they should be forced to give up sexual expression with one of the two sexes.91 Yet for the purposes of erasure, the inquiry is whether they are forgoing something rather than whether they should be forgoing it. And the answer to that positive, rather than normative, question is clearly affirmative. To the extent that bisexuals are not permitted to express their dual desires, they might fairly characterize themselves as harmed. To exclude the individual who has unexpressed dual desires again permits erasure to erase itself. For that reason, I believe that a purely desire-based definition of bisexuality is the most appropriate.

Even after desire is justified as the pertinent axis, we must determine how expansively or narrowly to define bisexuals based on desire. At one extreme, there is Freud's view that bisexual desire is a universal condition ${ }^{92}$-perhaps the most prestigious version of the "everyone is bisexual" position. At the other extreme is the view that only "true" or sex-blind bisexuals - those who have equal desire for men and women ${ }^{93}$-are bisexual, which asymptotically approaches the view that "no one is bisexual" depending on how seriously one takes the requirement of equality. 94 Isolating desire as the axis of definition thus still leaves the full spectrum of bisexual definition-from bisexual universality to bisexual nonexistence-available.

90. See Arthur A. Murphy \& John P. Ellington, Homosexuality and the Law: Tolerance and Containment II, 97 DICK. L. REV. 693, 709-10 (1993) (arguing that existing sodomy laws should be modified to exonerate "true homosexuals" but not bisexuals, on the ground that bisexuals can more easily modify their behavior).

91. See notes 353-357 infra and accompanying text.

92. See, e.g., Sigmund Freud, Analysis Terminable and Interminable, in 23 THE STANDARD EDITION OF THE COMPLETE PSYCHOLOGICAL WORKS OF SigMUND FREUd 211, 243 -44 (James Strachey trans., Hogarth Press 1973) (1937) [hereinafter WORKS OF SIGMUND FREUD] ("We have come to learn, however, that every human being is bisexual in this case and that his libido is distributed either in a manifest or latent fashion, over objects of both sexes."); Sigmund Freud, Civilization and Its Discontents, in 21 WORKS OF SIGMUND FREUD, supra, at 57, 105 (1930) ("Man is an animal organism ... with an unmistakably bisexual disposition."); Sigmund Freud, The Psychogenesis of a Case of Homosexuality in a Woman, in 18 WORKS OF SIGMUND FREUD, supra at 145, 158 (1920) ("In all of us, throughout life, the libido normally oscillates between male and female objects ...."); id. at 157 (noting "the universal bisexuality of human beings").

93. What it means to have "equal" desire for men and women is of course a deeply fraught question. Perhaps this is why true bisexuality is framed as "sex-blind" bisexuality-implying that, if bisexuals do not even "see" sex, they cannot disburse their desire unequally on the basis of sex. But, as discussed below, the rhetorical formulation of "sex-blindness" is somewhat misleading, as bisexuals can in fact tell the difference between men and women. And if the bisexual can differentiate, it seems unlikely that this differentiation will not affect her desire asymmetrically, given the power of sex as a diacritical trait in our society. See notes 314-318 infra and accompanying text.

94. See RUST, CHALLENGE, supra note 71, at $48-49$ (describing this definition of bisexuality and noting its restrictiveness). 
Here I choose a narrow view of bisexuality. I do not take this position because I reject the view that bisexuality is universal-I remain agnostic as to this point. Rather, I adopt this position because assuming universal bisexuality would make my argument too easy (and therefore too easy to dismiss).

I place two restrictions on my desire-based definition of bisexuality. The first restriction pertains to the nature of desire. Desire is a classic floating signifier, that is, a term without a clear referent. Especially in postmodern times, its ambiguity has been resolved in favor of an expansive definition. Thus, under a Foucaultian reading, sexual desire should not be distinguished from other pleasurable uses of the body. 95 And under a Sedgwickian reading, desire can incorporate its putative opposite, as in the theory that the homophobia of "homosexual panic" is in actuality fueled by an occluded, guilty, and surprised desire. ${ }^{96}$ But if the desire-based definition of bisexuality encompasses the nonsexual pleasure (and sexual displeasure) we feel in the company of other men and women, we are all indeed bisexuals.

To avoid such a dilution of the bisexual definition, I restrict the definition of desire to its more everyday meaning of "sexual appetite or lust."97 I thus take the categories of the "homosocial" and the "homosexual" (or, alternatively, the "hostile" and the "desirous") to be analytically distinct.98

The second restriction pertains to the frequency with which the desire is experienced. To be classified as a bisexual under my definition, an individual's sexual desire for each sex must be more than incidental. To understand this restriction, it is helpful to examine the analogous restrictions commonly placed on homosexuality. If Kinsey is to be believed, in the middle of this century, a single same-sex sexual experience was sufficient to brand an individual as a homosexual.99 That cultural consensus, if it ever existed, has

95. See 1 Michel Foucault, The History of SEXUALITY: AN INTRODUCTION 157-59 (Robert Hurley trans., Vintage Books 1990) (criticizing the privileging of sex over other economies of "bodies and pleasure").

96. See SEDGWICK, supra note 4, at 20. Sedgwick contends that "[j]udicially, a 'homosexual panic' defense for a person (typically a man) accused of antigay violence implies that his responsibility for the crime was diminished by a pathological psychological condition, perhaps brought on by an unwanted sexual advance from the man whom he then attacked." Id. at 19. Sedgwick goes on to observe that "the reason why this defense borrows the name of the (formerly rather obscure and little-diagnosed) psychiatric classification 'homosexual panic' is that it refers to the supposed uncertainty about his own sexual identity of the perpetrator ...." Id. at 20. Thus, the word "homosexual" in "homosexual panic" is aptly ambiguous, representing both the same-sex desire in the victim and the same-sex desire in the perpetrator. The ambiguity represents the transitivity (imagined or real) of same-sex desire, which could be described as the real cause of the panic.

97. 4 OED, supra note 9 , at 522 .

98. That these distinctions are made in many quarters, as in the case of sexual harassment, will be demonstrated below. See text accompanying notes 430-534 infra.

99. In 1948, Kinsey stated:

Everywhere in our society there is a tendency to consider an individual 'homosexual' if he is known to have had a single experience with another individual of his own sex. Under the law 
shifted in certain fora to one that holds that adventitious homosexual desire, even if manifested in explicit same-sex conduct, is not sufficient to strip an individual of heterosexual status. This latter view is perhaps best seen in the legal system - probably the preeminent cultural site in which public institutional determinations of sexual orientation are currently made. Congressional support for this view can be seen in the "don't ask, don't tell" statute.100 The statute generally makes homosexual conduct grounds for exclusion from the military.101 Yet it also contains an exemption through which an individual who has engaged in same-sex sexual conduct can remain in the military if he can demonstrate that such conduct is unlikely to recur. ${ }^{102}$ To the extent that we view Congress as attempting to weed out homosexuals, this so-called "queen-for-a-day" exemption 103 may be seen as a self-imposed check on labeling individuals as gay based on isolated same-sex sexual conduct. The judiciary also uses its interpretive faculty to restrict the definition of "homosexual" in this way. Judicial "queen-for-a-day" exemptions can be seen in the contexts of the civil service, 104 adoption, 105 and marriage. 106

an individual may receive the same penalty for a single homosexual experience that he would for a continuous record of experiences. In penal and mental institutions a male is likely to be rated 'homosexual' if he is discovered to have had a single contact with another male. In society at large, a male who has worked out a highly successful marital adjustment is likely to be rated 'homosexual' if the community learns about a single contact that he has had with another male.

KINSEY ET AL., MALE, supra note 5, at 647, 650.

100. 10 U.S.C. $\$ 654$ (1998).

101. The statute asserts that "[a] member of the armed forces shall be separated from the armed forces" if it is found "[ $t]$ hat the member has engaged in, attempted to engage in, or solicited another to engage in a homosexual act or acts . ..." 10 U.S.C. $§ 654(b)(1)(1998)$.

102. Even if a finding is made that a servicemember has engaged in homosexual conduct, the member can evade separation if he or she can show, inter alia, that "such conduct is a departure from the member's usual and customary behavior," 10 U.S.C. $\$$ 654(b)(1)(A) (1998); "such conduct, under all the circumstances, is unlikely to recur," id. $\S 654(\mathrm{~b})(1)(\mathrm{B})$; and "the member does not have a propensity or intent to engage in homosexual acts," id. $\S 654(\mathrm{~b})(1)(\mathrm{E})$.

103. See HALLEY, supra note 40 , at 39-48.

104. In Dew v. Halaby, 317 F.2d 582, 583 (D.C. Cir. 1963), for example, the court accepted that a veteran was not homosexual even though he had had four homosexual encounters as an adolescent. The court quoted the psychiatric evaluation of the appellant William Dew:

"I decidedly do not believe [Dew] to have a homosexual personality disorder. I believe that the several incidents which he gave a history of having engaged in while age 18 and a freshman in college were isolated incidents primarily the result of his curiosity. I do not feel that isolated episodes of homosexual behavior can be considered abnormal or perverted, but rather a process of normal sexual investigation and curiosity. There is considerable evidence in the psychiatric literature that this allegation is true."

Id. at $583 \mathrm{n} .3$ (quoting testimony of psychiatrist).

105. See In re Opinion of the Justices, 530 A.2d 21, 24 (N.H. 1987) (excluding from definition of homosexual in a proposed adoption statute those persons who, for example, had had one homosexual experience during adolescence, but who then engaged in exclusively heterosexual behavior).

106. See Freitag v. Freitag, 242 N.Y.S.2d 643, 644 (N.Y. Sup. Ct. 1963) (deciding that man's confession of homosexual experiences prior to marriage did not mean he had "a true case of homosexuality"). 
These exemptions can be read as precluding aberrant acts of same-sex desire from tainting an individual with a homosexual identity.

Since bisexuality is also a stigmatized identity, we would expect that isolated homoerotic conduct would not earn an individual a bisexual ascription. The evidence already adduced supports this, as it suggests that individuals maintain heterosexual (rather than bisexual or homosexual) identities despite isolated homosexual conduct.107 My definition of bisexuality thus also excludes individuals who only have incidental or occasional same-sex desire. 108 In the interest of symmetry, my definition further excludes individuals who only have incidental or occasional cross-sex desire. This eliminates from the bisexual category those who, for example, experimented with homosexual activity in their young adulthood but then engaged in completely heterosexual activity for the rest of their adult lives (or vice versa).

To summarize, my analysis adopts a restricted desire-based definition of bisexuality. I first chose and defended desire as the axis of definition. I then placed two restrictions on the desire-based definition: (1) I defined desire as sexual appetite; and (2) I required more than incidental desire for both sexes before classifying an individual as bisexual. The definition is not presented as perfect, even for these purposes, but simply as workable. ${ }^{109}$ Having defined bisexuality in this way, I now examine what the major sexuality studies say about the relative incidence of bisexuality and homosexuality in the population.

\section{The studies.}

How do the major sexuality studies describe the relative numbers of bisexuals and homosexuals in the population? I expected to find many secondary sources that set forth the answer to this question. To my surprise, this proved not to be the case.110 This might be explained by a certain reluctance to use the existing studies for any purpose, given that they suffer from a number of problems. These include problems with methodology in particular studies, problems with obtaining truthful accounts in any study, and problems with calibrating orientation even assuming truthful accounts.

107. See notes 100-106 supra and accompanying text.

108. I address the question of what constitutes "incidental or occasional desire" below. See note 146 infra and accompanying text.

109. The definition, for example, makes no attempt to calibrate "the erotic appeal of transgression," GARBER, supra note 11, at 29; the intensity of desire, see generally Michael D. Storms, Theories of Sexual Orientation, 38 J. PERSONALITY \& SOC. PSYCHOL. 783 (1980); or the ways in which desire is connected to other aspects of an individual's self-conception (such as her politics or self-identification), see SEDGWICK, supra note 4, at 25-26.

110. The source that came closest to a systematic comparison of the relative incidence of bisexuality and homosexuality was Fox, supra note 79, at 16-17. Even this source, however, left out many of the major studies. 
These are serious issues that anyone deploying the studies should address, and I do so below.111

The belief that these problems are keeping people from utilizing the studies, however, is probably incorrect. The famous ten percent figure for homosexuals, for example, arises from the Kinsey studies.112 This suggests that it is not a generic use of the studies, but rather specific uses of them, that are being suppressed. The stark discrepancy between the popularization of the Kinsey findings on homosexuality and the lack of popularization of the Kinsey findings on bisexuality 113 suggests that bisexual invisibility provides an alternative explanation for the absence of such comparisons. I therefore thought it useful to go through the major sexuality studies and to make a systematic comparison.

In evaluating the "studies that purport to tell about sex in America,"114 Robert T. Michael and his colleagues discussed seven major studies 115 : the Kinsey study (which is actually comprised of separate studies for men ${ }^{116}$ and women ${ }^{117}$ ), the Playboy study, ${ }^{118}$ the Redbook study, ${ }^{119}$ the Hite study, ${ }^{120}$ the Masters and Johnson study, 121 the Janus and Janus study, ${ }^{122}$ and the Laumann study.123 They also attested to the reliability of two unnamed studies from France and England, which are identifiable based on their other work as the

111. See notes 177-186 infra and accompanying text.

112. See, e.g., BRUCE BAWER, A PlaCE AT THE TABLE: THE GAY INDIVIDUAL IN AMERICAN SOCIETY 82 (1993) ("From the appearance of the Kinsey Reports in 1948 and 1953 until very recently, it was a truism that about 10 percent of Americans are homosexual."); Jennifer Gerarda Brown, Competitive Federalism and the Legislative Incentives to Recognize Same-Sex Marriage, 68 S. CAL. L. REV. 745, 776 (1995) ("Since 1948, when Alfred C. Kinsey and his associates released their path-breaking study, Sexual Behavior in the Human Male, the oft-cited statistic is that ten percent of the population is gay.").

113. See Martin S. Weinberg, Colin J. Williams \& Douglas W. Pryor, Dual ATTRACTION: UNDERSTANDING BISEXUALITY 4 (1994) (noting that Kinsey's findings about bisexuality "have been generally ignored").

114. Robert T. Michael, John H. Gagnon, EdWARD O. LAUMANN \& Gina KolatTa, SEX IN AMERICA: A DEFINITIVE SURVEY 15 (1994). It bears note that this is a companion volume to the Laumann study, see LAUMANN ET AL., supra note 75 , written by the same researchers who conducted that study.

115. See MiCHAEL ET AL., supra note 114, at 15-25.

116. KINSEY ET AL., MALE, supra note 5.

117. KINSEY ET AL., FEMALE, supra note 6.

118. The Michael study does not provide a citation for the Playboy study. As there are a number of Playboy studies to which it could refer, I do not attempt a citation here.

119. Carol Tavris \& Susan SAdD, The Redbook Report on Female Sexuality (1976).

120. Shere hite, The Hite Report: A Nationwide Study on Female Sexuality (1979).

121. William H. Masters \& Virginia E. Johnson, Homosexuality in Perspective

122. Samuel S. Janus \& Cynthia L. Janus, The Janus Report on Sexual Behavior (1993).

123. LAUMANN ET AL., supra note 75. 
Spira study 124 and the Wellings study. 125 Other sources corroborate that this list is a fairly comprehensive rendering of the major sexuality studies. ${ }^{126}$

I narrowed this list of nine studies in two ways. First, I eliminated the studies - the Redbook study, 127 the Hite study, 128 and the Spira study ${ }^{129}$ - that did not include data sufficient to permit a comparison of the relative incidences of bisexuals and homosexuals in the population. I then eliminated the Playboy study because I thought a magazine study was likely to be less accurate and less credible than the other studies. 130 This left five studies that I felt usefully compared the incidences of bisexuality and homosexuality.

The five studies defined sexual orientation differently, each using some permutation of the three axes of desire, conduct, and self-identification. ${ }^{131}$ Where possible, I adjusted the definition used by the study to conform to my restricted desire-based definition of bisexuality. As the studies used different definitions, and as even studies using the same definition used different scales ${ }^{132}$ or measures, ${ }^{133}$ it is not surprising that the studies differ widely in

124. See Alfred Spira, Nathalie Bajos \& THe ACSF Group, SeXual Behavior AND AIDS (1994).

125. Kaye Wellings, Julia Field, anNe Johnson \& Jane Wadsworth, SeXual BeHAVIOR IN BRITAIN: THE NATIONAL SURVEY OF SEXUAL ATTITUDES AND LIFESTYLES (1994).

126. See, e.g., Tamar Lewin, Monogamy More Prevalent than Believed, Survey Finds, L.A. DAILY NeWS, Oct. 7, 1994, at N1 (noting popularity of Hite, Redbook, and Playboy studies); Elizabeth Valk Long, To Our Readers, TiME, Oct. 17, 1994, at 4, 4 (indicating that the Hite, Laumann, and Masters and Johnson reports were featured as cover stories in Time magazine).

127. The Redbook survey asked a sample of women whether they had had a "sexual experience with another woman" since the age of 18 , without asking about whether the women who had had such experiences had also had sexual experiences with men. TAVRIS \& SADD, supra note 119 , at 163 .

128. The Hite Report asked a sample of women the question "Do you prefer sex with men, women, yourself, or not at all?" HITE, supra note 120, at 261. The report noted: "A hundred and forty-four women in this study (8 percent) said they preferred sex with women. Another seventythree identified themselves as 'bisexual,' and eighty-four more women had had experiences with both men and women but did not answer as to preference (another 9 percent)." Id. This statement could be read to mean that $8 \%$ of women could be characterized as lesbian, while $9 \%$ could be characterized as bisexual. The question, however, is infelicitously worded for my purposes, given that preference for women as sex partners might not be an exclusive or even a strong preference. Similar problems arise when one tries to characterize the remaining $9 \%$ as bisexual, given that it probably includes individuals with only incidental experiences with one sex (who are not considered bisexual under my definition). Thus, while the Hite Report is widely known, I do not rely on it here.

129. The Spira study does not clearly distinguish between homosexuals and bisexuals, making a comparison of the incidence of these two groups impossible. See generally SPIRA ET AL., supra note 124 .

130. Had I not already eliminated it, the Redbook study would also have been excluded on this basis.

131. See notes 136-176 infra and accompanying text.

132. Compare KINSEY ET AL., MALE, supra note 5, at 639-41 (arraying individuals according to the criteria of desire or behavior on a seven-point scale), with WELLINGS ET AL., supra note 125, at 179 (arraying individuals according to the criteria of desire or behavior on a five-point scale). 
many of their results. For example, according to these studies, bisexuals are estimated to comprise anywhere from 0.2 percent ${ }^{134}$ to fifteen percent ${ }^{135}$ of the total population. What is surprising, however, is that each study found that the incidence of bisexuality was greater than or comparable to the incidence of homosexuality.

\section{a. Kinsey (1948\& 1953).}

Begin at the beginning, ${ }^{136}$ with Alfred Kinsey's foundational studies of sexual behavior in the human male ${ }^{137}$ and female. ${ }^{138}$ In both studies, Kinsey defined sexual orientation according to a combination of desire ("psychosexual response"139) and conduct ("overt sexual experience"140), without reliance on self-identification. 141 Based on this definition, he created the famous "Kinsey scale," which limned a sexual orientation continuum spanning from 0 to 6.142 The numbers denoted the following orientations:

0 -No homosexual contacts involving psychic or physical response; exclusive heterosexual contacts

1-Incidental homosexual contacts; frequent heterosexual contacts

2-More than incidental homosexual contacts; but more frequent heterosexual contacts

3-Equal homosexual and heterosexual contacts

4-More than incidental heterosexual contacts; but more frequent homosexual contacts

5-Incidental heterosexual contacts; frequent homosexual contacts

6-No heterosexual contacts; exclusive homosexual contacts ${ }^{143}$

133. Compare the definition of a Kinsey 1 in KINSEY ET AL., MALE, supra note 5, at 639-41, and KINSEY ET AL., FEMALE, supra note 6, at 471, with the definition of a Kinsey 1 in MASTERS \& JOHNSON, supra note 121, at 14-15. For more on this comparison, see note 154 infra.

134. WELLINGS ET AL., supra note 125, at 183.

135. See KINSEY ET AL., MALE, supra note 5, at 650-51.

136. This analysis marches through the studies chronologically in order to provide a sense of the timeline on which the studies were conducted. It is probably worth pointing out, however, that the first two studies, which were conducted before 1980, are fundamentally different from the last three, which were all conducted in the 1990s. For example, it is somewhat surprising that the Kinsey studies remain the most widely cited of the studies, despite the fact that they were conducted in an era where sexual mores were dramatically different. See Mezey, supra note 8, at 104 (noting that Kinsey's work is still the most "widely cited research on sexuality in the United States").

137. KINSEY ET AL., MALE, supra note 5.

138. KINSEY ET AL., FEMALE, supra note 6. 647.

139. KINSEY ET AL., FEMALE, supra note 6, at 471; KINSEY ET AL., MALE, supra note 5, at 647.

140. KINSEY ET AL., Female, supra note 6, at 471; KINSEY ET AL., MALE, supra note 5, at

141. See KinSEY ET AL., FEMALE, supra note 6, at 471-72; KINSEY ET AL., MALE, supra note 5 , at 639-41.

142. See KINSEY ET AL., FEMALE, supra note 6, at 471-72; KINSEY ET AL., MALE, supra note 5 , at 639-41.

143. See KINSEY ET AL., FEMALE, supra note 6, at 471-72; KINSEY ET AL., MALE, supra note 5 , at $639-41$. 
This scale has proved immensely influential, not only in subsequent studies, ${ }^{144}$ but also in more popular literature. ${ }^{145}$

While Kinsey resisted breaking this continuum into the three categories of heterosexual, bisexual, and homosexual, ${ }^{146}$ it will be useful for me to do so. I defined bisexuality earlier as the ability to experience desire in a more than incidental way for both men and women. Because Kinsey himself created categories of incidental same-sex desire or behavior (Kinsey 5s) and incidental cross-sex desire or behavior (Kinsey 1s), it is easy to restrict his scale to fit my definition. I therefore categorize Kinsey 0s and 1s as "heterosexual," Kinsey 2s, 3s, and 4s as "bisexual," and Kinsey 5s and 6s as "homosexual." However, because Kinsey did not disaggregate desire and conduct, a complete adaptation of his standard to mine is impossible. To the extent that his definition captured individuals who had sexual conduct with both sexes without desire for both sexes, it will be overinclusive.

Under this definition, what is the ratio of bisexuals to homosexuals in the Kinsey studies? Kinsey found that " 25 per cent of the male population ha[d] more than incidental homosexual experience or reactions (i.e., rate[d] from 2-6) for at least three years between the ages of 16 and 55,"147 while "10 per cent of the males [were] more or less exclusively homosexual (i.e., rate[d] 5 or 6) for at least three years between the ages of 16 and 55."148 Under his time and age restrictions, Kinsey thus found that fifteen percent of the male population fell within the bisexual range (Kinsey $2 \mathrm{~s}$, 3s, and $4 \mathrm{~s}$ ) while only ten percent of the male population fell within the homosexual range (Kinsey $5 \mathrm{~s}$ and $6 \mathrm{~s})$. For women, an average of ten percent of unmarried females and 2.5 percent of married females rated from 2 to 6 "in each of the years between twenty and thirty-five years of age." 149 In contrast, only an average of four percent of unmarried females and less than one percent of married females rated 5 or 6 "in each of the years between twenty and thirty-five years

144. See, e.g., MASTERS \& JOHNSON, supra note 121 , at 8 (noting its deployment of the Kinsey scale); WELLINGS ET AL., supra note 125, at 179 (noting its deployment of a modified Kinsey scale).

145. See, e.g., Veronica Groocock, Alfred C. Kinsey: A Public/Private Life, NEw STATESMAN, Nov. 21, 1997, at 49 (reviewing book about Kinsey and his reports); William A. Henry, Born Gay?, TIME, July 26, 1993, at 36, 37 (noting Kinsey's estimate of the incidence of homosexuality in the population); John Leland, Bisexuality, NEWSWEEK, July 17, 1995, at 44, 47 (discussing Kinsey's findings on bisexuality); Jonathan Weiner, The Gay Science, THE NEW REPUBLIC, Jan. 2, 1995 , at 35, 36 (discussing methodology and results of Kinsey report).

146. See KINSEY ET AL., MALE, supra note 5, at 639 (noting that sexual orientation is better described as a continuum). Indeed, Kinsey cautioned that even his seven-point scale was a distortion of the continuum of sexual orientation. Id. at 647 ("Finally, it should be emphasized again that the reality is a continuum, with individuals in the population occupying not only the seven categofies which are recognized here, but every gradation between each of the categories, as well.").

147. Id. at 650 .

148. Id. at 651 .

149. KINSEY ET AL., FEMALE, supra note 6, at 473. 
of age."150 Under these time and age restrictions, Kinsey thus found that six percent of unmarried women and more than 1.5 percent of married women fell into the bisexual range, while only four percent of unmarried women and less than one percent of married women fell into the homosexual range. In the Kinsey studies, we see a remarkable consistency of result, in which the percentage of bisexuals (Kinsey 2s, 3s, and 4s) is 1.5 times the percentage of homosexuals (Kinsey $5 \mathrm{~s}$ and $6 \mathrm{~s}$ ) for both men and women.

\section{b. Masters and Johnson (1979).}

The Masters and Johnson study also deployed the Kinsey scale.151 The study, however, involved only "homosexual" subjects - it admitted into its data pool only individuals whom the researchers deemed to be Kinsey 1s to Kinsey $6 \mathrm{~s} .152$ The limitation was almost certainly too strictly enforced-for example, " $[t]$ he Kinsey 1 representatives were accepted into the program only if they could document that they were currently living in a homosexual relationship of at least three months' duration." 153 This implies that the researchers were deploying the Kinsey scale in a different way than Kinsey himself did, for it is extremely doubtful that the Kinsey researchers would have classified as a Kinsey 1 any individual who had been involved in a same-sex relationship of that duration. 154 The Masters and Johnson classification would thus underreport the number of individuals who would be bisexual under my definition. Despite this, however, the Masters and Johnson study also found that the incidence of bisexuality was greater than or comparable to the incidence of homosexuality. For men, the percentage of bisexuals (Kinsey $2 \mathrm{~s}, 3 \mathrm{~s}$, and $4 \mathrm{~s}$ ) in the sample was 46.8 percent, while the percentage of homosexuals (Kinsey $5 \mathrm{~s}$ and $6 \mathrm{~s}$ ) was 48.9 percent. 155 For women, the percentage of bisexuals was 59.8 percent, while the percentage of homosexuals was 36.6 percent. 156 Thus, while the ratio of bisexual men to gay men was lower than that in the Kinsey study, the study still found that bisex-

150. Id. at 473-74.

151. MASTERS \& JOHNSON, supra note 121 , at 8.

152. See id. at 14 .

153. Id. at $14-15$.

154. See KINSEY ET AL., FEMALE, supra note 6, at 471 ("Individuals are rated as 1's if their psychosexual responses and/or overt experience are directed almost entirely toward individuals of the opposite sex, although they incidentally make psychosexual responses to their own sex, and/or have incidental sexual contacts with individuals of their own sex... Such persons make few if any deliberate attempts to renew their homosexual contacts.") (emphases added); KINSEY ET AL., MALE supra note 5, at 639 ("Individuals are rated 1's if they have only incidental homosexual contacts which have involved physical or psychic response, or incidental psychic response without physical contact.”). The individuals described as Kinsey 1 s by Masters and Johnson seem highly unlikely to meet these criteria.

155. See MASTERS \& JOHNSON, supra note 121, at 29.

156. See id. at 32 . 
ual men existed in comparable numbers to gay men. And the ratio of bisexual women to lesbians was greater than that found in the Kinsey study.

\section{c. Janus and Janus (1993).}

The Janus study relied on self-identification alone, asking subjects to label themselves as heterosexual, homosexual, or bisexual.157 It is thus impossible to ascertain how subjects in the Janus pool would be defined according to my restricted desire-based definition. But it nonetheless bears note that the study reported a roughly one-to-one ratio of bisexuals to homosexuals for both men and women.158 Among male respondents, five percent selfidentified as bisexual while four percent self-identified as homosexual.159 Among female respondents, three percent self-identified as bisexual, while two percent self-identified as homosexual.160 The report also suggested that there may have been some under-reporting of bisexuality: "In our interviews, we found ... respondents who identified themselves as heterosexual and reported having homosexual relations [and] respondents who identified themselves as homosexuals and reported that they have heterosexual relations as well." 161

\section{d. Wellings (1994).}

In a study of sexual behavior in Britain, ${ }^{162}$ researchers used a five-point scale (adapted from the seven-point Kinsey scale) ${ }^{163}$ to ascertain sexual attraction and sexual experience among men and women. Attraction was not further defined, ${ }^{164}$ but sexual experience was defined as "any kind of contact with another person that [the subject] felt was sexual," including "kissing or touching, or intercourse or any other form of sex."165 Unlike the Kinsey study, the Wellings study disaggregated attraction and experience, yielding two sets of data. ${ }^{166}$ The five-point scale, to which I have assigned numbers, was as follows:

157. See JANUS \& JANUS, supra note 122 , at 70.

158. See id. While the Janus report obtained data on same-sex experiences, it did not report similar data on bisexual experiences, making a comparison of the two on this axis impossible.

159. See id.

160. See id.

161. Id. These individuals could, of course, be Kinsey $1 \mathrm{~s}$ and Kinsey 5 s respectively, in which case it would not be underreporting of bisexuality under my definition.

162. WELLINGS ET AL., supra note 125.

163. See id. at 179.

164. See id. at 181.

165. Id.

166. See id. 
Wellings 0 -only heterosexual attraction/experience

Wellings 1 -mostly heterosexual attraction/experience

Wellings 2-both heterosexual and homosexual attraction/experience

Wellings 3-mostly homosexual attraction/experience

Wellings 4 -only homosexual attraction/experience ${ }^{167}$

The Wellings scale is both easier and harder to adapt to my definition of sexual orientation than the Kinsey scale. It is easier in that the Wellings scale disaggregates desire and conduct, thereby permitting the isolation of desire. It is harder in that the Wellings scale does not clearly distinguish between incidental desire (or conduct) and nonincidental desire (or conduct). To be consistent with the Kinsey-based bisexual category above, the bisexual category should include (1) all Wellings $2 \mathrm{~s}$; and (2) some but not all Wellings 1s; and (3) some but not all Wellings $3 \mathrm{~s}$. I therefore indicate the number of "bisexuals" as a range extending from a narrow underinclusive definition (just Wellings 2s) to a broad overinclusive definition (Wellings $1 \mathrm{~s}, 2 \mathrm{~s}$, and $3 \mathrm{~s}$ ). By the same logic, I indicate the number of "homosexuals" as a range extending from a narrow definition (just Wellings $4 \mathrm{~s}$ ) to a broad definition (Wellings $3 \mathrm{~s}$ and $4 \mathrm{~s}$ ).

Insofar as attraction was concerned, for men, 0.5 percent (narrow definition) to 5.0 percent (broad definition) were attracted to both men and women, while 0.5 percent (narrow definition) to 1.0 percent (broad definition) were attracted (almost) exclusively to men. ${ }^{168}$ For women, 0.2 percent (narrow definition) to 4.2 percent (broad definition) were attracted to both men and women, while 0.3 percent (narrow definition) to 0.5 percent (broad definition) were attracted (almost) exclusively to women. ${ }^{169}$ The Wellings study thus also found bisexuals to exist in numbers greater than or comparable to the number of homosexuals. 170

167. See id. at 183.

168. See id.

169. See id.

170. The ratio of bisexuals to homosexuals according to the behavior-based definition was similar to that generated under the desire-based definition. In its behavior inquiry, the Wellings study asked two different sets of questions. The first set was similar to the attraction-based question described above. See id. at 182; note 165 supra and accompanying text. It determined that for men, $0.3 \%$ (narrow definition) to $4.8 \%$ (broad definition) had sexual experience with both men and women, while $0.4 \%$ (narrow definition) to $1.0 \%$ (broad definition) had sexual experience (almost) exclusively with men. See WeLLINGS ET AL., supra note 125 , at 183 . For women, $0.1 \%$ (narrow definition) to $2.5 \%$ (broad definition) had sexual experience with both men and women, while $0.1 \%$ (narrow definition) to $0.3 \%$ (broad definition) had sexual experience (almost) exclusively with women. See id.

The study asked a separate set of questions pertaining to the exclusiveness of same-sex experience. Men and women were asked about the sex of their sexual partners over different time periods-(1) ever; (2) in the last five years; (3) in the last two years; and (4) in the last year. Id. at 209. For men, the percentage of those with both male and female partners as opposed to the percentage of those with exclusively male partners for these time periods was as follows: (1) $3.4 \%$ v. $0.3 \%$ ever; (2) $0.8 \%$ v. $0.6 \%$ in the last five years; (3) $0.5 \%$ v. $0.6 \%$ in the last two years; and (4) $0.4 \%$ v. 


\section{e. Laumann (1994).}

The Laumann study categorized sexual orientation separately according to all three of the common indicia-desire, conduct, and selfidentification. ${ }^{171}$ Subjects were asked to complete the phrase "In general are you sexually attracted to ..." with one of five responses: "(1) only men; (2) mostly men; (3) both men and women; (4) mostly women; and (5) only women." 172 The scale for attraction is thus identical to the five-point Wellings scale; I therefore finesse the difficulties of mapping this onto my definition in the same way as above. ${ }^{173}$ For men, 0.6 percent (narrow definition) to 3.9 percent (broad definition) were attracted to both men and women, while 2.4 percent (narrow definition) to 3.1 percent (broad definition) reported attraction to men only. ${ }^{174}$ For women, 0.8 percent (narrow definition) to 4.1 percent (broad definition) reported attraction to both men and women, while 0.3 percent (narrow definition) to 0.9 percent (broad definition) reported attraction to women only. ${ }^{175}$ Taking the narrow and broad definitions as setting the endpoints of a range, the percentages of "bisexuals" are again greater than or comparable to those of "homosexuals."176

$0.7 \%$ in the last year. See id. For women, the percentage of those with both female and male partners as opposed to the percentage of those with exclusively female partners for these time periods was as follows-(1) $1.7 \%$ v. $0.1 \%$ ever; (2) $0.5 \%$ v. $0.2 \%$ in the last five years; $(3) 0.2 \%$ v. $0.2 \%$ in the last two years; and (4) $0.2 \%$ v. $0.2 \%$ in the last year. See id. Under both sets of questions, the percentage of individuals having sex with both men and women was greater than or comparable to the percentage of individuals having sex only with their own sex. See id.

171. See LAUMANN ET AL., supra note 75 , at 311.

172. Id. at 658 .

173. See note 168 supra and accompanying text.

174. See LAUMANN ET AL., supra note 75, at 311 . This statistic provides the most support for the nonexistence thesis of any in the studies surveyed. Under the narrow definition there are four times more homosexuals than there are bisexuals. If one takes the midpoint of each range, however, the ratio of bisexuals to homosexuals is close to parity $(2.25: 2.75)$.

175. See id.

176. In studying conduct, the Laumann study again asked a set of questions similar to that asked in the Wellings study. Subjects were asked about the sex of their sexual partners over different time periods-(1) since puberty, (2) since age 18, (3) in the past five years, and (4) in the last year. Id. For men, the percentages of those with both male and female partners as opposed to the percentage of those with exclusively male partners for these time periods were as follows: (1) $5.8 \%$ v $0.6 \%$ since puberty; (2) $4.0 \%$ v. $0.9 \%$ since age 18 ; (3) $2.1 \%$ v. $2.0 \%$ in the past five years; and (4) $0.7 \%$ v. $2.0 \%$ in the past year. Id. For women, the statistics were as follows: (1) $3.3 \%$ v. $0.2 \%$ since puberty; (2) $3.7 \%$ v. $0.4 \%$ since age 18 ; (3) $1.4 \%$ v. $0.8 \%$ in the past five years; and (4) $0.3 \%$ v. $1.0 \%$ in the past year. $I d$.

When asked to self-identify, $2.0 \%$ of men self-identified as "homosexual" and $0.8 \%$ of men self-identified as "bisexual." Id. $0.9 \%$ of women self-identified as lesbian, while $0.5 \%$ of women identified as bisexual. Id. 


\section{f. Critiques of the studies.}

The five studies considered above all came to roughly the same conclusion about the relative incidence of bisexuality to homosexuality-namely, that the incidence of bisexuality was greater than or comparable to the incidence of homosexuality. While three problems with these studies merit discussion, none ultimately damages the validity of this conclusion for my purposes.

The first problem concerns the flawed methodology of some of the studies. The primary methodological flaw concerned sampling practices. As the Laumann researchers noted, the Kinsey studies, the Masters and Johnson study, and the Janus and Janus study all failed to engage in probability sampling. 177 Of the studies canvassed above, only the Laumann study and the Wellings study used such sampling. 178 Another flaw related to the time variable. Again, all studies but the Laumann and Wellings studies failed to ask questions that adequately narrowed the timeframe in which individuals experienced desire. This led these studies to some version of the "once a bisexual, always a bisexual" position, in which a woman who had more than incidental desire for a woman in her adulthood but who had subsequently experienced only desire for men would still be considered bisexual.

The Laumann study and the Wellings study, however, did not suffer from either of these flaws. Both studies engaged in probability sampling, and both took the time variable into account.179 And the findings of these two studies about the relative numbers of bisexuals and homosexuals were comparable to the findings of the other studies. Thus, even if we accept that the Kinsey, Masters and Johnson, and Janus and Janus studies were illegitimate, this only means that there are fewer studies to support the same conclusion.

The second problem is one endemic to all sexuality studies, which is the problem of having to rely on subjective accounts to determine sexual orientation. Because desire and conduct were not calibrated directly by these studies, researchers were forced to rely on individual accounts of both. 180 In this sense, distinguishing desire and conduct on the one hand from selfidentification on the other is slightly misleading, since all of the data relied on some form of self-identification. The fact that all of the information col-

177. See LAUMANN ET AL., supra note 75 , at 44,46 (criticizing Masters and Johnson study and Janus study); MICHAEL ET AL., supra note 114, at 17 (criticizing Kinsey studies).

178. See LAUMANN ET AL., supra note 75 , at 46.

179. See notes 170,176 supra.

180. While attempts have been made to ascertain arousal (which is taken as a proxy for desire) directly, see ALAN HYDE, BODIES OF LAW 173-74 (1997), the studies canvassed here made no such attempts. 
lected was based on subjective accounts raises the concern that individuals gave untruthful responses.

For my purposes, the most damaging way in which subjects could have dissembled would have been for homosexual subjects to have said they were bisexual. If these homosexual subjects had engaged in such "defense bisexuality," there would have been underreporting of homosexuality and overreporting of bisexuality in these studies. 181 The confidentiality assured in all of the studies, 182 however, diminishes the motive to dissemble in this way. Moreover, bisexuals also have incentives to characterize themselves as homosexual183 or heterosexual, ${ }^{184}$ so we could also expect some overreporting of homosexuality and underreporting of bisexuality.

The third and most general concern is that no study will ever be able to tell us who is straight, who is gay, and who is bisexual. There are weak and strong versions of this concern. The weak version is that even if all individuals told the truth as they knew it, some may not have known the truth. ${ }^{185}$ The studies would then be flawed because they relied on some subjects with incomplete knowledge. This will, of course, always be a problem with survey data. Moreover, assuming that there is a truth to be known, I think it is reasonable to assume that the studies would give a closer approximation of the actual number of bisexuals than more quotidian forms of information. This is because the studies provided a relatively self-reflective and confidential forum in which individuals could articulate a stigmatized desire. But this does not mitigate the strong version of the concern, which is that experiences of sexual orientation are so different as not to be commensurable. Even assuming this, however, the studies might then be read not to ascertain the actual number of bisexuals, but rather to underscore a disjunction between academic and popular discourse. In other words, we might ask why academic knowledge about the number of homosexuals trickled so quickly into mainstream culture, ${ }^{186}$ while academic knowledge (produced in the same studies)

181. See notes 77-79 supra and accompanying text.

182. See JANUS \& JANUS, supra note 122, at 5 (discussing confidential nature of study); KINSEY ET AL., FEMALE, supra note 6, at 59 (same); KINSEY ET AL., MALE, supra note 5, at 44-45 (same); LAUMANN ET AL., supra note 75, at 71-73 (same); MASTERS \& JOHNSON, supra note 121, at 49 (same); WELLINGS ET AL., supra note 125, at 15, 20 (same).

183. For example, bisexuals have an incentive to characterize themselves as gay in order to interact socially with other sexual orientation groups. See RUST, CHALLENGE, supra note 71 , at 9598 (noting that some lesbians refuse to interact with or date openly bisexual women). They may also self-identify as gay simply because this is the most readily available template for same-sex desire. See text accompanying notes 397-398, infra.

184. Bisexuals have an incentive to characterize themselves as straight to partake of heterosexual privilege. See Brownfain, supra note 83, at 173 (describing married bisexuals who pass as straight).

185. See, e.g., SEDGWICK, supra note 4, at 26 (noting that Western romance tradition, including psychoanalysis, is predicated on the assumption that our sexual desires are not transparent to ourselves).

186. See note 112 supra and accompanying text. 
about the number of bisexuals did not. This in itself is suggestive of the erasure of the conceptual category of bisexuality, even if that category has no stable referent.

\section{Bisexual Erasure as a Cause of Bisexual Invisibility}

In this Part, I made two claims. My first claim was that bisexuals are invisible. In making that claim, I specified that while bisexuals are affected by at least three different kinds of invisibility, only one-the invisibility of bisexuals qua bisexuals-is the subject of this analysis. I maintained that the best way to isolate the extent of this kind of invisibility was to compare the relative visibilities of homosexuality and bisexuality. I then adduced both statistical and sociological evidence to demonstrate that bisexual invisibility is far more pervasive than its homosexual counterpart.

My second claim was that this invisibility betokens bisexual erasure rather than bisexual nonexistence. This required me to be more precise about my definition of bisexuality. I therefore adopted and defended a restricted desire-based definition. Applying this definition (where possible) to five major sexuality studies, I found that the studies all demonstrated that the incidence of bisexuals is greater than or comparable to the incidence of homosexuals.

Putting these two claims together, I conclude that bisexuals are invisible in modern American society and that this invisibility arises from erasure rather than from nonexistence. I now turn to the reasons for this erasure.

\section{THE EPISTEMIC CONTRACT OF BISEXUAL ERASURE}

There are at least three different explanations for why bisexuals are being erased in popular culture. While I describe all three, I focus on only one of them - the political explanation. This political explanation posits that bisexuals are being erased because the two most powerful sexual orientation constituencies-self-identified straights and self-identified gays-have mutual investments in the erasure of bisexuals. ${ }^{187}$ I call this the epistemic contract of bisexual erasure. I then support the existence of such mutual inter-

187. This hypothesis comports with Naomi Mezey's insightful account of bisexuality, which contends that "those who walk on either side of the boundary between heterosexuality and homosexuality tirelessly repair and define" that boundary to deny bisexuals any ontic ground. See Mezey, supra note 8, at 101. My analysis, however, extends beyond Mezey's in positing that the investments that straights and gays have in bisexual erasure subsume more than the desire to preserve the "ethics" of heterosexuality and homosexuality. Compare id. at 112-20 (explaining bisexual erasure by noting heterosexual and homosexual ethics), with text accompanying notes 258-394, infra (explaining bisexual erasure by noting investments in stabilizing orientation, preserving the importance of sex as a distinguishing trait, and maintaining norms of monogamy). 
ests by demonstrating how both straights and gays use the same strategies to erase bisexuals.

\section{A. Different Explanations}

There are three explanations for why bisexuality is invisible relative to homosexuality and heterosexuality. These explanations-which I call ontic, cognitive, and political - are general explanations for why any intermediate category that straddles a binary opposition might be rendered invisible. While all of these explanations are deeply intertwined, I will argue that the political explanation is the most powerful.

The ontic explanation is that we see things as binaries because they are binaries. 188 In describing how his philosophical predecessors adopted opposites as principles, Aristotle noted that "'they give no reason for doing so, but are, as it were, compelled by the truth itself." 189 A variety of modern thinkers have also maintained that binary classifications reflect "the twoness of reality," 190 or real oppositions in the world. 191 This is not necessarily to say that all aspects of reality are composed of opposed principles, merely that some - such as night/day, male/female, and life/death—seemingly are. 192 Under this theory, the binary opposition between gay and straight is such a "real" binary, and bisexuality is erased because it does not exist.

The ontic theory may be assailed on empirical and nonempirical grounds. The previous Part contested this theory by noting that studies have shown that the category of bisexuality is just as "real" as the category of homosexuality.193 One could also make a nonempirical case for skepticism of the straight/gay binary based on its suspicious convenience. The straight/gay binary is often seen as a simple back formation from the male/female binary, insofar as the sexual orientation binary categorizes individuals according to the sex of their object choice.194 But there is no reason to believe that because there are only two sexes (assuming for the sake of argument that this is

188. See RODNEY NEEDHAM, COUNTERPOINTS 35 (1987) (noting position that oppositions are "an unevadable response of consciousness to its environment").

189. G.E.R. LlOYD, POLARITY AND ANALOGY 15 \& n.2 (1966) (quoting Aristotle's Physics).

190. David Maybury-Lewis, The Quest for Harmony, in THE ATTRACTION OF OPPOSITES 1, 12 (David Maybury-Lewis \& Uri Almagor eds., 1989) (quoting C.R. HALLPIKE, THE FoUNDATIONS OF PRIMITIVE THOUGHT 234 (1979)).

191. See Maybury-Lewis, supra note 190, at 12 (citing HALLPIKE, supra note 190); ROBERT HERTZ, The Pre-Eminence of the Right Hand: A Study in Religious Polarity, in DEATH AND THE RIGHT HAND (1960); LLOYD, supra note 189.

192. Maybury-Lewis, supra note 190, at 12.

193. See text accompanying notes 110-186 supra.

194. As I demonstrate below, the male/female binary may also (counterintuitively) be seen as a back formation from the straight/gay binary. See notes 339-341 infra and accompanying text. 
true) ${ }^{195}$ individuals will themselves break into two discrete categories based on desire for one sex or the other. If anything, it is counterintuitive that two sets of desired objects would lead to two corresponding sets of desiring subjects (each of which only desired one set of objects). 196 Coffee and tea are two different objects, but we do not assume that all individuals break down into mutually exclusive sets of coffee drinkers and tea drinkers.

The cognitive explanation is that there is a human tendency to understand things in terms of binaries. ${ }^{197}$ In other words, even if the underlying reality is not a set of binaries, our limited cognitive capacity as human beings leads us to apprehend complex phenomena in terms of "[t]he extreme simplicity of ... binary structure," which "link[s] the fewest terms capable of sustaining a relation." 198 This theory, which is a hallmark of structural anthropology, 199 posits that binary thinking is "a spontaneous and necessary act of the mind, such that it is to be found in every type of culture."200 Under this theory, bisexuality disappears as a category because of a human blindness to all intermediate categories.

The cognitive theory can also be contested on empirical and nonempirical grounds. The empirical critique notes that our capture by binary epistemology is by no means complete. The intensity of binary thinking varies across and within cultures, 201 thereby demonstrating that it is not an inescapable fact of human cognition. The existence of alternative cognitive models also substantiates this point-think of the infinite subdivision model of the continuum, ${ }^{202}$ or the triadic model of dialectical thinking ("thesis-antithesissynthesis").203 This critique is supplemented by a nonempirical one. Bisexuality, after all, is not inimical to all binaries-consider the bisexual/monosexual binary. Thus, even if we believe that the human mind has a tendency to binarize, that does not explain why the straight/gay binary prevailed over the bisexual/monosexual binary. The answer to that question, I contend, is political.

195. As noted above, there is a growing literature challenging the binary nature of sex. See note 18 supra and accompanying text.

196. See note 8 supra (discussing how two forms of desire lead analytically to at least four categories of persons).

197. This view is perhaps most prominently associated with Claude Levi-Strauss. See generally Claude LeVI-STRAuSS, THE SAVAGE MIND 217-44 (George Weidenfeld \& Nicolson Ltd. trans., 1966) (observing that binary thinking manifests itself across a diverse array of societies).

198. NEEDHAM, supra note 188 , at xi.

199. See Uri Almagor, Dual Organization Reconsidered, in THE ATTRACTION OF OPPOSITES, supra note 190 , at $19,19$.

200. NEEDHAM, supra note 188 , at 1 .

201. See Maybury-Lewis, supra note 190 , at 12.

202. See NEEDHAM, supra note 188 , at 230-31.

203. See Michael H. Hoffheimer, Hegel's First Philosophy of Law, 62 TENN. L. REV. 823, 839 (1995). 
The political explanation is that some intermediate categories are harder to see because they are caught in the middle of a political struggle. Bisexuality is invisible not because we are innately blind to intermediate categories, but because agonistic politics have bifurcated the continuum we would otherwise see. ${ }^{204}$ Under this explanation, the clash between opposed forces has compelled a choosing of sides and a denial of intermediate ground. In the remainder of this article, I concern myself solely with this political explanation.

In considering how political struggle has erased bisexuals, I must first identify the relevant groups in that struggle. I believe that the relevant groups are still heterosexuals, homosexuals, and bisexuals. But here a crucial shift in definition occurs. When these groups define themselves politically, they define themselves according to self-identification rather than through conduct or desire. In speaking of the straight, gay, or bisexual investments in bisexual erasure, I thus mean the investments of self-identified straights, self-identified gays, and self-identified bisexuals.

My hypothesis is that bisexuals remain invisible because both selfidentified straights and self-identified gays have overlapping political interests in bisexual erasure. It is as if self-identified straights and self-identified gays have concluded that whatever their other disagreements, they will agree that bisexuals do not exist. Put another way, the sexual orientation continuum that runs from straight through bisexual to gay is a "loopified" one, in which straights and gays are actually closer to each other on this issue than either group is to bisexuals.205 Because of this, self-identified straights and self-identified gays enter into what I will call an epistemic contract of bisexual erasure.

\section{B. The Epistemic Contract Defined}

As I define it, an epistemic contract is a contract in the sense that a social contract is a contract. In other words, it is not a conscious arrangement be-

204. See generally GARBER, supra note 11 , at 80 (arguing that political struggle is defined by opposite poles which suppress the middle ground); Mezey, supra note 8, at 112-20 (noting the strict political enforcement of rigid categories of sexual identity).

205. $\rightarrow$ Akhil Reed Amar \& Vik Amar, President Quayle?, 78 VA. L. REV. 913, 934-35 (1992) (noting incentives for political parties at opposite ends of a political continuum to unite against the middle of the continuum). The term "loopification" appears to be Duncan Kennedy's coinage. $\rightarrow$ Duncan Kennedy, The Stages of the Decline of the Public/Private Distinction, 130 U. PA. L. REV. 1349, 1354-57 (1982) (describing theory of "loopification" in which the ends of a continuum are closer to each other than either is to the middle). Other scholars have also noted this political phenomenon. See, e.g. Herbert McClosky \& Dennis Chong, Similarities and Differences Between Left-Wing and Right-Wing Radicals, 15 BRIT. J. POL. SCI. 329, 343 (1985) (noting that the "programmatic differences between the radical left and the radical right frequently act to obscure the characteristics that are shared by the two camps" including "intolerance of ambiguity"). 
tween individuals, but rather a social norm that arises unconsciously.206 It might be fairly asked why the epistemic contract (or, for that matter, the social contract) is expressed as a contract as opposed to a norm. My answer is that I believe the contractual language better captures the fact that the arrangement arises between distinct groups who enter it because of overlapping but not congruent interests. Norms appear to arise from society as a whole, while "social contracts" seem to arise out of the constituencies into which society is fractured. "Don't ask, don't tell," for example, is a contractual formulation of the norm of gay silence that lays bare the interests (and implicitly the constituencies) involved: straights will not inquire if gays will not flaunt.207 The choice, however, is ultimately semantic - one could easily rephrase the substance of what follows in the language of norms.

The epistemic contract is epistemic insofar as it relates to the nature of knowledge. It is a social arrangement about what can be acknowledged or known. This arrangement arises between groups that have distinct but overlapping interests in the promulgation or repression of certain kinds of knowledge. In this article, I focus on the latter-that is, on an epistemic contract that relates to what cannot be known.

The epistemic contract is a political model that could be profitably applied beyond the sexual orientation context to other intermediate identity categories. Multiracials, for example, can be readily analogized to bisexuals in many regards. ${ }^{208}$ Multiracials, like bisexuals, are alternatively defined according to universalizing definitions which state that all (or almost all) individuals are multiracial,209 or according to minoritizing definitions which state that a small proportion of the population is multiracial.210 Multiracials, like bisexuals, are usually defined in the latter sense, and according to an analogously varied set of terms. ${ }^{211}$ As in the bisexual context, the tendency

206. See, e.g., JeAn-Jacques Rousseau, The Social ConTraCt AND DiscourSES 14 (G.D.H. Cole trans., 1950) ("The clauses of this contract ... have perhaps never been formally set forth, [but] they are everywhere the same and everywhere tacitly admitted and recognized ....").

207. See Yoshino, supra note 27, at 556.

208. Ruth Colker's book Hybrid usefully analogizes the problematic bipolar model of orientation with those that obtain in the contexts of race, gender, and disability. See generally COLKER, HYBRID, supra note 9.

209. See John A. Powell, The Colorblind Multiracial Dilemma: Racial Categories Reconsidered, 31 U.S.F. L. REV. 789, 797-98 (1997) (noting that if multiracial means that an individual has ancestry of different races, then "virtually everyone is multiracial").

210. See, e.g., Luther Wright, Jr., Who's Black, Who's White, and Who Cares: Reconceptualizing the United States's Definition of Race and Racial Classifications, 48 VAND. L. REV. 513, 55758 (1995) (noting that biracial people, defined as people with parents of different recognized races, comprise roughly three percent of births in the United States).

211. Such shifting definitions can be seen in the United States Census's categorization of individuals with both white and black ancestry. From 1790, when the Census began to distinguish (based on third-party reports) between whites and blacks, to 1850 , no intermediate category was recognized. See Christine B. Hickman, The Devil and the One Drop Rule: Racial Categories, African Americans, and the U.S. Census, 95 MICH. L. REV. 1161, 1182 (1997). This is similar to mod- 
to adopt narrow binarizing definitions of race can be traced to anxieties felt by both the dominant and the subordinate groups. 212 Recently, self-identified multiracials, like self-identified bisexuals, have organized to resist such binarizing definitions.213 And these self-identified multiracials, like selfidentified bisexuals, face the dilemma of whether simply to add the intermediate group as a third category or to deploy it to more deeply interrogate the principle of racial categorization. 214

At the same time, however, the political model adduced here clearly does not describe all intermediate categories. The contemporary American middle class, for example, is both an intermediate category (as its name would suggest) and much more visible than any other class. ${ }^{215}$ This should inspire caution in applying the model too quickly even to groups that seem superficially to be greatly illuminated by it. ${ }^{216}$ I therefore constrain myself in this analysis to the context of sexual orientation.

The epistemic contract of bisexual erasure is a particularly powerful one. This can be seen by contrasting it to the epistemic contract of homosexual erasure exemplified by the military's current "don't ask, don't tell" policy.217 "Don't ask, don't tell" satisfies both criteria of an epistemic contract. It is a

els of orientation that fail to recognize the bisexual possibility. See notes 226-232, 238-242 infra and accompanying text. From 1850 to 1910 , the Census recognized an intermediate category of "mulattoes." See Joel Williamson, New PeOPle: Miscegenation and Mulattoes IN THE UNITED STATES 24 (1995); Hickman, supra, at 1185 . Indeed, in the 1890 census, enumerators were asked to categorize the intermediate span between black and white according to a set of named fractions (octoroon, quadroon, mulatto). See WILLIAMSON, supra, at 112; Hickman, supra, at 1186. This partitioned continuum is reminiscent of the Kinsey scale. See note 143 supra and accompanying text. After the census of 1920, however, the Census Bureau moved away from the named fractions rule to the "one drop rule." See WilliamSON, supra, at 114; Hickman, supra, at 1187. This rule of hypodescent could be analogized to the "one act rule" in the orientation context. See note 99 supra and accompanying text.

212. See F. James Davis, Who Is Black? ONe Nation's Definition 137 (1991) (noting that both blacks and whites support a binarizing "one drop rule").

213. See Hickman, supra note 211, at 1164-65.

214. See id. at 1165 ("One wing of this new multiracial movement argues that a new 'multiracial box' should be made available for the growing number of children of interracial marriages. Another wing of this movement, in books and law review articles, suggests that the addition of this category should be a part of a wholesale redefinition of the racial identities of most Americans.").

215. This discrepancy in visibility between the middle class and other intermediate categories such as bisexuals and multi-racials may be due to the different incentives felt by the privileged class in each context. The "upper class" may feel pressure to erase itself in ways that heterosexuals and whites may not. See PeTER W. CoOKson, JR. \& Caroline Hodges Persell, Preparing for POWER: AMERICA'S ELITE BOARDING SCHOOLS 28 (1985) ("Part of the socialization for power is learning how to conceal wealth, or at least minimize its importance by never openly referring to it ...."). I am indebted to Bruce Ackerman for raising the discrepancy, and to Zachary Potter for suggesting this explanation for it.

216. Multiracials and bisexuals, for example, can be easily distinguished on a number of grounds, such as the fact that multi-racial identity is often thought to be genetic and heritable, while bisexual identity is often thought to be behavioral and not inherited.

217. 10 U.S.C. $\S 654$ (1998). 
contract insofar as it articulates the needs of two distinct constituenciescrudely, self-identified straights and self-identified gays. As conventionally told, each side gets something out of the policy218 - self-identified straights secure a military in which homosexuality is repressed ("don't tell"); selfidentified gays garner a military in which gays can ostensibly serve without being subjected to witchhunts or harassment ("don't ask").219 And "don't ask, don't tell" is epistemic insofar as what is really at issue in the contract is a joint repression of knowledge. Self-identified straights and self-identified gays have been led through their distinct but overlapping interests to agree that individuals in the military do not have to own what they know-that homosexuals exist in their ranks.

As I have argued elsewhere, the existence of the "don't ask, don't tell" policy signifies both continuity and discontinuity with prior social norms. 220 It signifies continuity in that the policy did not spring full-fledged from the head of Congress, but rather grew out of the underlying culture.221 In other words, "don't ask, don't tell" arises out of a pervasive strategy of silence that has long affected gays in public culture-a strategy that permits gays to live as equal citizens if and only if they agree to "pass" as straight.222 At the same time, however, "don't ask, don't tell" also signifies a breakdown of that underlying culture, for if that culture were still extant, there would be no need to codify it.223

In contrast to "don't ask, don't tell," bisexual erasure as such needs no explicit legal enforcement. This is because bisexual erasure is still sufficiently rooted in social culture and thus appears natural, just as homosexual erasure appeared natural when "don't ask, don't tell" was so rooted. What explains the discrepancy?

The answer is that straights and gays are the most powerful constituencies in both of these contracts, and that gays feel differently about homosexual erasure than they do about bisexual erasure. The epistemic contract of "don't ask, don't tell" is less a case of real interest convergence between straights and gays than it is a case of compromise. The policy splits the dif-

218. See, e.g., Eskridge \& Frickey, supra note 40, at 92 (describing "don't ask, don't tell" as a compromise); Diane H. Mazur, The Unknown Soldier: A Critique of "Gays in the Military" Scholarship and Litigation, 29 U.C. DAVIS L. REV. 223, $227-28$ (1996) (same); Francisco Valdes, Queers, Sissies, Dykes, and Tomboys: Deconstructing the Conflation of "Sex," "Gender," and "Sexual Orientation" in Euro-American Law and Society, 83 CAL. L. REV. 1, 370 (1995) (same).

219. There is evidence that the witchhunts have persisted under the "don't ask, don't tell" policy. See C. Dixon Osburn \& Michele M. BENECKE, SERVICEMEMBERS Legal DefENSE NETWORK, CONDUCT UNBECOMING CONTINUES: THE FIRST YeAR UNDER “DON'T ASK, DON'T TELL, DON'T PURSUE" 11 (1995) (noting documentation of 15 actual or attempted witchhunts under "don't ask, don't tell").

220. See Yoshino, supra note 27, at 556-57.

221. See id. at 556.

222. See id.

223. See id. at 556-57. 
ference between the self-identified straight interest in the removal of gays from the military and the self-identified gay interest in the ability of gays to serve openly (although it strongly favors the former).224 This is why this particular epistemic contract is so unstable-each side (and particularly the gay side) wants more than the status quo provides.225 In contrast, the epistemic contract of bisexual erasure is, at least insofar as gays and straights are concerned, a case of real interest convergence. Both straights and gays, for different reasons, want bisexuals to be invisible. Because these two groups-which again are the most powerful sexual orientation constituencies-want this invisibility, this epistemic contract is much more stable. Indeed, it is so stable as not to be perceived as a contract at all.

\section{Strategies of Erasure}

The existence of a bilateral contract of bisexual erasure is supported by the fact that both straights and gays engage in the same strategies of bisexual erasure. There are three such strategies: (1) class erasure, (2) individual erasure, and (3) delegitimation. These strategies imply the acceptance of successively stronger claims about bisexual existence-the first strategy does not recognize the category of "bisexuality"; the second acknowledges the category but excludes an individual from it; and the third accepts individual bisexuality as a stable identity but stigmatizes it.

\section{Straight deployments of the strategies.}

Class erasure occurs when straights deny the existence of the entire bisexual category. This can occur explicitly or implicitly. A few decades ago, explicit denial appears to have been fairly common even among academic theorists, some of whom believed that all self-identified bisexuals were actually homosexuals in denial.226 While the claim that "there is no such thing as bisexuality" remains part of the common wisdom today, ${ }^{227}$ perhaps the more prominent form of denial is now the implicit one. Such implicit denial often occurs through the use of the straight/gay binary as a complete means of describing all individuals.228 As discussed above, ${ }^{229}$ this was the strategy used

224. See COLKER, HYBRID, supra note 9, at 64 .

225. Gay dissatisfaction with the status quo can be seen in the legal challenges to the policy. See, e.g., Able v. United States, 155 F.3d 628, 631 (2d Cir. 1998) (upholding "don't ask, don't tell" against constitutional challenge); Philips v. Perry, 106 F.3d 1420, 1424 (9th Cir. 1997) (same); Richenberg v. Perry, 97 F.3d 256, 260 (8th Cir. 1996) (same); Thomasson v. Perry, 80 F.3d 915, 927 (4th Cir. 1996) (same).

226. See Fox, supra note 79 , at 21 . One theorist, for example, maintained that bisexuality was "a state that has no existence beyond the word itself," that is, "an out-and-out fraud." EDMUND BERGLER, HOMOSEXUALITY: DISEASE OR WAY OF LIFE 80-89 (1956).

227. GARBER, supra note 11 , at 16 .

228. See notes 45-46 supra and accompanying text. 
by the Romer Court. A more subtle strategy of implicit class erasure is the description of bisexuality as "bisexual chic" in the mainstream (and thus presumptively straight) press.230 As the phrase suggests, bisexuality is here made visible as a phase, fashion, or fad-its appearance is inscribed with its imminent disappearance.231 Indeed, impending evanescence may be the precondition for visibility. 232

Individual erasure recognizes that bisexuals exist as a class, but contests that a particular individual is bisexual. Such challenges by straights often arise when a self-identified bisexual is accused of being a duplicitous or nascent homosexual.233 In either case, the bisexual self-ascription is seen as a "phase" from which an individual will ultimately emerge. ${ }^{234}$ Such erasure replicates the "phase" paradigm of bisexual chic at the level of the individual-ontogeny here recapitulates phylogeny. Self-described bisexuality is thus seen not as a stable individual identity but a place from which a stable monosexual identity is acknowledged or chosen.

Finally, delegitimation occurs when straights acknowledge the existence of individual bisexuals but attach a stigma to bisexuality. It may seem odd to characterize delegitimation as a strategy of bisexual invisibility, given that it makes bisexuality more visible. But because it chills the expression of bisexuality by portraying it only in a negative way, I include it here. Common straight stereotypes of bisexuals portray them as promiscuous, as duplicitous, as closeted, and especially as bridges for HIV infection from the "high risk" gay population to the "low risk" straight population. 235

229. See notes 47-52 supra and accompanying text.

230. See, e.g., Bisexual Chic: Anyone Goes, NEWSWEEK, May 27, 1974, at 90, 90 (noting that bisexuality "was probably inevitable," since "his-and-her clothes, hair styles and role assignments blurred the line between the sexes until they overlapped, the only thing left to swap was sex itself'); The New Bisexuals, TIME, May 13, 1974, at 79 (describing fashionability of bisexuality); see also GARBER, supra note 11, at 18-24 (describing bisexual chic).

231. See GARBER, supra note 11, at 20 (asking whether bisexual chic turns bisexuality into "a fashion-like platform shoes, bell-bottomed trousers, or double-breasted suits-that appears and then disappears, goes underground, only to be 'revived' with a difference?").

232. An analogy may be made to Leo Bersani's hypothesis that AIDS has made gays more visible in part because it promises their ultimate disappearance-gay visibility is made most palatable at the moment its transience is underscored. LEO BERSANI, HOMOS 21 (1995). While obviously less sinister, the concept of bisexual chic may operate in the same way, reassuring straight culture that it is safe to look at bisexuals by characterizing them as a passing fancy.

233. See GARBER, supra note 11 , at 145 .

234. The instability of bisexuals, which is framed here in temporal terms as a "phase" argument, can also be framed in spatial terms, as in descriptions of bisexuals as being "on the fence." See, e.g., Amber Ault, Hegemonic Discourse in an Oppositional Community: Lesbian Feminist Stigmatization of Bisexual Women, in QUEER STUDIES, supra note 15, at 204, 206.

235. See Ochs, supra note 63, at 227. 


\section{Gay deployments of the strategies.}

That gays and lesbians would collude with straights in the erasure of bisexuals is superficially surprising. 236 As sexual minorities who have themselves been rendered invisible, one would expect that gays and lesbians would be loath to assume the role of oppressor relative to other sexual minorities.237 Yet gays deploy all of the strategies of bisexual erasure used by straights. This supports the thesis that bisexual invisibility must be understood not as the unilateral erasure of bisexuals by straights, but the bilateral erasure of bisexuals by both straights and gays.

Self-identified gays deploy all three strategies of bisexual erasure-class erasure, individual erasure, and delegitimation. Speaking of class erasure, Christopher James laments the phenomenon in which a queer, gay, or lesbian theorist "excludes bisexuality as a relevant category of sexual identity," and then "claims behaviorally bisexual people or texts with bisexual characters or content as 'queer,' 'gay,' or 'lesbian."'238 James goes on to give examples of scholarly texts that elide the bisexual category and unself-consciously categorize individuals whom he believes would be more appropriately deemed bisexual as queer, gay, or lesbian.239 This practice of elision, of course, is not limited to the academy. As Marjorie Garber notes, popular compendiums of gay "lists," such as The Gay Book of Days 240 and The Gay/Lesbian Almanac, ${ }^{241}$ purport to list only gays (as their titles would suggest), but include many bisexuals in their pages. ${ }^{242}$

Even when gays formally recognize bisexuals as a category, they can peremptorily evacuate individuals from that category. ${ }^{243}$ A classic example

236. See WEINBERG ET AL., supra note 113 , at 8 (noting with surprise that bisexuals reported homosexuals to be just as negative as heterosexuals about bisexuality).

237. See id. at 117 (noting that bisexuals, when confronted with hostility from gays, may be dismayed because they view themselves victimized by the same kind of prejudice as gays).

238. James, supra note 15 , at 228 . To his credit, James acknowledges that some usages of the words "queer," "gay," and "lesbian" might be thought to encompass bisexuality. Id. at 228-29. (I think this is most true for the term "queer"-bisexuals, for example, would seem to fit comfortably within the usage of the word "queer" to denote all those who fall outside of the regimes of the "normal," see supra note 3.) But James points out that because these words signify exclusive homosexuality for many others, theorists who use the terms expansively should declare and justify such usage. James, supra note 15 , at 229.

239. See id. at 229 (criticizing David Bergman, Gaiety TRANSFIGURED: GAY SELFREPRESENTATION IN AMERICAN LITERATURE (1991) for appropriating Herman Melville, Henry David Thoreau, and Henry James as gay men); James, supra note 15, at 229-30 (criticizing KARLA JAY \& JOANNE GLASKOW, LESBIAN TEXTS AND CONTEXTS: RADICAL REVISIONS (1990) for appropriating Emily Dickinson, Virginia Woolf, H.D., and Djuna Barnes as lesbians).

240. MarTin Greif, THe Gay BoOK of Days: AN EVocatively Illustrative Who's Who of Who Is, Was, May HaVe BeEn, PROBably Was, and Almost Certainly SEEMS to HAVE BEEN GAY DURING THE PAST 5,000 YEARS (1982).

241. Jonathan Ned KatZ, The Gay/Lesbian AlmanaC: A New Documentary (1983).

242. See GARBER, supra note 11, at 49-50.

243. See Ault, supra note 234, at 208. 
of such individual erasure can be found in the beginning of lesbian theorist Terry Castle's The Apparitional Lesbian.244 Castle there invokes the figure of Greta Garbo, whom she views as exemplifying the book's thesis-that "[w]hen it comes to lesbians ... many people have trouble seeing what's in front of them."245 This social myopia seems to extend to bisexuals as well, because Castle characterizes Garbo as a "lesbian actress" 246 even after observing that Garbo "occasionally had affairs with men as well as women."247 Castle's subsequent concession that Garbo could be characterized as a bisexual exonerates her from the charge of class erasure. 248 But her summary rejection of that characterization implicates her in individual erasure-Castle believes it "more meaningful to refer to [Garbo] as a lesbian"249 because "while Garbo sometimes makes love to men, she would rather make love to women."250 But how do we know that Garbo prefers women to men? And, even assuming that we know that Garbo sexually preferred women to men, why does this make her a lesbian?

Like straights, gays can often engage in this kind of erasure by characterizing individuals who self-describe as bisexual as going through a "phase" that will end in monosexuality. ${ }^{251}$ The belief that bisexuals are protohomosexuals is a particularly prevalent one among gays. ${ }^{252}$ The greater force with which this belief is expressed in the gay community may be partially explained by experiential skepticism. Like straights, gays have observed "bisexuals" subsequently come out as gay. ${ }^{253}$ But presumably unlike selfidentified straights, some self-identified gays have gone through this phase themselves. ${ }^{254}$ This experience may lead them to be suspicious of those who claim bisexuality as a stable identity. The claim that bisexuals are protohomosexuals may also be more intensely held in the gay community, perhaps

244. Terry Castle, The Apparitional Lesbian: Female Homosexuality and ModERN CULTURE (1993).

245. Id. at 2.

246. Id.

247. Id. at 15 .

248. See id.

249. See id.

250. Id.

251. See WEINBERG ET AL., supra note 113 , at 117 . This characterization is particularly ironic given that gays themselves are often told by straights that their homosexuality is just a phase on their way to heterosexuality. See Teemu Ruskola, Minor Disregard: The Legal Construction of the Fantasy that Gay and Lesbian Youth Do Not Exist, 8 YALE J.L. \& FEMINISM 269, 280 (1996).

252. See, e.g., Paula C. Rust, Sexual Identity and Bisexual Identities: The Struggle for SelfDescription in a Changing Sexual Landscape, in QUEER STUDIES, supra note 15, at 64, 65.

253. See GARBER, supra note 11, at 145 (describing how Boy George, David Geffen, and Elton John all self-identified as "bisexual" before "coming out" as gay).

254. See, e.g., RUST, CHALLENGE, supra note 71, at 44 ("Bisexual identity is often considered a stepping stone on the way to coming out as a lesbian. Slightly more than half of [the lesbians in the study] called themselves bisexual before they came out as lesbians; in hindsight, these women might well see their earlier bisexual identity as a transitional stage."). 
because gays have more to lose than straights when bisexuals abandon them.255 Politicized homosexuals may be particularly prone to holding this view. 256

Finally, gays delegitimate bisexuals in two ways. Again, the more obvious way is simple denigration - "the lesbian and gay community abounds with negative images of bisexuals as fence-sitters, traitors, cop-outs, closet cases, people whose primary goal in life is to retain 'heterosexual privilege,' [or] power-hungry seducers who use and discard their same-sex lovers ...."257 Less intuitively, gays can also delegitimate bisexuals by impersonating them. Some might contend that such "defense bisexuality" increases, rather than decreases, bisexual visibility, as gays who say they are bisexual swell the ranks of the bisexual category. But the transience and the quality of the visibility must also be considered-such gays may later reveal themselves to be gay, thereby detracting from the credibility of those who experience their bisexuality as a stable identity.

\section{The Epistemic Contract as a Cause of Bisexual Erasure}

While the erasure of the bisexual category can be explained through a variety of hypotheses, the political hypothesis is the most plausible. I therefore focus on that explanation, maintaining that self-identified straights and self-identified gays have shared political interests that lead them into an epistemic contract of bisexual erasure. The existence of such a contract is demonstrated by the fact that both straights and gays use the same strategies to erase bisexuals. This suggests that the erasure is being driven not just by straight interests, but also by gay interests. I now explore the nature of those interests.

\section{MONOSEXUAL INVESTMENTS IN THE EPISTEMIC CONTRACT}

In this Part, I hypothesize that bisexuals are erased because their visibility is threatening to three interests that both straights and gays possess: (1) an interest in the stability of sexual orientation categories; (2) an interest in the primacy of sex as a diacritical characteristic; and (3) an interest in the preservation of monogamy. While these interests overlap in some ways, they are also distinct in others. I thus disaggregate each interest into three portions: (1) the portion of the interest that is shared by both straights and gays;

255. See Mezey, supra note 8, at 118 ("As an oppressed subculture, homosexual communities rely on an ethic of homosexual identity to maintain strength and coherence against the constant onslaught of virulent attacks . ...").

256. See WEINBERG ET AL., supra note 113, at 117.

257. Lisa Orlando, Loving Whom We Choose, in BI ANY OTHER NAME: BISEXUAL PEOPLE SPEAK OUT 223, 224 (Loraine Hutchins \& Lani Kaahumanu eds., 1991). 
(2) the portion of the interest that is distinctively straight; and (3) the portion of the interest that is distinctively gay.

It will be useful to enter two qualifications before embarking on this analysis. First, I am mindful that separating the parties and attributing viewpoints to them in the way that I have risks essentializing the opinions that members of each category have about the others. After some thought, I have overridden this weighty objection. I do so because I believe that certain opinions are more likely to be held by one group than another, although it will not be held by all members or only members of that group. 258 Thus, when I speak of the "investment of self-identified gays in bisexual erasure," I do not mean that all gays or only gays have this investment. Rather, I indicate the investment in bisexual erasure that is more likely to be held by selfidentified gays than by any other group.

Second, I wish to stress the importance of distinguishing between stereotypes of bisexuality and the realities underlying those stereotypes. The following analysis will sometimes identify a viewpoint as a stereotype but nonetheless give it weight in the analysis. That weight, however, arises only from the fact that the investments of self-identified straights and selfidentified gays will often be driven by perceptions rather than by realities. Indeed, I will argue that the stereotypes that bisexuals are (1) politically unreliable, (2) completely sex-blind, or (3) intrinsically promiscuous, are extremely powerful in shaping straight and gay attitudes about bisexuals. Such argumentation, of course, should not be taken as accession to the validity of those stereotypes.

\section{A. Stabilization of Sexual Orientation}

Bisexuality destabilizes sexual orientation by making it logically impossible to prove that one has a monosexual identity. Both straights and gays have shared investments in stabilizing their identities, as members of all groups are likely to draw some comfort from rigid social orderings. Straights and gay, however, also have distinctive investments in stabilizing orientation categories. For straights, it is an investment in the retention of heterosexual privilege; for gays, it is an investment in the retention of the immutability defense and one in the ability to form an effective political movement.

\section{Shared investment.}

Bisexuality calls into question the sexual orientation of the self. To see this, contrast the ease of proving one is straight or gay in a world in which

258. Compare, e.g., COLKER, HYBRID, supra note 9, at 21-24 (noting that many gays have negative opinions about bisexuality), with, e.g., id. at 24 (noting that some gays were more tolerant of Colker's fluid sexuality than she herself was). 
bisexuals are not acknowledged to exist with the difficulty of proving the same thing in a world in which bisexuals are recognized. In a world that denies bisexual existence, cross-sex desire and same-sex desire are mutually exclusive. ${ }^{259}$ This means that the presence of cross-sex desire ipso facto negates the presence of same-sex desire, and vice versa. Thus, demonstrating cross-sex desire is sufficient to prove that one is heterosexual and not homosexual.

That we live in this world - and under this analytic regime-is demonstrated by how sexual orientation is proved here. As I will show in some detail, alleged harassers in the sexual harassment context have adduced exactly such claims of cross-sex desire as dispositive of their heterosexuality. 260 Similarly, legal institutions assigning individuals a homosexual identity have presumed that any individual who has manifested same-sex desire (and not deployed the queen-for-a-day exception) is homosexual.261

In a world that recognizes bisexuals, a would-be heterosexual must show (1) that he is not gay and (2) that he is not bisexual. (While I take heterosexuality as my example, it should be clear that this analysis is equally applicable to homosexuality.) The first he can do by showing cross-sex desire. The second he can only do by proving the absence of same-sex desire. But this is impossible to do, as it is impossible to prove a negative. Thus, after the bisexual possibility is acknowledged, it is not only harder, but logically impossible, to prove one's heterosexuality. Evidence of cross-sex desire is nonresponsive to the charge that one harbors same-sex desire, for no amount of loving attention that a man gives to his wife can prove that he does not lust in his heart for men. In order to safeguard a regime in which "straightness" (or "gayness") can be proved, all monosexuals must repress bisexual existence.

Both straights and gays have a shared investment in stabilizing their identities, as members of all groups take comfort in knowing their place in the social order. This interest may seem less intuitive for gays, who occupy a disfavored place in that order. But as Mary McIntosh has noted, rigid categorization may be comforting even to those stigmatized within it, because "it appears to foreclose on the possibility of drifting back into normality and

259. This analysis assumes, without endorsing, the erasure of asexuality as an analytic possibility. See note 8 supra.

260. See notes 520-534 infra and accompanying text. See, e.g., N.H. REV. STAT. ANN. § 170B:2 (1992) (defining anyone who engages in same-sex oral or anal sex as a homosexual); Woodward v. United States, 871 F.2d 1068, 1069 n.1 (Fed. Cir. 1989) (quoting Secretary of the Navy Instruction 1900.9A) (describing Navy's pre-1993 policy defining anyone with same-sex desire as a homosexual).

261. See COLKER, HYBRID, supra note 9, at 45-56 (discussing the legal definition of homosexuality in adoption and military contexts). 
thus removes the element of anxious choice."262 Robin Ochs provides anecdotal support for this hypothesis:

When I have asked gay men to explain their fears about bisexuality and bisexual people, one theme has repeatedly arisen. As one gay man put it, "Coming out as gay was the hardest and most painful thing I have ever done in my life. Now I'm finally at a place where I have a solid identity, a community, a place to call home. Bisexuals make me uncomfortable because their existence raises for me the possibility that I might be bisexual myself. And coming to terms with my identity was so hard for me the first time around, I cringe at the thought of having to go through such a long, hard, painful process a second time."263

Thus gays, along with straights, share an interest in identity stabilization, since such stabilization roots them in a community and relieves them of the anxious work of identity interrogation.

\section{Straight investment.}

As members of the privileged orientation class, straights have a distinctive interest in maintaining their identity. That identity must be assured at both the individual and at the collective levels.

At the individual level, bisexuality threatens heterosexuals in the manner described above, by making it impossible for them definitively to prove their heterosexuality. The investment in stabilizing their orientations at the individual level leads self-identified straights to take different stances toward homosexuals and bisexuals. Ironically, the investment in heterosexual privilege can lead straights to increase the visibility of homosexuals. Prior to the introduction of the concept of homosexuality, no such incentive existed, as the concept of heterosexuality was so universal as to be itself invisible. ${ }^{264}$ Since the introduction of the concept of homosexuality, ${ }^{265}$ however, heterosexuality's stability has been predicated on opposition to homosexuality, as

262. Mary McIntosh, The Homosexual Role, in FORMS OF DESIRE: SEXUAL ORIENTATION AND THE SOCIAL CONSTRUCTIONIST CONTROVERSY 25, 28 (Edward Stein ed., 1990).

263. Ochs, supra note 63, at 232.

264. See John D'Emilio, Sexual Politics, Sexual Communities: The Making of a HOMOSEXUAL MINORITY IN THE UNITED STATES 1940-70, at 10 (1983) (noting that in colonial America, where "the existence of lesbians and gay men was inconceivable," the term “'[h]eterosexuality' remained undefined, since it was literally the only way of life"); GARBER, supra note 11, at 40 (asserting that '[b]efore people began to speak of 'homosexuals' as a kind of person, a social species, there was no need for a term like 'heterosexual'"). The fact that the term heterosexuality is a conceptual back formation from the term homosexuality is reflected linguistically in the fact that the word "heterosexual" post-dated the word "homosexual." See GARBER, supra note 11, at 40; DAVID M. HALPERIN, ONE HUNDRED YEARS OF HOMOSEXUALITY 155 n.1 (1989).

265. See, e.g., 1 FoUCAULT, supra note 95 , at $42-43$ (dating creation of concept of the homosexual to the late nineteenth century). 
"the denotation of any term is always dependent on what is exterior to it."266 That opposition in turn is only possible if homosexuals are visible enough to be distinguished away. Thus, even attempts to exorcise homosexuality beyond the pale of discourse do so only by naming it.267 It is in this sense that D.A. Miller claims that heterosexuals "unabashedly need" homosexuals. 268

While straights need gays, they do not need bisexuals. To the contrary, the very system in which straights need homosexuals is undergirded by bisexual nonexistence. This is because straights need gays to exorcise the possibility of same-sex desire from themselves. But this exorcism can only occur in a world where bisexuals do not exist.

Two linked objections might be raised. The first is that most heterosexuals actually do not spend much time worrying about whether they are straight. Like whiteness in the race context, ${ }^{269}$ heterosexuality in the orientation context is sufficiently privileged as to achieve a kind of transparency. 270 It might thus be contended that straights cannot be repressing bisexuality out of any need to prove their straightness since they do not feel this need. This contention, however, has grown harder to make, as the greater visibility of sexual minorities (indicatively gays) has somewhat denaturalized heterosexuality. More to the point, the fact that straights can leave their sexual orientations undertheorized should itself be seen as a precious entitlement.271 Even straights who do not feel as if they must prove their sexual orientation may have an interest in not having to think about their sexual orientation. And bisexuality, more than homosexuality, requires them to do precisely this.

A related objection is that, as a practical matter, we assess orientation by gestalt intuitions rather than by analytic proof. A woman might not be able to "prove" that her husband is straight, but she may believe she can comfortably infer this from any number of small gestures he makes towards her and other women and men. And if no analytic proof is required, it arguably does not matter that no such proof exists. But this is debatable-being told that there is no logical way to prove one is straight could plausibly affect

266. Diana Fuss, Inside/Out, in InSIDE/OUT: LESBIAN ThEORIES, GAY THEORIES 1, 1 (Diana Fuss ed., 1991).

267. "Don't ask, don't tell" is a good instance of this dynamic as it makes homosexuality unspeakable by naming it for the first time in the United States Code. See 10 U.S.C. $\S 654$ (1994).

268. D.A. Miller, Anal Rape, in INSIDE/OUT: LESBIAN THEORIES, GAY THEORIES, supra note 266 , at 135 .

269. See Barbara J. Flagg, "Was Blind, But Now I See": White Race Consciousness and the Requirement of Discriminatory Intent, 91 MiCH. L. REV. 953, 957 (1993). As Flagg notes: "The most striking characteristic of whites' consciousness of whiteness is that most of the time we don't have any. I call this the transparency phenomenon: the tendency of whites not to think about whiteness, or about norms, behaviors, experiences, or perspectives that are white-specific." Id.

270. See, e.g., Janis Bohan, PSYCHOLOGY AND SEXUAL ORIENTATION 31-34 (1996).

271. See EVE KosOFSKY SEDGwick, Privilege of Unknowing: Diderot's The Nun, in TENDENCIES 23, 23 (1993) (discussing this "privilege of unknowing"). 
even one's informal orientation ascriptions. Indeed, the popular press, when linking bisexuality with AIDS, often sought to affect orientation ascriptions in exactly this way, suggesting that women could not know for certain that their husbands were straight.272 Moreover, something closer to the rigorous form of proof may be required in specialized contexts. As I will show, 273 this includes the legal realm, a context in which orientation determinations have some of their most serious consequences.

Bisexuality challenges the integrity of heterosexuality at the collective as well as at the individual level. Individual straights wish to stabilize the straight/gay binary because they wish to locate themselves as belonging to the heterosexual group. What membership in that group means, however, is determined at the collective rather than at the individual level. As Naomi Mezey has argued, straights collectively attempt to preserve a "heterosexual ethic," that is, an ethic that heterosexuality has the monopoly on sexual virtue. ${ }^{274}$ In order for the heterosexual ethic to present itself as congruent with virtue, however, the homosexual ethic must be presented as congruent with vice. 275 The survival of the heterosexual ethic is thus dependent on a binary world view of "right and wrong, of health and sickness, of heterosexual and homosexual."276

Mezey describes the martial rhetoric of homophobia as arising out of this dependence. ${ }^{277}$ She then astutely notes that the real enemy to the heterosexual ethic is not the named enemy of homosexuality, but the unnamed enemy of bisexuality.278 By deconstructing the straight/gay binary, bisexuality reveals that it cannot be isomorphic with the virtue/vice binary. It thus threatens the heterosexual ethic at the collective level as well as threatening heterosexual identity at the individual level.

\section{Gay investment.}

Gays, as well as straights, have distinctive investments in stabilizing their sexual orientation. Again, their interest in such stabilization is less intuitive. I earlier noted that gays, like straights, have a generic interest in simply "knowing their place" in the social order, even if that place is a stigmatized one. But gays also have interests in identity stabilization that arise

272. See, e.g., Richard A. Knox, Bisexuals Put Women at Risk, Studies Say, Boston Globe, June 20, 1990, at 57 (describing difficulty of knowing whether a "straight" man is actually bisexual); Jon Nordheimer, AIDS Specter for Women: The Bisexual Man, N.Y. TIMES, Apr. 3, 1987, at 1 (similar).

273. See notes 503-534 infra and accompanying text.

274. Mezey, supra note 8, at 112-21.

275. See id. at 116.

276. Id. at 115 .

277. See id.

278. See id. 
not in spite of, but because of, their stigmatized status. Insofar as these investments are related to stigma, they will be held by gays but not by straights. These interests may also be broken into individual and collective interests.

The individual gay interest in identity stabilization arises out of a desire to retain the immutability defense. Gays often defend their homosexuality by characterizing it as an immutable trait.279 This defense can sometimes mitigate the stigma associated with homosexuality, both in the eyes of others 280 and in the eyes of gays themselves. 281 Immutability has exonerative force because of the widely held belief that it is abhorrent to penalize individuals for matters beyond their control. ${ }^{282}$ That belief has found widespread expression in American anti-discrimination jurisprudence. ${ }^{283}$

Bisexuals threaten the immutability defense. The reasoning here is not immediately obvious. Formally, bisexuality and immutability are not necessarily inconsistent. There could, after all, be four immutable categoriesimmutable heterosexuality, immutable homosexuality, immutable bisexuality, and immutable asexuality. 284 Indeed, there might be an infinite number of categories on (and off) the sex-of-object choice spectrum, all of which are immutable.

But as a practical matter, the introduction of bisexuals complicates the immutability defense through a two-step process. First, once the bisexual possibility is introduced, it becomes impossible for the self-identified gay to prove he is gay, in precisely the same way it becomes impossible for the selfidentified straight to prove he is straight. ${ }^{285}$ Even assuming discrete immutable categories, it will be unclear whether the individual manifesting same-sex desire who says he is immutably gay is immutably gay, or whether he is in truth immutably bisexual. Second, to the extent that an individual is immu-

279. $\rightarrow$ Janet E. Halley, Sexual Orientation and the Politics of Biology: A Critique of the Argument from Immutability, 46 STAN. L. REV. 503, 507 (1994) [hereinafter Halley, Biology].

280. See id. at 567 (noting potency of immutability argument to persuade non-gays of the humanity of gays); see also id. at 518 n.62 (citing studies showing that people who think homosexuality is immutable are more likely to disapprove of discrimination against homosexuals).

281. See id. at 535 (describing researcher's elation at discovering an alleged biological basis for homosexuality, because the researcher had "'always felt that [he] was born gay"').

282. See, e.g., ESSAYS IN MORAL RESPONSIBILITY (John M. Fischer ed., 1986) (collecting essays describing relationship between moral responsibility and free will).

283. See, e.g., Frontiero v. Richardson, 411 U.S. 677, 686 (1973) (plurality opinion) (quoting Weber v. Aetna Cas. \& Sur. Co., 406 U.S. 164, 175 (1972)) (noting that legally burdening immutable characteristics violates "the basic concept of our system that legal burdens should bear some relationship to individual responsibility"). The Supreme Court has called this reliance on immutability into question in subsequent dictum. See City of Cleburne v. Cleburne Living Ctr., 473 U.S. 432, $442-43$ n. 10 (1985).

284. Cf. WEINBERG ET AL., supra note 113, at 4 (asking "[i]f homosexuality and heterosexuality are genetically predetermined, does that mean we need to look for a bisexual gene as well?").

285. See notes 259-273 supra and accompanying text. 
tably bisexual, his immutability will generally not work to exonerate him. This is because immutability offers absolution by implying a lack of choice. 286 But even an immutable bisexual is perceived to have a choice-he can choose to fit into the heterosexual matrix by selecting a partner of the opposite sex.287 The gay investment in bisexual erasure may thus arise in part because it problematizes the immutability defense.

Such an investment could be challenged on normative grounds, as immutability has the vices of its virtues. The virtue of the immutability defense is that it forecloses the question of validity. ${ }^{288}$ In so doing, however, it constantly defers the normative debate that could establish the identity's validity. 289 Indeed, avid use of the immutability argument may be read as an implicit concession of the identity's invalidity-for if an identity were truly perceived to be valid, many would not ask if it was immutable.290 Just as immutability moots the question of validity, so too does validity moot the question of immutability.

As the gay rights movement progresses, some theorists are privileging the validity argument over the immutability argument, contending that being gay is valid regardless of whether it is chosen. ${ }^{291}$ This may in part be fueled

286. See Halley, Biology, supra note 279 , at 518-19 (noting that immutability operates as an exoneration strategy because it eliminates choice).

287. See id. at 528 (noting that the immutability theory "does not explain why bisexuals-by hypothesis capable of satisfactory sexual encounters with members of the so-called 'opposite' sex-should not be encouraged or forced to do so"). To be sure, one could say that homosexuals also have this choice. But a social distinction appears to be drawn between the bisexual and the homosexual based on the perceived sacrifice each must make to choose to live as a heterosexual. The immutable bisexual, unlike the immutable homosexual, is not giving up all sexual pleasure in conforming to heterosexual norms of conduct, but merely giving up sexual pleasure with one of two sexes. See notes 90-91 supra and accompanying text.

A similar kind of logic can be seen in judicial treatments of bilingual individuals. In Garcia v. Gloor, 618 F.2d 264 (5th Cir. 1980), for example, the Fifth Circuit considered a Title VII employment discrimination claim brought by a bilingual Mexican-American employee to challenge his former employer's prohibition on speaking Spanish on the job. The court noted that " $[\mathrm{t}] \mathrm{o}$ a person who speaks only one tongue ... language might well be an immutable characteristic like skin color." Id. at 270 . It then went on to note, however, that "the language a person who is multilingual elects to speak at a particular time is by definition a matter of choice." Id. (emphasis added). Thus, the court reasoned that while people who do not possess a favored trait may be protected on grounds of immutability, people who possess both a favored and a disfavored trait will never be so protected, because they may always choose to manifest only the favored trait.

288. See Vera WhISMAN, QUEER BY CHOICE 11-13 (1996).

289. See id. at 6 ('If we argue against only the 'possible to change' assertion, we leave unchallenged the more insidious assumption that it is desirable or necessary to do so. And to the extent that homosexuality is acceptable only if it is not chosen it remains stigmatized, illegitimate, deviant.").

290. Cf. BERSANI, supra note 232, at 57 ("[T]he very question of 'how we got that way' would in many quarters not be asked if it were not assumed that we ended up the wrong way, the purpose behind the question has generally been to learn how we might best go back and right the wrong.").

291. See WhISMAN, supra note 288 , at 30-32. 
by the fact that the immutability defense is not available for gays who do not experience their orientation as immutable.292 (As conventionally told, lesbians are more likely than gay men to fall into this group because of lesbianism's nexus to feminism. ${ }^{293}$ To the extent that the immutability strategy it threatens becomes less important, bisexual visibility will become more palatable. Indeed, those wishing to hasten the move from immutability arguments to validity arguments might embrace bisexual visibility. This is because bisexuals, in contrast to homosexuals or heterosexuals, will always be seen as having a choice. ${ }^{294}$ As such, they literally embody the fact that individuals might choose (and choose to acknowledge) same-sex sexuality.

As a positive matter, however, the day when gays (or at least gay men) renounce the immutability defense appears distant. Even commentary deeply critical of the use of immutability in the courts recognizes that immutability remains a potent argument in the political forum. ${ }^{295}$ The immutability argument is often the only effective strategy for gays "seeking to persuade their parents, coworkers, and neighbors that they can love someone of the same sex and remain fully human."296 Continued gay reliance on the immutability argument may lead to continued gay reliance on bisexual erasure.

The other gay interest in stabilizing gay identity is a collective interest in effective political mobilization. Even (or perhaps especially) gays who believe that all individuals are somewhat bisexual may feel that bisexuals should nonetheless ally themselves with gays in order to combat homophobia. This is in part because bisexuals are seen as flight risks-individuals who could at any time abandon the gay community to lead straight lives.297 And even if they do not actually leave, bisexuals may be seen as less committed to fighting heterosexual privilege because of their ability to partake of

292. See Halley, Biology, supra note 279, at 520 .

293. See RUST, CHALLENGE, supra note 71 , at 163 (noting that some feminists see a connection between lesbianism and feminism, relying on the assumption that "lesbianism is a possible choice for all women").

294. Whether this is actually the case is open to question. In the Weinberg study, a group of bisexuals were asked: "Is it possible that someday you could behave either exclusively homosexual or exclusively heterosexual?" WEINBERG ET AL., supra note 113, at 33. Approximately eighteen percent of bisexuals said "no." Id. at app. A at 317 tbl. 3.2. This does not necessarily, but might, reflect the fact that some bisexuals do not experience themselves as being able to restrict themselves to one sex, such that they do not experience themselves as having a "choice" between sexes. Another way of putting this is that some bisexuals may actually fit the stereotypical view of bisexuals which holds that bisexuals feel intrinsically incomplete in sexual relations with only one sex.

295. See Halley, Biology, supra note 279, at 567-68 (criticizing reliance on immutability in legal context, but not in extra-legal political context).

296. Id. at 567.

297. See Ochs, supra note 63 , at $228-29$ (noting that "[m]any lesbians and gay men believe that bisexuals have less commitment to 'the community' and that whatever a lesbian or gay man might have to offer to their [sic] bisexual partner will not be enough to outweigh the external benefits offered to those who are in heterosexual relationships"). 
it. Moreover, even if bisexuals appear to be deeply committed to fighting heterosexism, they can be seen as inherently traitorous, insofar as solidarity requires not just supporting a group but also fighting (as opposed to consorting with) the group's enemies. ${ }^{298}$

This interest in bisexual erasure is thus an interest in ensuring that the line of battle is clearly drawn. The conflict between sexual minorities and those who oppress them is framed as isomorphic with the conflict between gays and straights, thus making the battle line the virgule in the "straight/gay" binary. ${ }^{299}$ Precisely because gays view themselves as a beleaguered minority, their tolerance for those who might sap their political solidarity by blurring that battle line is limited. .00

This interest may be more powerful for lesbians than for gay men. This may seem counterintuitive, as I earlier implied that because lesbians may have less invested in the immutability defense than gay men, bisexuals might not be as threatening to them along the axis of immutability. ${ }^{301}$ But it may be exactly because lesbians are more likely to view their orientation as fluid that bisexuals may be more deeply threatening to lesbians on the axis of political mobilization. If biology is believed not to provide a substrate for lesbian identity, then the fear that any given lesbian might become bisexual and thereby abandon the lesbian community looms larger. ${ }^{302}$

Like the investment in immutability, this investment in political stability can be challenged. Destabilization actually has four pro-gay deployments, which I speculatively order here from least to most radical. First, the bisexual possibility suggests that the straight category is not as monolithic or secure as it may originally seem. To the extent that bisexuals are waverers, gays should court, rather than suppress, bisexuals who are living as straights. This is especially true if we accept the results of the sexuality studies considered above, ${ }^{303}$ which indicate that the addition of bisexuals could significantly swell the ranks of homosexuals. Second, gays could deploy bisexuality's tendency to destabilize heterosexuality to enlist straights in the fight

298. See id. at 230 (describing lesbian hostility to bisexuals, and noting that part of the objection was that some lesbians "'believed that only lesbians had an antipatriarchal sexuality, which meant that only lesbians were working against sexism ... [and] conflated sexual practice and political action and believed that what one did in bed, and with whom, had direct consequences for supporting or dismantling a patriarchal power structure"' (citation omitted)).

299. See Mezey, supra note 8, at 115 (noting that "in a discourse of militant hetero- and homosexuality the divisions are clear; one knows who the enemy is and hence one knows oneself").

300. See id. at 118 (noting that "[a]s an oppressed subculture, homosexual communities rely on an ethic of homosexual identity to maintain strength and coherence against the constant onslaught of virulent [homophobic] attacks").

301. See note 293 supra and accompanying text.

302. Another way in which lesbians may be more threatened by bisexuals on the axis of political mobilization concerns the interest lesbians have in combatting patriarchy. I consider this interest below. See notes 345-352 infra and accompanying text.

303. See notes 110-176 supra and accompanying text. 
against the regulation of homoerotic conduct. Straights may be less likely to burden such minorities if they are worried about drifting into the stigmatized category themselves. 304 Third, bisexuals could be seen as performing a mediating or conciliatory office. If bisexuals are being erased in order to preserve the binary logic of agonistic conflict, it seems intuitive that bisexual visibility might challenge the paradigm of conflict itself. 305 Finally, bisexuals could be deployed not just as a third party alongside gays and straights, but as a category that permits gays to challenge any sexual orientation categorization. Something akin to this insight is neatly captured in the bisexual retort to being called a fencesitter-namely, "your fence is sitting on me."306 In this formulation, it is not fencesitting, but the fence, that is the problem; and it is not bisexuality, but the line establishing binary categorization, that needs to be erased.

The last possibility merits further discussion. A utopian version of the argument would use bisexuality as a means of retiring all sexual orientation classifications. ${ }^{307}$ The argument that the prevailing orientation classifications should be retired should be a familiar one to gays, as it is an argument they espoused even before the patterned visibility of bisexuality.308 At the beginning of the 1970s, gay liberationists "prophesied the disappearance of both 'the homosexual' and 'the heterosexual' through the abolition of constraining categories." 309 One theory of why this movement to retire categories ultimately did not reach fruition is that it was difficult to create a politics out of it. 310 Activists were faced with the perennial problem-how does one resist a categorization without organizing around the oppressed category?311 And

304. Cf. JOHN HART ElY, DEMOCRACY AND DISTRUST 160 (1980) (describing age as a category on which discrimination is less likely to occur because individuals understand that they will "drift" into the stigmatized category of old age).

305. See Highleyman, supra note 12 , at 90 (noting that "[m]any bisexuals object in principle to the gay and lesbian movement's 'us' versus 'them' paradigm").

306. Rebecca Kaplan, Your Fence Is Sitting on Me: The Hazards of Binary Thinking, in BISEXUAL POLITICS, supra note 7, at 267, 267.

307. See Mezey, supra note 8, at 99.

308. See Amanda Udis-Kessler, Identity/Politics: A History of the Bisexual Movement, in BISEXUAL POLITICS, supra note 7, at 17, 19 (noting that "[t]he word 'bisexual' existed before Stonewall, and there were people who lived as bisexuals, even famous ones at times" but that "the focus on bisexuality as a core aspect of one's identity does not seem to have arisen in any patterned way until after Stonewall").

309. Steven Epstein, Gay Politics, Ethnic Identity: The Limits of Social Constructionism, in FORMS OF DESIRE: SEXUAL ORIENTATION AND THE SOCIAL CONSTRUCTIONIST CONTROVERSY 239, 252 (Edward Stein ed., 1990). According to Epstein, this post-Stonewall activism was a departure from homosexual politics in the preceding decades, which stressed the goal of integration without challenging the straight/gay dichotomy. See id.

310. See id. at 253-54.

311. See id. at 254 ("This is a familiar dilemma, and one that is by no means peculiar to the gay movement: How do you protest a socially imposed categorization, except by organizing around the category? Just as blacks cannot fight the arbitrariness of racial classification without organizing 
how can one organize around the category without reifying the very categorization one seeks to retire?

It is worth revisiting these questions, as bisexuality provides an ingenious answer to them. This is because bisexuality may be "not just another sexual orientation but [also] a sexuality that undoes sexual orientation as a category." 312 One paradox is answered by another-the general paradox that one can only challenge a classification through classes that reify it is answered by the specific paradox that bisexuality is a class that challenges the very classification that creates it. Precisely because bisexuality no sooner asserts itself as a category than it questions its own boundaries, bisexuality is arguably the post-Stonewall activist's dream. ${ }^{313}$

Again, however, these normative objections may not sway many gays who hold this particular investment in bisexual erasure. Gays face significant political oppression under the prevailing straight/gay paradigm. Given this, many gays feel that the energies of the movement should be devoted to arguing within, rather than against, that paradigm. This is particularly true since gays have used that paradigm to create an effective politics of opposition.

\section{B. Bisexuality Destabilizes the Primacy of Sex}

The second investment straights and gays have in bisexual erasure is that bisexuals are seen to destabilize the primacy of sex as a diacritical axis. Straights and gays have a shared investment in the primacy of sex because their orientation identities rely on it. Straights have a peculiar investment in the primacy of sex because sex identities are currently determined by a straight matrix. And gays have a peculiar investment because homosexuality is sometimes deployed as a means of sex separatism, which both reflects and reinforces the primacy of sex.

as blacks, so gays could not advocate the overthrow of the sexual order without making their gayness the very basis of their claims.").

312. GARBER supra note 11 , at 65 ; see also Mezey, supra note 8 , at 99 ("Bisexuality as a critique of the hetero/homo paradigm actually facilitates [a] more radical analysis, which concludes, ironically, that bisexuality works no better than the other two categories in accurately describing concrete sexual behavior, and that a new conceptualization of sexual identities, such as one based on acts, is needed.").

313. Or is it? One could contend that the conundrum is not so easily solved, for bisexuality's instability, which prevents it from reifying the categorization, also arguably makes it a politically ineffective category. Under this view, bisexuality offers the worst rather than the best of both worlds, being too inchoate to be an effective class and too rigid truly to contest the reification of orientation categories. 


\section{Shared investment.}

Bisexuality disrupts the primacy of sex as a diacritical trait. One disquieting aspect of the bisexual is that she refuses to require that an object of desire belong to a particular sex. In the stereotypical view, this is because the bisexual is sex-blind, ${ }^{314}$ refusing to distinguish at all between men and women in her erotic life. ${ }^{315}$ Under this characterization, the world the bisexual sees is like Foucault's "world in which grins $\mathrm{h}[\mathrm{a}] \mathrm{ng}$ about without the cat." 316 In this world, sexual pleasure becomes a (literally) floating signifier, a sexless smile left by a fading body.

The stereotypical view appears to misdescribe the majority of bisexuals. Some bisexuals claim to be sex-blind in the sense that they fall in love with a person rather than with a sex. ${ }^{317}$ But most appear to desire men as men and to desire women as women. Thus in the Weinberg study, over four-fifths of the bisexuals interviewed distinguished between being sexual with a man and being sexual with a woman, citing behavioral, bodily, and emotional differences. ${ }^{318}$ That finding comports with common sense- sex distinctions are so pervasive in contemporary American society that it is hard to believe that bisexuals could evade such distinctions.

314. By "sex-blind," I mean that a person does not take sex into account in choosing erotic partners. Following Neil Gotanda's analysis of colorblindness, I distinguish between literal and figurative forms of sex-blindness. See Neil Gotanda, A Critique of "Our Constitution Is ColorBlind," 44 STAN. L. REV. 1, 18-19 (1991). The literal form posits that the person does not even register other people's sexes. Literal sex-blindness is like medical color-blindness-just as the person who has red-green colorblindness cannot tell the difference between the two colors, so too does the person who has literal sex-blindness find it impossible to tell the difference between the sexes. Cf. id. The figurative form, in contrast, notes that the person registers other people's sexes, but attaches no consequence to that perception. Figurative sex-blindness is like juridical colorblindness. Just as those who espouse the colorblindness ideal say that they recognize differences in colors but attach no salience to those differences, so too do those espousing figurative sex-blindness say that they recognize differences between sexes but attach no salience to those differences. In my review of the literature on bisexuality, I have not come across any instances of individuals who claim that they are literally sex-blind. By "sex-blindness" I therefore mean figurative sexblindness.

315. This is the view that underlies the fears surrounding the "bisexual harassment exemption" discussed below. See notes 464-474 infra and accompanying text.

316. Michel Foucault, Introduction to HERCULINE BARBIN, BEING THE RECENTLY DisCOVERED MEMOIRS OF A NINETEENTH-CENTURY FRENCH HERMAPHRODITE vii, xiii (Michel Foucault ed., Richard McDougall trans., 1980). Foucault describes this world as the world seen by the hermaphrodite, but it seems more aptly the (stereotypical) view of the bisexual's world.

317. See COLKER, HYBRID, supra note 9, at 27 (describing bisexuals who state "'that when they fell in love it was with a person rather than a gender"') (quoting BETTY FAIRCHILD \& NANCY HaYWARD, NOW that YOU KNOW: What EVERY PARENT SHOUld KNOW ABOUT HOMOSEXUALITY 75 (1989)); Paula C. Rust, Who Are We and Where Do We Go from Here? Conceptualizing Bisexuality, in CLOSER TO HOME: BISEXUALITY \& FEMINISM 281, 298 (Elizabeth Reba Weise ed., 1992) (describing attitudes of lesbian women toward bisexuality ranging from "bisexuals are indiscriminate" to "bisexuals fall in love with a person, not a gender").

318. See WEINBERG ET AL., supra note 113, at 50-53. 
Despite the fact that "sex-blind" bisexuals may comprise only a small minority of all bisexuals, bisexuality still presents a deep threat to sex norms. Even if bisexuals are not completely sex-blind, they still do not presumptively eliminate one sex from their fields of erotic possibility. For all bisexuals, whether sex-blind or not, sex matters less. ${ }^{319}$

Why is a challenge to the priority of sex so threatening to monosexuals? There appear to be two answers-challenging the primacy of sex destabilizes monosexual identity and underscores a tension between public and private attitudes toward sex.

\section{a. Destabilization.}

Challenging the primacy of sex destabilizes not only monosexual identity, but human identity. Judith Butler posits that in contemporary American culture, we are not viewed as human until we have a sex, that "the moment in which an infant becomes humanized is when the question, 'is it a boy or girl?' is answered." 320 Thus, "[t]hose bodily figures who do not fit into either gender fall outside the human, indeed, constitute the domain of the dehumanized and the abject against which the human itself is constituted."'321 Suzanne Kessler's study of the intersexed corroborates Butler's claim. ${ }^{322}$ Kessler describes how the medical profession preserves the existing binary at all costs through surgical "reconstruction" shortly after the birth of the intersexual ${ }^{223}$ - literally doctoring the data to fit the binary sex hypothesis. Even in situations where the intersexed infant is healthy, 324 the surgery is cast as a "neonatal psychosexual medical emergency," 225 supporting the claim that the infant's status as a human being is endangered by the mere fact of intersexuality itself. In such a culture, not to possess a sex is not to be human.

319. Marjorie Garber recounts the story of a woman, "Elizabeth," who fell in love with someone on the internet who was purported to be a man. See GARBER, supra note 11, at 33-34. When they finally met and the "man" revealed herself to be a woman, Elizabeth overcame her initial resistance over the course of the hour's conversation and then made love to her. See id. at 34 . Garber notes that Elizabeth does not self-identity as a bisexual, id., and she certainly would not seem to qualify as a "sex-blind" bisexual. Yet in her refusal to permit sex of object choice to be "the overriding consideration," id., she perhaps represents the anxiety of the bisexual possibility.

320. BUTLER, supra note 24, at 111. Linguistic support for this claim can be found in the fact that the infant who is not a "he" or a "she" must be an "it," a pronoun reserved for nonhuman subjects.

321. Id.

322. See generally KESSLER, supra note 18.

323. See id. at 12-32.

324. Kessler distinguishes between three kinds of genital surgery-(1) that which is lifesaving; (2) that which improves the quality of life; and (3) that which is aesthetic. See id. at 34 . By "healthy" I mean a child who does not require the first two kinds of surgery.

325. Id. 
But if this is true, does bisexuality, which stereotypically does not pass desire through the lens of sex, threaten human identity? Much more would need to be said before answering in the affirmative. Even without that discussion, however, it can be noted that bisexuality, like intersexuality, suggests that the question "Is it a boy or a girl?" is the wrong question to be asking. And if this is the question that determines our humanity, it should come as no surprise that the capacity of bisexuals to undermine the sex category is deeply threatening to individuals of all categories. 326

But while the bisexual's ability to undermine sex categories is generically troubling for all individuals in contemporary American society, it is arguably distinctively troubling for monosexuals. This is because monosexuals, unlike bisexuals, define their orientation identities according to that distinction - that is, by their attraction to men but not women, or vice versa. An individual's orientation can be affected not only by challenging the fixity of his orientation, but also by challenging the fixity of the sex of his object choice. Without a clear and privileged distinction between "man" and "woman," there is no clear and privileged distinction between "straight" and "gay." In the previous analysis, we saw that bisexuality directly challenged sexual orientation categories by destabilizing them. 327 Here we see that bisexuality indirectly challenges sexual orientation by destabilizing sex.

\section{b. The tension between public and private treatments of sex.}

There is a second reason why monosexuals might be peculiarly disturbed by the ability of bisexuals to call the primacy of sex into question. This relates to a tension in how sex is treated in the erotic and nonerotic realms. It is not quite true, as I said before, that it is always threatening to suggest that the "Is it a boy or a girl?" question is the wrong question. In the nonerotic realm, this question is widely marked as immoral. Thus, American antidiscrimination law prohibits the state and many employers from attaching consequence to the answer to this question. ${ }^{328}$ To some extent these norms carry over into the nondesirous private realm - those who discriminate on the basis of sex in their private affiliations are increasingly subjected to moral, if not legal, censure. 329 But when we enter the erotic realm, the norms shift dra-

326. That bisexuals may also be threatened by bisexuality's capacity to undermine sex categories may be seen in the insistence of many bisexuals, as noted above, that they are attracted to men as men and women as women. See note 318 supra and accompanying text.

327. See notes 259-313 supra and accompanying text.

328. See generally CASES AND MATERIALS ON SEX-BASED DISCRIMINATION (Herma Hill Kay \& Martha S. West eds., 4th ed. 1996).

329. See, e.g., Harvard Woman Sues Male 'Flies,' S.F. CHRON., Mar. 3, 1988, at B6 (describing legal challenge to all-male student clubs); Andrea Estes \& Erin N. O'Leary, Judge Orders Club to Put Women on Par with Men, BOSTON HeRALD, Dec. 2, 1998, at 4 (describing court order mandating sex integration of tournaments at Massachusetts golf club); Patricia Wen, Single-Sex 
matically in the other direction, such that sex distinctions are not only permitted, but expected. Monosexuals routinely discriminate on the basis of sex in choosing their erotic partners; indeed, that practice constitutes them as monosexuals.

There is thus a fundamental tension in the treatment of sex in the nondesirous and desirous realms. If I discriminate between male and female employees in the workplace, I can expect in many quarters to be criticized for political insensitivity. But if I discriminate between male and female partners in my erotic attachments, I am much less likely to encounter such criticism. Indeed, to the extent that I discriminate in favor of a same-sex erotic partner, it is my critic who can expect (in some quarters) to be criticized for political insensitivity.

This tension requires justification, not only because of its facial inconsistency, but also because of its deep consequentiality. Specifically, acceptance of discrimination in the desirous private realm may render it impossible to fully reject discrimination in the public realm. In the law, this problem is perhaps best seen in the judicial refusal to mandate that legal distinctions between the sexes be completely abolished. Thus, while the Supreme Court's equal protection jurisprudence subjects race-based classifications to strict scrutiny, 330 it subjects sex-based classifications only to intermediate scrutiny. ${ }^{331}$ Even as the actual nature of intermediate scrutiny has tacked closer to strict scrutiny, 332 the Supreme Court has retained the rhetorical distinction between race-based and sex-based classifications. ${ }^{333}$ We have thus not been able to push jurisprudential norms against sex discrimination as far as we have pushed norms against race discrimination.

While commentators have justified this distinction in a number of ways, ${ }^{334}$ the justification most pertinent to this analysis relates to desire. George Rutherglen explains the lower tier of scrutiny associated with sex by noting that sex-based "classifications are valued for their own sake within an

Health Clubs Get Protection, Boston GloBe, Feb. 7, 1998, at B1 (noting NOW's opposition to bill legalizing single-sex health facilities).

330. See, e.g., Bush v. Vera, 517 U.S. 952, 952 (1996); Adarand Constructors, Inc. v. Pena, 515 U.S. 200, 201 (1995).

331. See, e.g., United States v. Virginia, 518 U.S. 515, 515 (1996); J.E.B. v. Alabama ex rel. T.B., 511 U.S. 127, 127 (1994).

332. See Cass R. Sunstein, The Supreme Court, 1995 Term-Foreword: Leaving Things Undecided, 110 HARV. L. REV. 4, 75 (1996) (noting that the Court in Virginia "did not merely restate the intermediate scrutiny test but pressed it closer to strict scrutiny").

333. Cf. Virginia, 518 U.S. 515.

334. For example, they have noted that women, unlike blacks, are not a minority, see JOHN HART ELY, DEMOCRACY AND DISTRUST 164 (1980); that women, unlike blacks, have historically been integrated with the dominant group, see id.; and that women, unlike blacks, exhibit "real" physical differences that distinguish them from the group to which they have been historically subordinated, $\rightarrow$ Sylvia A. Law, Rethinking Sex and the Constitution, 132 U. PA. L. REV. 955, 1007 (1984). 
important area of human life, namely sexual conduct, whereas racial classifications are neither so widely nor so openly valued in everyday life." 335 Sex is different from race insofar as we not only permit, but expect, individuals to have desires vectored toward only one sex.

The extent to which the monosexual presumption in the desirous realm blocks an advance to a sex-blind regime in the nondesirous realm should not be underestimated. Our erotic relationships, after all, are often viewed as simultaneously constituting and reflecting our most important emotional attachments. If we routinely structure these crucial relationships by discriminating on the basis of sex, it should come as no surprise that we (and our judicial institutions) experience a failure of nerve when asked to categorically abolish all sex-based distinctions.

Monosexuals could defend the distinction between public sex-blindness and private sex-consciousness in a variety of ways. 336 I do not seek to evaluate these rationales here, as my point is simply that bisexuals may occasion anxiety because they hold out the conceptual possibility that these rationales are not dispositive. Bisexuality implies that sex need not be as important in our desirous lives as we have made it. .337 Bisexuals and asexuals are thus the only individuals who at least have the capacity not to discriminate on the basis of sex in any aspect of their lives. ${ }^{338}$ As such, they have the potential to evade the public/private tension with regard to sex in which monosexuals find themselves.

\section{Straight investment.}

Straights have a distinctive investment in bisexual erasure relating to the primacy of sex. This is because sex is currently understood through a heterosexual matrix; that is, straights have a monopoly on sex norms. And bisexuality, unlike homosexuality, has the potential to disrupt that monopoly. (1979).

3: $\rightarrow$ George Rutherglen, Sexual Equality in Fringe-Benefit Plans, 65 VA. L. REV. 199, 209

336. First, they could point to the fact that they experience their orientations to be immutable, such that the desire is beyond their control. Second, they could rely on autonomy arguments relating to their right to discriminate in an immensely intimate and consequential sphere of their life. Third, they could contend that their private norms of sex-discrimination rely on "real differences" between men and women, which are recognized as permissible even by public anti-discrimination norms. Fourth, they could contend that differentiation between the sexes for desirous purposes should not be considered "discrimination" because it does not have subordinating effects. There are doubtless many other possible rationales.

337. See COLKER, HYBRID supra note 9, at 30 (noting that "embracing the category of bisexuality would help society recognize that one can find an organizing principle other than biological sex to define sexual attractiveness").

338. I thank Ian Ayres for this point. 
To see this, begin with the increasingly accepted view that we all perform our sex to some degree.339 Sex, no less than any other performance, is always shaped by its audience. When we perform our sexes, for whom are we performing? The answer is at least partially that we are performing for those who might potentially desire us, and that the performance is an attempt to convert that potentiality into an actuality. The performance of sex will thus always be affected by prevailing codes of desire. When (as now) heterosexuality is the prevailing code of desire, women will be encouraged to perform their sex in a way that is attractive to men (and vice versa, although the symmetry is not complete). To be a "woman" is to be attractive to men, to be a "man" is to be attractive to women. 340

It is therefore an error to accede to the conventional wisdom that sex is a stable, prediscursive substrate from which heterosexuality is a simple back formation. ${ }^{341}$ While heterosexuality is a back formation from sex, it is also paradoxically true that sex is a back formation from heterosexuality. Current norms of sex and current norms of heterosexuality are thus implicated in a feedback loop in which each shores up the other.

Homosexuality does not present much of a challenge to prevailing sex norms in this regard. Even if men begin to look with desire at other men, this may not significantly change sex performance, as that desirous look is read as the familiar look of the heterosexual woman now displaced in a man's body. This is the modern vestige of the older trope of the homosexual as "invert"- a "woman trapped inside a man's body" or vice versa. ${ }^{342}$ The logic of the invert is the means through which homosexuality is read back into a straight paradigm. ${ }^{343}$

339. See, e.g., BUTLER, supra note 24, at 24-25. While Butler refers to gender rather than sex in this quotation, she elsewhere hypothesizes that there is no real distinction between gender and sex. See id. at 7 (describing the distinction as "no distinction at all").

340. See DUNCAN KENNEDY, SEXY DRESSING, ETC. 161 (1993) ("So long as I am a straight man, a part of my being is hostage to women: I want them to exist as women, not men, as bearers of the possibility of my own sexual excitement.").

341. See note 194 supra and accompanying text.

342. See Tim Edwards, Beyond Sex and Gender: Masculinity, Homosexuality and Social Theory, in MEN, MASCULINITIES \& SOCIAL THEORY 110, 112 (Jeff Hearn \& David Morgan eds., 1990) (noting characterization of male homosexuals as those who suffer from having a "feminine soul in a male body").

343. As Bersani notes, sometimes the infliction of the male gaze on a male performer is read back into the heterosexual matrix by inverting the sex of the performer rather than that of the observer:

The New York Times reported on April 3, 1993, that a radar instructor who chose not to fly with an openly gay sailor, Keith Meinhold, feared that Meinhold's "presence in the cockpit would distract him from his responsibilities." The instructor "compared his 'shock' at learning there was a gay sailor in his midst to a woman discovering 'a man in the ladies' restroom." Note the curious scatological transsexualism in our radar instructor's (let us hope momentary) identification of his cockpit with a ladies' restroom. In this strange scenario, the potential gay attacker becomes the male intruder on female privacy, and the "original" straight man is 
The bisexual, on the other hand, deeply destabilizes sex norms because her desirous look cannot be as easily collapsed into a straight paradigm. How does a man make a bisexual desire him? Not by adopting aspects that have traditionally been described as "masculine" as the bisexual is also potentially attracted to the "feminine." The logic of inversion is insufficient here to protect traditional sex norms from bisexuality because bisexuality does not simply invert cross-sex desire, but rather supplements it with samesex desire. Bisexuality, then, contests heterosexuality's current monopoly on sex performance in a way that homosexuality cannot.

\section{Gay investment.}

Gays, as well as straights, have investments in preserving the primacy of sex as a diacritical trait. Unlike straights, gays can deploy their homosexuality to engage in a sex separatism that is not only social, but also erotic. Bisexuals threaten this sex separatism by creating a bridge to the opposite sex.

All gays can engage in a more total form of sex separatism than is possible for noncelibate heterosexuals. Gays have at least the capacity to live a full erotic (as well as a social and a political) life in a community from which the other sex is completely excluded. Thus, at least along the axis of separatism, lesbians and gay men are just as, if not more, likely than straights to privilege the importance of sex as a diacritical trait. ${ }^{344}$

The best example of gay sex separatism is when women's political solidarity (feminism) is hypothesized to be connected to their same-sex erotic attachment (lesbianism). As articulated in the old slogan "Feminism is the theory, lesbianism is the practice," 345 the view is that the authenticity of a

metamorphosed, through another man's imagined sexual attention, into the offended, harassed, or even violated woman.

BERSANI, supra note 232, at 16-17 (citations omitted).

344. This insight may be somewhat counterintuitive, given that homosexuality is often seen as undermining the importance of sex. It is of course true that homosexuality is often seen as subverting sex expectations, given that many stereotypically deem gay men to be less masculine and lesbians to be less feminine than their straight counterparts. It is also true that homosexuality can be seen as diminishing certain forms of hierarchy between the sexes to the extent, for example, that lesbianism can be seen as empowering feminism. But diminishing sex-based hierarchy and diminishing sex-based consciousness are two different things, and I would contend that homosexuality can do the former not in spite of, but because of, the fact that it does not do the latter.

345. The slogan "Feminism is the theory, lesbianism is the practice," is usually attributed to Ti-Grace Atkinson. See, e.g., Nancy Chater \& Lilith Finkler, "Traversing Wide Territories": $A$ Journey from Lesbianism to Bisexuality, in PLURAL DESIRES: WRITING BISEXUAL WOMEN'S REALITIES 14, 15 (Leela Acharya, Nancy Chater, Dionne Falconer, Sharon Lewis, Leanna McLennan \& Susan Nosov eds., 1995) (attribution of quotation to Atkinson by Finkler). As Nancy Chater notes, however, the original quote was actually "Feminism is a theory, lesbianism is a practice." Id. at $36 \mathrm{n} .1$; see also GARBER, supra note 11, at 44 (quoting Atkinson correctly as saying "Feminism is a theory, lesbianism is a practice"). As Chater notes, the alteration in the slogan is "subtle but 
politics is determined by how it plays out in erotic practice. While this is an extreme position, one way of reading it is to note that, as Adrienne Rich has famously argued, this distinction between political and erotic same-sex attachments may itself falsely binarize a continuum of practices in which women identify with other women. ${ }^{346}$

Like lesbians, gay men can also create communities that are totally sex segregated. Indeed, given the dominance of men in almost every sphere of public life (perhaps most pertinently employment) it is likely to be easier for a gay man than for a lesbian to live a life that entirely excludes those of the other sex. But while gay men have more opportunity to engage in sex separatism, they may have less motive to do so. For if "Masculinism is the theory, gay maleness is the practice," does not trip off the tongue, it must be in part because men as a group are not disempowered. ${ }^{347}$ Lesbians may draw synergistic connections between their disempowered status as women and their disempowered status as homosexuals. In contrast, the gay man's privileged status as a man can be experienced as conflicting with his stigmatized status as a homosexual. Patriarchy makes the social meaning of lesbian separatism different from the social meaning of gay male separatism.

This difference in turn may make bisexuals more threatening to lesbians than they are to gay men. If homosexuality permits a dream of a social world without the other sex, bisexuality disrupts that dream by constantly holding out the possibility of cross-sex attachment. But the awakening may be ruder for lesbians than for gay men, precisely because cross-sex attachment may signify capture by patriarchy.

One way of understanding this is to consider so-called lesbian pornography, that is, the "[p]ortrayals of allegedly lesbian 'scenes"' that "are a staple of heterosexual pornography." 348 It might be asked why the straight male consumers of this pornography find the scene so titillating, as it could actually signify an erotic world in which there is no need for men. ${ }^{349}$ Many of the possible answers cluster around the power of the male gaze to override

crucial," Chater, supra at $36 \mathrm{n} .1$, arguably shading an ostensibly neutral distinction between feminism and lesbianism into a hierarchical formulation favoring the latter.

346. See Adrienne Rich, Compulsory Heterosexuality and Lesbian Existence, in POWERS OF DESIRE: THE POLITICS OF SEXUALITY 177-205 (Ann Snitow, Christine Stansell \& Sharon Thompson eds., 1983). This breakdown of the distinction between the political and the personal may partially explain why lesbians are less likely than gay men to deploy immutability as an etiological explanation for their homosexuality. Whether it is in actuality chosen or not, lesbians may feel as if their same-sex attachments are more constructed than essential, given that such attachments are political as well as erotic.

347. See SEDGWICK, supra note 4, at 36 (describing this position).

348. John Stoltenberg, Pornography, Homophobia and Male Supremacy, in PORNOGRAPHY: WOMEN, VIOLENCE, \& CIVIL LIBERTIES 145, 155 (Catherine Itzin ed., 1992).

349. See Rich, supra note 346 , at 187 (describing the male fear that "women could be indifferent to them altogether, that men could be allowed sexual and emotional-therefore economicaccess to women only on women's terms"). 
any intimation that the women are unavailable to straight men. 350 If, for example, the male spectator believes that the women are both available to him, their numerosity enlivens rather than excludes: He sees two odalisques rather than one couple. The same inability to imagine a woman who does not desire men may lead to the belief that the absence of men in the sexual scene signifies that he himself is that man, that the invisibility of men in the mise en scène is the invisibility of subject position. Yet again, the spectator may believe that the scene depicts women out of control of their sexuality, such that a man's entry would lead them to direct greater attention toward him. Undergirding all of the above interpretations is the assumption that the male gaze is so powerful that there is no female body that is not ultimately arrayed for male delectation. And this in turn means that there is no woman who does not care about the male gaze; there is no woman who does not desire men.

One might therefore think that the male gaze reads all women into straight women. But the denomination of the scene as "lesbian" pornography, as well as the scene's surface depiction of a woman's desire for a woman, would seem to undercut this. I think we must entertain the possibility that part of the appeal of these scenes lies in the male gaze's ability to override the desire that women have for each other. In other words, even when women are acknowledged to desire each other, that desire is nonetheless only there to be trumped by the desire that men have for them. In the context of "lesbian" pornography, the male gaze may be an optic where sexism and heterosexism are powerfully fused-men sexually conquer women at the same time as heterosexuality conquers homosexuality. Under this reading, the charge of the scene derives from the man's triumph over both feminism and lesbianism, sexual conquest is political conquest. For that charge to exist, then, the women cannot be straight, as the charge depends on an overridden same-sex desire.

But this means that the "lesbians" in the pornography are being read not as straight women, but as "bisexuals." 351 Straights in this context may thus be using precisely the set of analytic moves described earlier, in which bisexuality destroys the ability of monosexuals to prove that they are monosexual.352 No matter how ardently the women express their desire for each other, they are unable to exorcise the possibility raised by the male gaze, in which that desire not only coexists with, but is superseded by, a desire for

350. See ANDREa DWORKIn, PoRnography: MEN PoSSESSING WOMEn 47 (1989) (describing "lesbian" pornography as "the ultimate tribute to male power: the male is not in the room, yet the women are there for his pleasure").

351. This might be seen as an anomalous way in which straight males make bisexuals more, rather than less, visible. What is curious, however, is that they do not make bisexuals visible as such-recall that the pornography is still viewed as "lesbian" pornography, rather than as "bisexual" pornography.

352. See notes 259-263 supra and accompanying text. 
men. Bisexuality in this formulation may threaten lesbians as the trope through which women's attachments to women are imaginatively destroyed and falsified. Indeed, if I am right, the destruction and falsification are what in part stimulate male desire.

The analysis may be generalized beyond pornography-bisexuals may be threatening to lesbians as a cultural trope for the phantasmatic subversion of their same-sex desire by straight men. Patriarchy, here especially the male gaze, may thus make bisexuals more threatening along this axis to lesbians than to gay men.

\section{Bisexuality Destabilizes Norms of Monogamy}

Even in its nomenclature, bisexuality is framed as excess. To be "bi" is to be doubled,353 to be "mono" is to be one. ${ }^{354}$ To defamiliarize these formulations, we might return to the Freudian conception of originary bisexuality, which frames bisexuality as an prelapsarian wholeness from which we fall away. ${ }^{355}$ Rather than denominating the monosexual as whole and the bisexual as surfeit, we might denominate the bisexual as whole and the monosexual as fragment. Viewed in this light, the flaw might be seen not as the bisexual's excess, but rather the monosexual's lack. ${ }^{356}$

That we do not view things in this light can be seen not only in the way we name bisexuals, but also in the way that we otherwise portray them. Bisexual desire is seen not as a completion, but rather as an excess. This is perhaps most clearly seen in the stereotype of bisexuals as promiscuous. 357

It should therefore not surprise that the final investment straights and gays have in bisexual erasure stems from their perception that bisexuality threatens norms of monogamy. The investment in that norm shared by

353. See 2 OED, supra note 9 , at 165.

354. See 9 id. at 1008-09.

355. See note 92 supra and accompanying text.

356. A similar paradigm shift was made in The Symposium with regard to sex. See Plato, SYMPOSIUM 41-45 (Benjamin Jowett trans., Hayden Pellicia rev., 1996). There Aristophanes recounts the story of how each man and woman was originally conjoined at the back to another man or woman. As punishment for arrogance, each man and woman was cut away from his or her other half. This is why men and women now go about searching for other men and women, in the hopes that by finding their lost other halves, they can regain their prelapsarian wholeness. Again, this challenges our view that individual men and women are whole units and that paired men and women are doubled units. It instead encourages us to view the couple as the unit and individual men and women as incomplete halves of that unit. That view, of course, has more credence in contemporary American culture (think of descriptions of couples as "unions" or descriptions of spouses as "better halves") than the view that bisexuals represent a desired wholeness.

357. See WEINBERG ET AL., supra note 113, at 69. The self-conception of some bisexual groups demonstrates the strengths of this stereotype. The Washington, D.C. Bi-Women's (and Men's) Network, for example, was formed for "more traditionally oriented bis into monogamous or duogamous relationships only." See Political Activism: A Brief History, in BI ANY OTHER NAME, supra note 257 , at 359,361 . 
straights and gays is the sexual jealousy both groups experience in nonmonogamous (or potentially nonmonogamous) relationships. The distinctively straight investment relates to the perception that bisexual nonmonogamy leads to the transmission of HIV from the gay community to the straight community. The distinctively gay investment relates to the desire of some gays to evade the portrayal of gays as promiscuous.

\section{Shared investment.}

For both straights and gays, bisexuality can raise deep issues of sexual jealousy that may ultimately require its denigration or disavowal. I take the straight man who is romantically involved with a bisexual woman as my paradigm example. However, it should be clear that the anxieties discussed are not specific to his orientation or sex.

At the most basic level, the straight man is threatened by his female partner's bisexuality because he must compete not only with other men, but also with other women. One might say he is made to understand Woody Allen's famous quip that bisexuality doubles one's chances of getting a date on a Saturday night 358 from the other side. This fear, understood purely quantitatively, seems illogical. As a preliminary matter, it is based on bad mathshifting from being a "straight" woman to being a "bisexual" woman does not necessarily "double" your dating pool, as many straight men and lesbians will not date avowed bisexuals. ${ }^{359}$ More importantly, it seems unlikely that a significant part of the jealousy engendered by bisexuality can be explained by the anxiety of entering a larger dating pool. Does it make a difference whether one is competing with five billion people rather than two-and-a-half billion people? Or even fifty rather than twenty-five people?

These questions suggest that the threat of bisexuality is qualitative rather than quantitative. It is not that one's bisexual partner can leave you for twice as many people, but that she can leave you for a different kind of person. The anxiety is aroused not by rivals who might also offer what you possess, but by rivals who might offer what you do not possess.

While this qualitative concern is more intelligible, it is not beyond criticism. This is because the qualitative concern is based in part on the assumption that if one desires both sexes, one must consummate that desire with both sexes. As Paula Rust has noted, "the bisexual's ability to form relationships with members of both sexes is interpreted as a need for relationships

358. See Joseph P. Kahn, The New Book on Bisexuality, Boston GLOBE, Sept. 6, 1995, at 75 ("To be bisexual, Woody Allen once said, immediately doubles your chances for a date on Saturday night.").

359. See, e.g., RUST, CHALLENGE, supra note 71, at 101 (noting reluctance of lesbians to associate with bisexuals). 
with members of both sexes." 360 Rust then criticizes this logic, asking readers to "imagine concluding that a person who finds both blue and brown eyes attractive would require two lovers, one with each eye color, instead of concluding that this person would be happy with either a blue-eyed or a browneyed lover."361

Even if one retires the assumption that those who desire both sexes must consummate their desires for both sexes, the qualitative concern still survives. This is because the straight man may be certain of his bisexual partner's fidelity, but may still be concerned that because of her stated bisexuality, he is not satisfying all of her desires. Her articulation of her desire for women is read as an articulation of his erotic inadequacy.

But even this refined defense seems inadequate. As one commentator has noted, it would be incredibly hubristic to believe that any individual could ever satisfy all of another individual's desires, whether erotic or otherwise. 362 In emphasizing this limitation, bisexuality could thus sound a healthy note of realism about the incompleteness of all human relation. 363 Moreover, one could argue that to be found inadequate because of one's sex would be less threatening than to be found inadequate on some other ground, ${ }^{364}$ as all of us are inadequate in possessing only one sex. ${ }^{365}$

A final response might be that there is a difference between inarticulate and articulate bisexuality. To return to the earlier example, one might see a difference between a woman who mentions to her brown-eyed husband that she is also particularly attracted to men with blue eyes and a woman who keeps reiterating this to her husband. The difference between saying that you are attracted to others once and saying it repeatedly is the difference between realism and sadism; the first comports with norms of courteous monogamy while the second does not. Even if the woman continues to be attracted to men with blue eyes, she is not only supposed to refrain from acting on that attraction, but also to refrain from repeatedly articulating it. Carrying oneself as a bisexual must be read against this norm of courtesy. A man might accept that it is irrational to feel particularly inadequate because his partner

360. Paula C. Rust, Monogamy and Polyamory: Relationship Issues for Bisexuals, in BISEXUAlity: The PSYChOlogy AND POLITICS OF AN INVISIBLE MINORITY 127, 128 (Beth A. Firestein ed., 1996).

361. Id. One response to this is that an individual's sex is so much more important than an individual's eye color that the analogy is inapt. As discussed above, however, bisexuals may not necessarily hold the view that an individual's sex is more important than eye color. See notes 314319 supra and accompanying text.

362. See GARBER, supra note 11, at 451-52 (quoting interview with Brian Ford).

363. Id. at 451.

364. See WEINBERG ET AL., supra note 113 , at 108 (noting that bisexuals who dated bisexuals were more jealous of "outside" partners of their own sex because "a person of the same sex as themselves could meet similar needs and thus replace them."); see also GARBER, supra note 11, at 449-50 (discussing study).

365. I assume here that intersexuals also possess one, rather than two, sexes. 
stated to him once that she was attracted to women. He might, however, find it rational to feel inadequate if his partner kept reminding him of this.

The rub here is that the man is interpreting his partner's carrying herself as a bisexual to be such a reminder. But this is not necessarily the case, at least in the sense that his partner might carry herself as a bisexual for reasons other than to occasion jealousy.

As ever, there are normative rebuttals to each of the potential reasons why bisexuals might occasion jealousy. As ever, these normative rebuttals do not mean that the jealousies will diminish. To the extent that they endure, they will act as an incentive for bisexual erasure.

\section{Straight investment.}

Under the monogamy heading, the distinctively straight investment in bisexual erasure relates to AIDS. Bisexuality has been prominently portrayed as a bridge that transmits HIV from the gay community to the so-called general population. ${ }^{366}$ "In the minds of many heterosexual Americans, bisexuality has come to be strongly identified with images of married, dishonest, closeted men sneaking out on their unsuspecting wives, contracting AIDS through unsafe sex with other men, then infecting their innocent wives and children." 367 In the late 1980 s and early 90 s, the mainstream press ran a flurry of stories concerning the AIDS threat bisexuals posed to heterosexuals. ${ }^{368}$

I earlier showed that bisexuals were viewed as an avenue through which heterosexuality was called into question. ${ }^{369}$ Bisexuals are thus perceived to be a bridge along which two undesirable traits-same-sex desire and HIVpass from a gay minority to a straight majority. In the sexual orientation context, the majority is characterized as straight and HIV-negative, while the minority is characterized as gay and HIV-positive. The bisexual challenges both characterizations - the first epistemologically, the second epidemiologically. His mere existence calls the heterosexuality of the majority into question. And his sexual practices call its HIV-negative status into question.

Alongside this convergence, however, is an important divergence. We saw that characterizing the bisexual as a carrier of same-sex desire plunged the bisexual into obscurity. In contrast, the characterization of the bisexual as a carrier of HIV lofted the bisexual into temporary visibility. The discrep-

366. See Ochs, supra note 63, at 227.

367. Id.

368. See, e.g., David Gelman, A Perilous Double Love Life: In the AIDS Era, Bisexuals Are Becoming the Ultimate Pariahs, NEWSWEEK, July 13, 1987, at 44; Knox, supra note 272, at 57; Katie Leishman, Heterosexuals and AIDS, ATLANTIC MONTHLY, Feb. 1987, at 39, 48; Nordheimer, supra note 272 , at 1 .

369. See notes 264-278 supra and accompanying text. 
ancy can be explained by the perceived role of social visibility in perpetuating each. Homosexuality is generally regarded to be spread through its visibility - the mere utterance of the "contagious word" of same-sex desire is thought to perpetuate it. ${ }^{370} \mathrm{HIV}$, on the other hand, is generally seen as spread through its invisibility-making HIV more visible, figuratively through education, ${ }^{371}$ or literally through tattooing, ${ }^{372}$ is viewed to be prophylactic. Straights who wish to control both homosexuality and HIV are thus in a double bind vis à vis bisexual visibility. To the extent that they wish to safeguard their own heterosexuality, they will wish to erase bisexuals, as the existence of the bisexual makes it impossible for them to conclusively prove their heterosexuality. To the extent that they wish to safeguard their HIV-negative status, however, they will seek to keep the bisexual visible. ${ }^{373}$ HIV has forced straights to confess the bisexual they would otherwise deny. 374

370. See Judith Butler, Excitable Speech: A Politics of the Performative 103-26 (1997).

371. See CINDY PATTON, Inventing AIDS 52 (1990) ("In private conversations, in public health campaigns, and in the scientific and para-scientific literature, 'knowledge' is promoted as the essential ingredient in the effort to slow the transmission of HIV. To the fearful citizen, knowledge means information which proves that she/he will not develop AIDS.").

372. See LARRY Gross, CONTESTEd Closets 59 (1993) (noting William F. Buckley, Jr.'s proposal that men who test HIV-positive be tattooed).

373. This double bind cinches particularly tightly because one way in which both homosexuality and HIV might properly be described as infectious is that one individual can affect an entire community. Leo Bersani says that the number of homosexuals in a population may be irrelevant insofar as homophobia is fueled by the "fearful excitement at the prospect of becoming what one already is." BERSANI, supra note 232, at 28 . "One gay man ... deep in a distant province of a nation otherwise totally successful in its genocidal campaign against gays would be enough to hold up, for his appalled and expectant countrymen, the mirror in which they could not escape recognizing their already recruited selves." Id. (I am assuming that this analysis would apply just as strongly to bisexuals). Similarly, it has been said that "'[i]t also takes only one bisexual to introduce the AIDS virus [sic] into the heterosexual community."' Jan Zita Grover, AIDS: Keywords, in AIDS: CUltural ANALYSIS/Cultural ACTIVISM 17, 21 (Douglas Crimp ed., 1988) (quoting ART ULENE, SAFE SEX IN A DANGEROUS WORLD (1987)). Thus, straights must ensure that not a single bisexual enters the cultural imagination while simultaneously ensuring that every single bisexual remains visible.

374. No similar double bind occurs relative to homosexual visibility, where a generic invisibility rule has worked. This may seem counterintuitive, insofar as the straight goal would still be to cabin the two "diseases" of homosexuality and HIV, and insofar as the two "diseases" have opposed relationships to discourse, with homosexuality being spread through discourse and HIV being spread by a lack of it. The significant difference between the bisexual and the homosexual, however, is that homosexuals are not perceived as spreading HIV into the straight community. Thus one strategy to evade the double bind has been to spread HIV discourse only insofar as it does not pertain to same-sex sexual conduct. See PATTON, supra note 371, at 55-56 (describing state and federal funding restrictions on AIDS education that forbid funding of projects that "promote homosexuality"). This cabins HIV among straights while decreasing the spread of homosexuality, not only through dampening discourse about homosexuality, but also by leaving homosexuals more at risk for HIV. 
It may seem ironic to list the visibility of bisexuals as carriers of AIDS in the mainstream press as a symptom of bisexual erasure. But that case can be defended on two grounds. First, visibility about the bisexual AIDS threat has not been sustained, perhaps suggesting a straight investment in repressing straight vulnerability to AIDS.375 In other words, bisexuality may be repressed not in spite of, but because of, the perception that it is an epidemiological bridge. Such denial about risk can be seen in many other contexts, such as the minoritizing discourse of AIDS as a disease that only affects certain socially marginal groups. ${ }^{376}$ Second, to the extent that the bisexual has been made visible as an AIDS threat, that visibility has been so narrow and so negative as to be entirely delegitimating. ${ }^{377}$ And such delegitimation,

375. An alternative explanation for why the role of bisexuals in the transmission of HIV has not achieved sustained visibility is that research has demonstrated that this threat is not significant. This explanation seems weak, as the studies on the role of bisexuality in cross-sex HIV transmission have been indeterminate.

Some studies minimize the importance of bisexuality's role in such transmission. See, e.g., Maria L. Ekstrand, Thomas J. Coates, Joseph R. Guydish, Walter W. Hauck, Linda Collette \& Stephen B. Hulley, Are Bisexually Identified Men in San Francisco a Common Vector for Spreading HIV Infection to Women?, 84 AM. J. PUB. HEALTH 915, 919 (1994) (concluding "that single, bisexually identified men in San Francisco do not appear to be a common vector for spreading HIV disease to women"); James G. Kahn, Jill Gurvey, Lance M. Pollack, Diane Binson \& Joseph A. Catania, How Many HIV Infections Cross the Bisexual Bridge? An Estimate from the United States, 11 AIDS 1031, 1031 (1997) (concluding "that [cross-sex] transmission via bisexuality is a relatively minor component of the estimated 40,000 annual HIV infections in the USA").

Other studies, however, contend that bisexuality's role in cross-sex transmission of HIV has been underestimated. See, e.g., Theresa Diaz, Susan Y. Chu, Margaret Frederick, Pat Hermann, Anna Levy, Eve Mokotff, Bruce Whyte, Mary Herr, Patricia J. Ehecko, Cornelis A. Rietmeijer, Frank Sorvillo \& Qaiser Mukhtar, Sociodemographics and HIV Risk Behaviors of Bisexual Men with AIDS: Results from a Multistate Interview Project, 7 AIDS 1227, 1231 (1993) (documenting "multiple risk behaviors that may be more common among behaviorally bisexual men"); Thomas Lerner \& Mary Ann Chiasson, Seroprevalence of Human Immunodeficiency Virus Type 1 and Sexual Behaviors in Bisexual African-American and Hispanic Men Visiting a Sexually Transmitted Disease Clinic in New York City, 147 AM. J. EPIDEMIOLOGY 269, 271 (1998) (noting that "[i]t is conceivable that HIV transmission from bisexual men to their female sexual partners plays a greater role in heterosexual transmission in African-American and Hispanic communities than was previously recognized").

I make no attempt to weigh the merits of these studies. I simply register the conflict between them as an indication that there has never been a scientific consensus that bisexuality has a minimal role in cross-sex HIV transmission. Indeed, studies reviewing the existing literature note that not enough research has been done to support any such view. See, e.g., Lynda S. Doll \& Carolyn Beeker, Male Sexual Behavior and HIV Risk in the United States: Synthesis of Research with Implications for Behavioral Interventions, 8 AIDS EDUC. \& PREVENTION 205, 219-220 (1996) (review of existing research which notes that the role of bisexuals in HIV transmission may be significant in certain contexts, but that "[f]urther epidemiologic and behavioral research is urgently needed to more fully describes the[se] contexts").

376. See Paula A. Treichler, AIDS, Homophobia, and Biomedical Discourse: An Epidemic of Signification, in AIDS: CULTURAL ANALYSIS/CULTURAL ACTIVISM, supra note 373, at 31, 65-67.

377. This particular genre of visibility should not be taken as solicitude for bisexuals, but rather as solicitude for the way in which bisexuals can infect the straight population. In this, the bisexual occupies a parallel position to the prostitute. As Sedgwick has recognized, "[i]t has been notable ... that media coverage of prostitutes with AIDS has shown no interest in the women them- 
as noted above, 378 contributes to bisexual erasure by chilling bisexuals from expressing their identities.

\section{Gay investment.}

The distinctively gay investment in bisexual erasure pertaining to monogamy has two elements. First, many gays and lesbians wish to retire the stereotype of gays as promiscuous. Second, some lesbians view bisexuals as carrying HIV into the relatively unaffected lesbian community.

Self-identified gays, of course, do not speak univocally against promiscuity. Some in the gay community view monogamy as an oppressive cultural institution of the heterosexual establishment. ${ }^{379}$ But over time, those seeking to disestablish the stereotype (and any underlying reality beneath it) ${ }^{380}$ have increased in number. ${ }^{381}$ One potential explanation for this shift is the AIDS epidemic, which has made many gays reconsider their nonmonogamous sexual practices. 382 Another is that the growing acceptability of homosexuality has made assimilation more of a possibility.

selves, but only in their potential for infecting men." SEDGWICK, EPISTEMOLOGY OF THE CLOSET, supra note 4, at $5 \mathrm{n} .8$. Similarly, media coverage of bisexuals with HIV has shown little interest in the bisexuals themselves, but only in their potential for infecting straights. See GARBER, supra note 11 , at 93-96.

378. See note 235 supra and accompanying text.

379. See, e.g., Pat Califia, UnMonogamy: Loving Tricks and Tricking Lovers, in PUBLIC SEX: THE CULTURE OF RADICAL SEX 199, 199-204 (1994) (criticizing monogamy as utopian and repressive); Douglas Crimp, How to Have Promiscuity in an Epidemic, in AIDS: CULTURAL ANALYSIS/CULTURAL ACTIVISM, supra note 373, at 237, 272 ("Gay male promiscuity should be seen ... as a positive model of how sexual pleasures might be pursued by and granted to everyone if those pleasures were not confined within the narrow limits of institutionalized sexuality."); Douglas Sadownick, SeX BetweEn MEN: AN INTIMATE History of tHe SeX Lives OF Gay MEN POSTWAR TO PRESENT 86 (1996) (noting arguments against monogamy made by gay activists in the 1960s).

380. This stereotype finds more support in the gay male community than in the lesbian community. See Donna Binder, Monogamy: Is It For Us?, THE ADVOCATE, June 23, 1998, at 29, 30.

381. See, e.g., Bruce Bawer, Sex-Negative Me, in BEYOND QuEer: CHALlENGING GAY LeFT ORTHODOXY 171, 172 (Bruce Bawer ed., 1996) [hereinafter BEYOND QUEER] ("To suggest that gays are more defined by their libidos [than straights] is to collaborate in the widespread, dehumanizing view that gay sex is invariably mechanical, impersonal, even bestial, while straight sex is an integral part of the complex web of human feeling, connectedness, and commitment before God."); MiCHELANGELO SignORILE, LIFE OUTSIDE: THE SIGNORILE REPORT ON GAY MEN: SEX, DRUGS, MUSCLES, AND THE PASSAGES OF LIFE 208-65 (1997) (discussing the prevalence of monogamous relationships in the gay male community).

382. See, e.g., John W. Berresford, A Gay Right Agenda, in BEYOND QUEER, supra note 381, at 105,108 (noting that "[i]n a curious way, AIDS itself may be helping [gay men] find social acceptance," since it "has brought to a screeching halt" the gay male promiscuity of the 1970s and 1980s); Frederick R. Lynch, Nonghetto Gays: An Ethnography of Suburban Homosexuals, in GAY CULTURE IN AMERICA: ESSAYS FROM THE FIELD 165, 166 (Gilbert Herdt ed., 1992) (noting that "the advent of AIDS must have had some degree of adverse effect on the lure of the 'swinging single' life-style for homosexuals and heterosexuals alike"). Others-most prominently represented in the Sex Panic movement-have argued that AIDS should not push gays toward monogamy, but 
The classic situs of the gay debate over promiscuity is the marriage context. Marriage is seen as deeply connected to monogamy, insofar as it is the state's sanction of an ostensibly life-long and erotically exclusive relationship between two individuals. ${ }^{383}$ While this nexus remains imperfect in practice, the fiction of the marriage as both reflecting and reinforcing monogamous commitment remains strong. ${ }^{384}$ Many gays have rejected marriage in the same way that they have rejected monogamy, as exemplifying heterosexist (and sexist) norms. ${ }^{385}$ Here as elsewhere, however, there is a growing assimilationist faction in the gay community that seeks the entitlement of marriage. Members of this faction express disdain for promiscuity in general and polygamy in particular (since the latter is often viewed as a potential consequence of sanctioning same-sex marriage). ${ }^{386}$

To the extent that bisexuals are viewed as intrinsically promiscuous, assimilationist gays will be loath to recognize them as political allies, as such an affiliation might corroborate, rather than rebut, the stereotype of gays as promiscuous. Bisexuals may thus pose the gay rights movement with a milder version of the question posed by pedophiles ${ }^{387}$ or polygamists. 388 On the one hand, solidarity with other sexual minorities suggests that they should be included within the movement; on the other, realism suggests that the legitimacy of the movement may be undermined by such affiliations.

An additional concern voiced by lesbians against the ostensible promiscuity of bisexuals is that bisexuals might carry HIV into the lesbian community. Despite the fact that HIV is often characterized as a "gay" disease, lesbians are less at risk for sexual transmission of HIV than either gay men or

rather toward the practice of safe sex. See, e.g., Joseph Sonnabend \& Richard Berkowitz, Safer-Sex Panic, in SEX PANIC! 13, 14 (1997) (arguing that "it is the call for sexual restraint and monogamy with its inherent deemphasis of safer sex that now constitutes the greater hazard to the health of gay men"); Jim Eigo, The Monogamy Code, in SEX PANIC!, supra, at 15, 16 (arguing against the "attack on safer sex" and the promotion of "global gay male monogamy").

383. See William N. ESKRIDge, JR., THe CASE FOR SAME-SeX MARriage 1 (1996).

384. See id. at 1 .

385. See, e.g., Paula Ettelbrick, Since When Is Marriage a Path to Liberation?, in SAME-SEX MARRIAGE: PRO AND CON: A READER (Andrew Sullivan ed., 1997). 278-79.

386. See Andrew Sullivan, Three's a Crowd, in SAME-SEX MARRIAGE, supra note 385, at

387. See, e.g., Duncan Osborne, The Trouble with NAMBLA, THE ADVOCATE, Dec. 14, 1993, at 40 (reporting the International Lesbian and Gay Association's request that the North American Man-Boy Love Association resign from the organization); Joyce Price, Pedophiles Resisting Expulsion from Gay Umbrella Organization, WASH. TIMES, Nov. 27, 1993, at A4 (similar).

388. See, e.g., David L. Chambers, Polygamy and Same-Sex Marriage, 26 HOFSTRA L. REV. 53,53 (1997) ("During the hearings and debates that led to the Defense of Marriage Act, many members of Congress and many witnesses drew comparisons between polygamy and same-sex marriage."); Sullivan, supra note 386 (arguing that polygamy and same-sex marriage are easily distinguishable). 
straights. 389 It is thus unsurprising that some lesbians, like some heterosexuals, 390 fear the potential of bisexuals to serve as an epidemiological bridge from a "high-risk" to a "low-risk" community. One bisexual commentator notes that "gay women are hesitant to become involved with bi-the-way-girls because WE SPREAD AIDS or will leave them for a man," 391 while another suggests that she is perceived as an "AIDS-carrying high-risk parasite on the movement." 392 The propinquity of the charge of HIV transmission to the charge or capitulation to patriarchy (framed either individually as the ultimate rejection of a woman for a man or politically as the inability of the bisexual parasite to reject heterosexual privilege) may be purely coincidental. It may, however, suggest that just as the straight community occasionally appears to make HIV stand for the "disease" of homosexuality, ${ }^{393}$ so too does the lesbian community make HIV stand for the "diseases" of patriarchy and capitulation to heterosexual privilege.

\section{Overlapping Monosexual Investments as a Cause of the Epistemic Contract}

This Part has suggested that straights and gays have entered into the epistemic contract of bisexual erasure because of three different investments: (1) an investment in stabilizing sexual orientation; (2) an investment in retaining the primacy of sex; and (3) an investment in preserving norms of monogamy.

Straights and gays have an investment in stabilizing sexual orientation categories. The shared aspect of this investment is the security that all individuals draw from rigid social orderings. The distinctively straight investment is the retention of heterosexual privilege. And the distinctively gay investment relates to the perception that bisexuality endangers the immutability defense and effective political mobilization.

Both straights and gays may also wish to erase bisexuals because bisexuality has disturbing consequences for the current sex regime. All monosexuals are created through a regime that privileges sex, and they thus have an investment in bisexual erasure that relates to their own constitution. Straights have a specific investment in bisexual erasure because bisexuality disrupts the power heterosexuality has to determine sex performance. And

389. See William N. Eskridge, Jr., Multivocal Prejudices and Homo Equity, 74 IND. L.J. 1085,1118 (1998) (noting that while gays are often characterized as carrying HIV, "the data makes it clear that ... lesbians seem to have the lowest rates of AIDS ... of any of the groupings").

390. See notes 366-368 supra.

391. Karen and Miranda Augustine, What Some Call Community ... Others Call Clicks, in PLURAL DESIRES, supra note 345, at 37, 37.

392. Michelle Spring-Moore, Queergirl, in PlURAL DeSIRES, supra note 345, at 226, 243.

393. JUDITH BUTLER, BODIES THAT MATTER: ON THE DisCURSIVE LiMITS OF "SEX" 64 (1993) (describing the conflation of homosexuality and AIDS as pathological diseases). 
gays have a specific investment because bisexuality interferes with complete sex separatism.

Finally, both straights and gays are disquieted by bisexuals insofar as bisexuals are thought to represent nonmonogamy. Straights and gays have a shared investment in decreasing sexual jealousy. Straights are peculiarly threatened insofar as they believe that bisexual nonmonogamy bridges the gap between the HIV-infected gay population and the uninfected straight population. And gays are distinctively threatened by bisexual nonmonogamy to the extent that they wish to retire the stereotype of gays as nonmonogamous.

These multiple and overlapping investments in bisexual erasure explain the longevity of the epistemic contract. But they are not insurmountable. The very fact that bisexual erasure has been recognized indicates this, for the paradox of status hierarchy is that the oppressed category must have some power to be recognized as such. 394 But this means that even as there are investments in bisexual invisibility, there are simultaneous and countervailing investments in bisexual visibility.

The group with the most powerful investment in bisexual visibility is composed of self-identified bisexuals. In the next Part, I look at how bisexuals have responded to the epistemic contract. That narrative is one of both capitulation and resistance, testifying to both the strength of the epistemic contract and the possibility of its gradual dissolution.

\section{SELF-IDENTIFIED BISEXUALS AND THE EPISTEMIC CONTRACT}

The longevity of the epistemic contract can be explained in two ways. The first is that bisexuals are not harmed by the contract, or, more strongly, that bisexuals benefit from their own erasure such that the contract could be characterized as trilateral rather than bilateral. The second is that despite the fact that bisexuals are harmed by the contract, it is so powerful that bisexuals are prevented from fully conceiving of themselves as bisexuals, or from effectively dissolving that contract even if they do. The two explanations are not mutually exclusive, insofar as bisexuals are not a monolithic group. Some bisexuals fit the stereotype of those who take advantage of heterosexual privilege while engaging in clandestine homosexual activity. ${ }^{395}$ Others experience bisexual erasure as a harm and militate for bisexual visibility. 396

394. Cf. Martha Minow, The Supreme Court, 1986 Term-Foreword: Justice Engendered, 101 HARV. L. REV. 10, 68 (1987) ("Power is at its peak when it is least visible, when it shapes preferences, arranges agendas, and excludes serious challenges from discussion or even imagination.").

395. See notes 83-85 supra and accompanying text.

396. See notes $402-429$ infra and accompanying text. 
Which explanation we view as dominant, however, has significant consequences for how serious we view the problem of bisexual erasure to be.

While it is difficult to arbitrate between the two explanations, I will argue in this Part that we should seriously entertain the viability of the second one. I begin this argument by observing that the epistemic contract prevents the articulation of bisexual identity at every phase of bisexual development, impeding the formation of a bisexual subject that could meaningfully consent to its own erasure. I then note that despite the demands of the contract, an increasingly visible bisexual movement has articulated its desire for visibility.

\section{A. Bisexual Capitulation to the Epistemic Contract}

The epistemic contract obstructs every phase of bisexual development. I consider three phases here: (1) pre-coming out as bisexual; (2) post-coming out to some others; and (3) post-coming out to "all" others.

The process of coming out as a bisexual may be retarded by the fact that no robust template of bisexual identity exists. Even in a time where there is an increasingly available model of gay identity, there is no equivalent one for bisexual identity. Many individuals who might otherwise identify as bisexual may refrain from doing so only because they cannot imagine that identity. ${ }^{397}$ Possible support for this hypothesis can be found in a recent study showing that bisexuals come out as bisexual relatively later than homosexuals come out as homosexual.398

Even after a bisexual comes out to some others, she encounters enormous pressure to present herself to the rest of the world as straight. A study of the relative degrees of "outness" in the workplace among (1) gays, (2) bisexuals, and (3) straights with unorthodox sexual practices found that gays were most likely to be out, followed by bisexuals, followed by heterosexuals with unorthodox sexual practices. ${ }^{399}$ It is surely no accident that this exactly tracks the ascending degree to which these identities can be hidden within a heterosexual matrix. Moreover, even after a bisexual comes out to some others, she will be under pressure to be selectively closeted. This is perhaps most true in the dating context, where bisexuals find that both straights and gays can often be reluctant to date bisexuals.

Finally, even a bisexual who is out to "all" others will have a difficult time communicating this. The monosexual presumption means that if a

397. See GARBER, supra note 11 , at $48-49$ (giving accounts of bisexuals who were introduced to the bisexual category relatively late); WEINBERG ET AL., supra note 113, at 121 (noting that bisexuals generally "come out" later than homosexuals "because there is a less clear identity with which to "come out"').

398. See WEINBERG ET AL., supra note 113 , at 121.

399. See id. at 188-89. 
woman walks down the street holding hands with a man, we are likely to think of her as straight; if she does the same thing with a woman, we are likely to think of her as lesbian. ${ }^{400}$ This presumption leads us to code individuals as monosexual unless they evidence concurrent bisexuality.

This synchronic approach to orientation assignation can obtain even when a diachronic account of the individual's erotic life is available. Ruth Colker supports this point by noting the reflexive use of the term "hasbian" to describe women who shift from a sustained same-sex relationship to a sustained cross-sex relationship. 401 Such a shift could equally be described as sequential bisexuality-the pattern of conduct is thus overdetermined and requires narratological resolution. That this ambiguity is resolved before being recognized suggests a synchronic approach to orientation attribution: The "hasbian" classification reads the current conduct as the "true" one and the past conduct as the repudiated one, rather than reading them both as an embrace of sequential bisexuality. Such a synchronic approach will tend to eliminate all but concurrent bisexuals from the bisexual category.

\section{B. Bisexual Resistance to the Epistemic Contract}

The argument that bisexuals capitulate to bisexual erasure because they are not harmed by it is also undercut by an increasingly visible bisexual movement. The movement's development can be crudely divided into three phases by decade.

The bisexual movement did not begin in a patterned way until after Stonewall.402 One could do worse than date its inauguration to the formation of the National Bisexual Liberation (NBL) group in New York City in the early 1970s. 403 The NBL began publication of a magazine, Bisexual Expression, in 1975, roughly coinciding with the first books and mainstream press about bisexuality.404 The magazine provided an antidote to the delegitimating treatments of "bisexual chic" in the popular press (including Time ${ }^{405}$ and Newsweek ${ }^{406}$ ) that suggested that bisexuality was the perquisite

400. See Ochs, supra note 63, at 225.

401. See Ruth Colker, A Bisexual Jurisprudence, 3 LAW \& SEXUALITY 127, 129-30 (1993) [hereinafter Colker, Bisexual Jurisprudence].

402. San Francisco's Sexual Freedom League, founded in 1967, might be seen as a precursor to the bisexual movement in that it encouraged experimentation with both sexes. It was not, however, explicitly a bisexual organization.

403. See Stephen Donaldson, The Bisexual Movement's Beginnings in the 70s: A Personal Retrospective, in BISEXUAL POLITICS, supra note 7, at 31, $42-43$.

404. See Donaldson, supra note 403 , at 43.

405. See The New Bisexuals, supra note 230, at 79.

406. See Bisexual Chic, supra note 230, at 90. 
of androgynous rock stars such as David Bowie or Elton John.407 The NBL's meetings consisted of monthly social events and consciousness-raising exercises. ${ }^{408}$ In its social cast, the organization was similar to many that followed in that decade 409 such as New York City's Bisexual Forum (founded in 1975), ${ }^{110}$ San Francisco's Bisexual Center (founded in 1976), 411 and Chicago's Bi-Ways (founded in 1978). ${ }^{412}$ Bisexual activists were also occasionally prominent in early gay-identified endeavors. For example, Alan Rockway, a "gay-identified bisexual," co-authored the well-known Dade County, Florida ordinance that became the first ordinance to protect gay rights, and which spawned the national anti-gay "Save Our Children" crusade. 413

In the 1980s, the bisexual movement shifted toward claims for greater recognition as a political movement, ${ }^{414}$ with activists attempting to distinguish bisexuality from sexual swinging. BiPOL, the first bisexual political action group, formed in San Francisco in 1983.415 And many date the birth of the national bisexual movement to the second March on Washington for Lesbian and Gay Rights in 1987, where a national bisexual network, later known as BiNET USA was formed. 416 The shift might have been expected as a simple byproduct of the increased maturity and self-consciousness of the bisexual movement, with increasing numbers of bisexual organizations pro-

407. See Jay P. Paul, San Francisco's Bisexual Center and the Emergence of a Bisexual Movement, in BISEXUALITIES: THE IDEOLOGY AND PRACTICE OF SEXUAL CONTACT WITH BOTH MEN AND WOMEN 130, 132 (Erwin J. Haeberle \& Rolf Gindorf eds., 1998); see also GARBER, supra note 11, at 18-19 (describing Time and Newsweek articles); Donaldson, supra note 403, at 35 (same). It was at this time that the term "AC/DC" became popularized to describe bisexual people. See GARBER, supra note 11, at 38.

408. See Donaldson, supra note 403 , at $42-43$.

409. See Udis-Kessler, supra note 308, at 22-23.

410. See Chuck Mishaan, The Bisexual Scene in New York City, 11 J. HomosexuAlity 223, 224 (1985). The organization folded in 1983. See id.

411. See Danielle Raymond \& Liz A. Highleyman, Brief Timeline of Bisexual Activism in the United States, in BISEXUAL POLITICS, supra note 7, at 333, 334. The Bisexual Center of San Francisco held its first press conference on June 30, 1977. Speakers included Dr. Benjamin Spock, Dr. Phyllis Lyon and Ruth Falk. Many of these speakers challenged Anita Bryant's efforts to bar homosexuals from employment as school teachers and discussed other civil rights issues. See Maggi Rubenstein \& Cynthia Ann Slater, A Profile of the San Francisco Bisexuality Center, $11 \mathrm{~J}$. HOMOSEXUALITY 227, 228-30 (1985).

412. See George Barr, Chicago Bi-Ways: An Informal History, 11 J. HOMOSEXUALITY 231, $232-34$ (1985). In the early 1980s, Action Bi-Women was formed in the Chicago area to develop a feminist-oriented bisexual group. See id. at 234. 363.

413. See Political Activism: A Brief History, in BI ANY OTHER NAME, supra note 257, at 359,

414. See Udis-Kessler, supra note 308 , at 26 (discussing increasing political activity of bisexual movement).

415. See id.; Raymond \& Highleyman, supra note 411, at 334.

416. See Paul, supra note 407, at 137; Political Activism, supra note 413, at 364; Raymond \& Highleyman, supra note 411 , at 335 . 
liferating across the country.417 But the shift can also be attributed to the AIDS crisis, which came into public visibility in the early years of the decade. In 1987, Time ${ }^{418}$ and Newsweek ${ }^{419}$ would again publish articles touching upon bisexuality, but this time not about "bisexual chic," but about bisexuality and AIDS.420 Bisexuality had now acquired a serious edge: Newsweek called bisexuals the "ultimate pariahs" of the AIDS crisis. ${ }^{421}$

In the 1990s, bisexual politics has risen to greater national and international prominence. The First National Bisexual Conference convened in San Francisco in 1990, with Bisexual Pride Day proclaimed by the San Francisco Board of Supervisors.422 The following years saw the First International Bisexual Conference held in Amsterdam, ${ }^{423}$ the publication of two major bisexual anthologies, 424 and the inauguration of a national bisexual magazine.425 By 1993, the March on Washington for Lesbian and Gay Civil Rights had become the March on Washington for Lesbian, Gay and Bi Equal Rights and Liberation. 426 Whether to name or not to name bisexuals alongside gays and lesbians has become an explicit issue of debate. ${ }^{427}$ That debate has also trickled into the law. As evidenced by Colorado's Amendment 2428 and the military's “don't ask, don't tell" policy, ${ }^{429}$ bisexuals are increasingly nominally visible, even if politically repressed.

417. These included the Boston Bisexual Women's Network in 1983, the East Coast Bisexual Network in 1985, the Seattle Women's Bisexual Network in 1985, and the Washington D.C. BiWomen's (and Men's) Network in 1989. See Political Activism, supra note 413, at 360-61.

418. See Martha Smiglis, Scott Brown, Dave Morrow \& Leslie Whitaker, The Big Chill: Fear of AIDS, TIME, Feb. 16, 1998, at 50, 52.

419. See Gelman, supra note 368.

420. See Paul, supra note 407, at 137-39 (describing articles).

421. Gelman, supra note 368, at 44; see also GARBER, supra note 11, at 93 (describing article).

422. See Raymond \& Highleyman, supra note 411 , at 335-36. The conference was attended by over four hundred people from twenty-two states and five countries. See Paul, supra note 407, at 137 .

423. See KLEIN, supra note 81 , at 169 . The second and third international bisexual conferences occurred in London and New York in the mid-1990s. See id.

424. See BI ANY OTHER NAME, supra note 257; ClOSER to HOME: BiSEXUALITY AND FEMINISM (Elizabeth Rebea Weise ed., 1992).

425. The Bay Area Bisexual Network began publishing the magazine Anything That Moves in January, 1991. See GARBER, supra note 11, at 54 .

426. See Raymond \& Highleyman, supra note 411 , at 337.

427. See, e.g., GARBER, supra note 11, at 80-81 (describing controversy over removal of word "bisexual" from Northampton, Massachusetts Lesbian and Gay Pride March in 1990); id. at 53 (describing controversy over inclusion of word "bisexual" in masthead of San Francisco Bay Times, which then read, "The Gay/Lesbian/Bisexual Newspaper \& Calendar of Events for the Bay Area").

428. See Romer v. Evans, 517 U.S. 620, 624 (1996) (quoting Colorado's Amendment 2, which prohibits protection of bisexual status); notes 48-52 supra and accompanying text.

429. See 10 U.S.C. § 654(b)(2) (1994) (making unrebutted statements of bisexual selfidentification grounds for separation from service); supra note 44 and accompanying text. 
The bisexual movement's aims are diverse, and both converge and diverge with those of the gay rights movement. Thus, bisexuals, like gays, can be seen deploying bisexuality both as a means of retiring all sexual orientation categorizations and as a means of contesting placement within those categorizations. On the other hand, bisexuals also have interests in their visibility that are specific to them: that is, interests that combat biphobia rather than homophobia. These interests include the retirement of stereotypical views about bisexuality, such as the perceptions that they are indecisive, duplicitous, and promiscuous.

\section{The Dissolution of the Epistemic Contract}

The rise of the bisexual movement is probably the main factor leading to the dissolution of the epistemic contract of bisexual erasure. But as I have shown in critiquing the investments of both straights and gays in bisexual erasure, monosexuals also have undertheorized investments in bisexual visibility. The gay investments in bisexual visibility are perhaps easier to seebisexuality, for example, can operate as a useful heuristic for evaluating the immutability defense, as well as a means of eroding heterosexual privilege by problematizing the concept of heterosexuality itself. Straights, however, have investments in bisexual visibility as well, such as challenging sexseparatism in the gay community or defending conventional norms of monogamy.

Given the rise of the bisexuality movement, it seems safe to say that bisexuals will only grow more visible in the future. It is therefore time to consider how a world in which the epistemic contract no longer obtained might look. In the next Part, I consider how a particular world-the legal worldmight be transformed by enhanced bisexual visibility.

\section{BISEXUALITY AND SEXUAL HARASSMENT LAW}

Despite the fact that it is one of the main public sites in which formal determinations of sexual orientation are made, the legal system is complicit in cultural ignorance about sexuality.430 It should therefore not be surprising that bisexuals are for the most part as invisible in the law as they are in our general culture. Indeed, if academic commentary is any indication, bisexuality is far more undertheorized in the legal realm than it is in the social science realm. In 1993, Ruth Colker began an essay entitled $A$ Bisexual Jurisprudence with the statement: "A bisexual jurisprudence? Until I decided to write this essay, there was no such thing as a bisexual jurisprudence." 431 A

430. Cf. POSNER, supra note 30, at 1 (noting that "judges know next to nothing about the subject [of human sexuality] beyond their own personal experience").

431. Colker, Bisexual Jurisprudence, supra note 401, at 127. 
computer search of law review articles that deal with the subject of bisexuality bears out her claim: Only a half-dozen articles take bisexuality in the law as their primary subject. 432

How might increased bisexual visibility affect the law? To begin thinking about this question, I take the case of sexual harassment law. I do so for three reasons. First, bisexuals are more visible in this area of jurisprudence than in others. ${ }^{433}$ This visibility arises because liability under Title VII only lies if the sexual harassment occurs "because of ... sex." Under one interpretation, this doctrinal formulation permits bisexuals to evade liability when they sexually harass both men and women, because no victim can claim that the harassment occurred "because of" the victim's "sex." Bisexuals are thus not only distinguished from heterosexuals and homosexuals, but are rhetorically privileged above both.

As we shall see, this exemption has been closed as a practical matter. But both in recognizing and in closing the exemption, the courts have had to grapple with the reality of bisexuality in a way that they have not had to in other areas. Thus, while the bisexual harassment exemption is unimportant as a practical matter, it has made bisexuals uniquely visible in antidiscrimination doctrine.

Second, bisexual visibility has the normative consequence of narrowing another pernicious exemption in the sexual harassment jurisprudence.434 This exemption, which I call the "horseplay exemption," arises when selfidentified straights defend against charges of same-sex sexual harassment by stating that the alleged homosexual harassment was in fact heterosexual horseplay. Because sexual harassment jurisprudence (at least in the past decade) has directed much more solicitude toward sexual harms than nonsexual harms, an alleged harasser who is deemed to have engaged in heterosexual horseplay is much more likely to be exempted from liability than one who is deemed to have engaged in homosexual harassment. This horseplay exemption is pernicious because it makes liability turn on status rather than on conduct-more specifically, on the sexual orientation of the actors rather

432. I found three articles, two essays, and one student note that took the role of the bisexual in the law as their main subject. See Ruth Colker, Bi: Race, Sexual Orientation, Gender and Disability, 56 OHIO ST. L.J. 1 (1995) (article); Ruth Colker, An Embodied Bisexual Perspective, 7 YALE J.L. \& HUMAN. 163 (1995) (article); Mezey, supra note 8 (article); Colker, Bisexual Jurisprudence, supra note 401 (review essay); Douglas S. Miller, Rumpole and the Equal Opportunity Harasser (or Judge Bork's Revenge), 20 J. LEGAL PROF. 165 (1996) (essay); Robin Applebaum, The "Undifferentiating Libido": A Need for Federal Legislation to Prohibit Sexual Harassment by a Bisexual Sexual Harasser, 14 HOFSTRA LAB. L.J. 601 (1997) (note). As this list shows, Ruth Colker has done the most writing in this area; her article entitled Bi: Race, Sexual Orientation, Gender, and Disability has also been expanded into a prescient book. See COLKER, HYBRID, supra note 9.

433. I omit further citation in this paragraph as well as the ones that follow as the points made here are explored more deeply with citations below. See text accompanying notes 464-502 infra.

434. See text accompanying notes 503-534 infra. 
than on the nature of the allegedly harassing acts. And unlike the bisexual harassment exemption, the horseplay exemption is wide open.

For reasons I will describe more fully, the horseplay exemption as it currently stands is predicated on bisexual invisibility. Bisexual visibility thus has the salutary consequence of significantly narrowing this exemption. And because the courts have already made bisexuality visible in the context of the bisexual harassment exemption, this argument has a certain elegant force. While the courts have sought to keep the bisexual harassment exemption closed and the horseplay exemption open, this status quo is inconsistent. Narrowing the bisexual harassment exemption through bisexual visibility logically compels courts to significantly narrow the horseplay exemption. Call this the conservative critique.

Finally, closing the horseplay exemption has its own spillover effects on the degree to which the sexual harassment jurisprudence will continue to fetishize desire as determinative of liability. ${ }^{435}$ The conservative critique is conservative in the sense that it accepts, rather than contests, the aforementioned premise that sexual harm is more serious than nonsexual harm. As Vicki Schultz has recently and persuasively argued, however, this premise is deeply problematic. ${ }^{436}$ Her argument is timely, as the Supreme Court's recent decision in Oncale v. Sundowner Offshore Services ${ }^{437}$ suggests that sexual harassment jurisprudence is at a cross-roads. It can either continue to privilege sexual harm over nonsexual harm or break with that practice to treat sexual and nonsexual harm equally.

Bisexual visibility might act as a goad to force courts down the correct path after Oncale. Closing the horseplay exemption leaves many putative straights more at risk of earning the ascriptions of homoeroticism and harassment. Bisexual visibility might thus encourage straights, as well as gays, to resist a regime in which liability turns solely on desire. Call this the radical critique.

After briefly summarizing the development of sexual harassment jurisprudence, this Part considers each of these reasons for considering bisexual visibility in sexual harassment law. It then briefly considers the implications bisexual visibility might have outside the sexual harassment context.

\section{A. A Summary of the Development of the Sexual Harassment Jurisprudence}

Title VII of the Civil Rights Act of 1964 makes it "an unlawful employment practice for an employer ... to discriminate against any individual with respect to his compensation, terms, conditions, or privileges of employment,

435. See text accompanying notes 535-554 infra.

436. See Vicki Schultz, Reconceptualizing Sexual Harassment, 107 YALE L.J. 1683 (1998).

437. 523 U.S. 75 (1998). 
because of such individual's . . . sex." 438 This language has been interpreted to prohibit sexual harassment in the workplace. As Katherine Franke has noted, however, courts have long been unclear about why sexual harassment is sex discrimination prohibited by Title VII, and have generated at least three different theories. ${ }^{439}$ The first is that sexual harassment is actionable insofar as it would not have occurred but for the victim's sex; that is, insofar as it occurred "because of ... sex" under the language of the statute. 440 The second is that it is actionable because it is sexual in nature.441 The third is that sexual harassment is actionable because it enacts one sex's subordination of another. ${ }^{442}$

The first two theories have been the most dominant. The struggle between them can be characterized as passing through four conceptual phases. In the first phase, the "because of . . . sex" theory was the ascendant theory. Indeed, the desire-based theory was not even acknowledged —early claims of desire-based harassment were rejected as not raising a cognizable claim under Title VII. Thus, in Corne v. Bausch \& Lomb, Inc., 443 the judge dismissed allegations of desire-based harassment by reasoning that no Title VII claim could lie when the alleged harasser was merely "satisfying a personal urge," 444 as opposed to acting pursuant to a company policy. ${ }^{445}$ And in Tomkins v. Public Service Electric and Gas Co., 446 the district court refused to recognize desire-based claims under Title VII because otherwise "[a]n invitation to dinner could become an invitation to a federal lawsuit." 447 Characterizing the sexual conduct as idiosyncratic, or as raising slippery slope problems, the courts essentially sidestepped the question of whether this was discrimination "because of . . . sex." 448

438. 42 U.S.C. § 2000e-2(a) (1994).

439. See Katherine M. Franke, What's Wrong with Sexual Harassment?, 49 STAN. L. REV. 691, 692-93 (1997).

440. See, e.g., Rabidue v. Osceola Refining Co., 805 F.2d 611, 620 (6th Cir. 1986); Bundy v. Jackson, 641 F.2d 934, 942 n.7 (D.C. Cir. 1981); Barnes v. Costle, 561 F.2d 983, 989 n.49 (D.C. Cir. 1977); see also Franke, supra note 439, at 705-14.

441. See, e.g., Yeary v. Goodwill Indus.-Knoxville, Inc., 107 F.3d 443, 445 (6th Cir. 1997); Mattern v. Eastman Kodak Co., 104 F.3d 702, 706 (5th Cir. 1997); Fuller v. City of Oakland, 47 F.3d 1522, 1527 (9th Cir. 1995); see also Franke, supra note 439, at 714-25.

442. See Vandeventer v. Wabash Nat'l Corp., 887 F. Supp. 1178, 1181 (N.D. Ind. 1995); Goluszek v. Smith, 697 F. Supp. 1452, 1456 (N.D. Ill. 1988); see also Franke, supra note 439, at 725-29.

443. 390 F. Supp. 161 (D. Ariz. 1975), vacated, 562 F.2d 55 (9th Cir. 1977).

444. Id. at 163 .

445. For similar reasoning, see Miller v. Bank of America, 418 F. Supp. 233, 235-36 (N.D. Cal. 1976) (finding that no Title VII claim could lie for the isolated and unauthorized sex misconduct of one employee to another), rev'd, 600 F.2d 211 (9th Cir. 1979).

446. 422 F. Supp. 553 (D.N.J. 1976), rev'd, 568 F.2d 1044 (3d Cir. 1977)

447. Id. at 557. problem).

448. See Franke, supra note 439 , at 700 (noting judicial concern over the slippery slope 
In the second phase, courts rejected this evasion as illogical, finding that desire-based harassment typically occurred "because of ... sex." The impetus for this belief came from feminist activists such as Kerri Weisel, who contended that desire-based harassment was sex-based harassment because an individual usually directs desire only at one sex or the other. ${ }^{449}$

The first court to adopt this theory was the D.C. Circuit, in the 1977 case of Barnes v. Costle.450 The district court in Barnes had granted summary judgment to the defendant because it found that Paulette Barnes " "was discriminated against, not because she was a woman, but because she refused to engage in a sexual affair with her supervisor."' 451 A panel of the D.C. Circuit reversed, noting that desire-based claims and "because of ... sex" claims could not be dissociated in this way. It stated:

We cannot accept this analysis of the situation .... But for [Barnes's] womanhood, from aught that appears, her participation in sexual activity would never have been solicited. ... [Barnes] became the target of her superior's sexual desires because she was a woman, and was asked to bow to his demands as the price for holding her job. The circumstance imparting high visibility to the role of gender in the affair is that no male employee was susceptible to such an approach by appellant's supervisor. Thus gender cannot be eliminated from the formulation which appellant advocates, and that formulation advances a prima facie case of sex discrimination within the purview of Title VII. ${ }^{452}$

Other circuits soon adopted this theory.453 And in 1986, in Meritor Savings Bank v. Vinson, 454 the Supreme Court noted that: "Without question, when a supervisor sexually harasses a subordinate because of the subordinate's sex, that supervisor 'discriminate[s]' on the basis of sex."455

In the third phase, as Schultz has shown, a chiasmus occurred between the two theories. ${ }^{456}$ The desire-based theory, which had been the subordinate theory, became the dominant theory; the "because of . . . sex" theory, which had been the dominant theory, became the subordinate theory. Desire was now often framed as either a precondition or an important component of a successful Title VII sexual harassment claim. The ascendancy of the desirebased theory manifested itself in a number of ways, perhaps most promi-

449. See Schultz, supra note 436, at 1702 (citing Kerri Weisel, Title VII: Legal Protection Against Sexual Harassment, 53 WASH. L. REV. 123, 133-35 (1977)).

450. 561 F.2d 983 (D.C. Cir. 1977). 1974)).

451. Id. at 986 (quoting Barnes v. Train, Civ. No. 1828-73, slip op. at 3 (D.D.C. Aug. 9,

452. Barnes, 561 F.2d at 990.

453. See, e.g., Miller v. Bank of America, 600 F.2d 211 (9th Cir. 1979); Tomkins v. Public Serv. Elec. \& Gas. Co., 568 F.2d 1044 (3d Cir. 1977).

454. 477 U.S. 57 (1986).

455. Id. at 64 .

456. See Schultz, supra note 436, at 1690 ("Ironically, courts that once refused to recognize that sexual advances may occur because of sex now insist on such advances and fail to perceive many other problems that confront women workers as sex-based."). 
nently in the denomination of the cause of action as "sexual harassment" rather than as "sex-based" or "gender-based" harassment.457 It could also be seen in the EEOC guidelines, which advanced a desire-based theory of harassment.458 That ascendancy could also be seen in the case law. Some courts held desire to be a prerequisite for a successful Title VII claim, 459 and even courts that considered both sexual and nonsexual claims often ignored or subordinated the latter. 460

The Supreme Court's recent opinion in Oncale can be seen as potentially ushering in a fourth phase. In Oncale, the Supreme Court had to ascertain whether same-sex sexual harassment was actionable under Title VII, and if so, under what restrictions. In so doing, it had to choose a theory from a set that included the desire-based theory461 and the "because of ... sex" theory. 462

The Supreme Court embraced the "because of ... sex" theory.463 This holding has obvious implications for all of sexual harassment jurisprudence, insofar as it rejected the view that desire is a requirement for a successful Title VII suit. As I demonstrate below, however, whether Oncale can truly be seen as breaking from the third phase remains to be seen.

\section{B. Bisexual Visibility-The Recognition and Closing of the Bisexual Harassment Exemption}

Sexual harassment jurisprudence is distinctive in that it not only names bisexuality but treats it differently (and rhetorically more favorably) than either heterosexuality or homosexuality. It would be a mistake, however, to

457. See id. at 1692.

458. See id. at 1704 \& nn.95 \& 97 (noting that that EEOC guidelines could be and were read to privilege sexual harm) (citing EEOC Guidelines on Discrimination Because of Sex, 62 Fed. Reg. 63,622 (1980) (codified at 29 C.F.R. § 1604.11 (1997))).

459. See Schultz, supra note 436, at 1718 \& n.167 (citing, inter alia, Yeary v. Goodwill Indus.-Knoxville, Inc., 107 F.3d 443, 445 (6th Cir. 1997); Mattern v. Eastman Kodak Co., 104 F.3d 702, 706 (5th Cir. 1997); Fuller v. City of Oakland, 47 F.3d 1522, 1527 (9th Cir. 1995)).

460. See Schultz, supra note 436, at 1710-29 (citing, inter alia, Harris v. Forklift Sys., Inc. 510 U.S. 17 (1993); King v. Board of Regents, 898 F.2d 533 (7th Cir. 1990); Scott v. Sears, Roebuck \& Co., 798 F.2d 210 (7th Cir. 1986); Reynolds v. Atlantic City Convention Ctr., 53 Fair Empl. Prac. Cas. (BNA) 1852 (D.N.J. 1990), aff'd, 925 F.2d 419 (3d Cir. 1991); Raley v. Board of St. Mary's Comm'rs, 752 F. Supp. 1272, 1280-81 (D. Md. 1990); Graham v. American Airlines, 731 F. Supp. 1494, 1500-01 (N.D. Okla. 1989); Ross v. Double Diamond, Inc., 672 F. Supp. 261 (N.D. Tex. 1987); Sapp v. City of Warner Robins, 655 F. Supp. 1043, 1049-50 (M.D. Ga. 1987)).

461. Compare McWilliams v. Fairfax County Bd. Of Supervisors, 72 F.3d 1191, 1195 (4th Cir. 1996) (ruling that same-sex sexual harassment claim was not actionable where defendants were heterosexual), cert. denied, 519 U.S. 819 (1996), with Wrightson v. Pizza Hut, 99 F.3d 138, 143-44 (4th Cir. 1996) (ruling that same-sex sexual harassment claim was actionable where defendants were homosexual).

462. See Quick v. Donaldson Co., Inc., 90 F.3d 1372, 1377 (8th Cir. 1996).

463. See Oncale v. Sundowner Offshore Servs., Inc., 523 U.S. 75,78 (1998). 
take the court's recognition of the bisexual harassment exemption as an indication of bisexual privilege. As a practical matter, the bisexual harassment exemption has been closed. Nonetheless, in order to close the bisexual harassment exemption in a coherent way, courts have been forced into theorizing bisexuality with some sophistication. Thus, despite the fact that the exemption is not jurisprudentially important, it has compelled a significant admission about bisexual existence.

\section{The recognition of the bisexual harassment exemption- bisexual visibility.}

Bisexuals were first made visible in the sexual harassment jurisprudence when the shift from the first phase to the second phase was being contemplated. In Corne, 464 the court stated that it would be "ludicrous" to call desire-based harassment sex discrimination, "because to do so would mean that if the conduct complained of [male sexual advances on females] was directed equally to males there would be no basis for suit." ${ }^{465}$ The bisexual possibility was thus adduced to problematize the extension of Title VII's coverage to desire-based claims.

While it made the shift from the first phase to the second phase despite this problem, the D.C. Circuit in Barnes was not able to solve it. Barnes simply buried the unresolved issue in a footnote, noting that "[i]n the case of the bisexual superior, the insistence upon sexual favors would not constitute gender discrimination because it would apply to male and female employees alike." 466 This left the Barnes theory vulnerable to attack, as could be seen in a subsequent case in the circuit adopting that theory. In dissenting from a denial of rehearing in Vinson v. Taylor, ${ }^{467}$ then-judges Scalia, Bork, and Starr argued as follows:

[T]his court has twice stated that Title VII does not prohibit sexual harassment by a "bisexual superior [because] the insistence upon sexual favors would ... apply to male and female employees alike." [citing Barnes v. Costle, 561 F.2d 983, 990 n.55 (D.C. Cir. 1977); Bundy v. Jackson, 641 F.2d 934, 942 n.7 (D.C. Cir. 1981)).] Thus, this court holds that only the differentiating libido runs afoul of Title VII, and bisexual harassment, however blatant and however offensive and disturbing, is legally permissible. Had Congress been aiming at sexual harassment, it seems unlikely that a woman would be protected from unwelcome heterosexual or lesbian advances but left unprotected when a bisexual attacks. That bizarre result suggests that Congress was not thinking of individual harassment at all but of discrimination in conditions of employment because of gender. If it is proper to classify harassment as discrimination for Title

464. 390 F. Supp. 161 (D. Ariz. 1975).

465. Id. at 163 .

466. Barnes v. Costle, 561 F.2d 983, 990 n.55 (D.C. Cir. 1977).

467. 760 F.2d 1330 (D.C. Cir. 1985) (dissenting from denial of rehearing en banc). 
VII purposes, that decision at least demands adjustments in subsidiary doctrines. 468

These judges thus contended that Title VII could not have been intended to reach desire-based discrimination because doing so would permit bisexuals to evade liability.

The embarrassment that bisexuality causes sexual harassment jurisprudence is clear. An individual who would be liable for engaging in certain conduct can evade liability for that conduct by engaging in more of the conduct directed at the opposite sex. I call this the "double for nothing" problem - by doubling the proscribed conduct, the harasser lowers his liability to nothing. 469 This result is so counterintuitive that commentators who usually seem far apart on the political spectrum - such as Robert Bork and Catharine MacKinnon - can agree that this result is anomalous. 470

The problem of the bisexual harasser demonstrates the manner in which bisexuality destabilizes norms that privilege sex-based distinctions. Title VII privileges sex as a diacritical axis-only discrimination that occurs on this axis (or on another enumerated axis) is actionable. As such, the statute cannot encompass bisexuals who are truly sex-blind within its prohibitions. I earlier noted that the sex-blind bisexual (or asexual) might be celebrated as the only type of individual who could credibly say that she never discriminated on the basis of gender. ${ }^{471}$ But the sex-blind bisexual may express hostility to others indiscriminately as well. And when she does so, our norms against sex discrimination will be insufficient to hold her liable.

The fact that bisexuals have garnered this "advantage" over both heterosexuals and homosexuals explains their relative visibility in the sexual harassment jurisprudence. In areas of the law where differential treatment of the sexes is not required, bisexuals are neither privileged nor visible. A bisexual

468. Id. at 1333 n.7.

469. It bears note that this "double for nothing" problem is not just a problem in the desirebased harassment context, insofar as a harasser who harassed both men and women in nonsexual ways would also evade liability under a strict application of the "because of . . . sex" test. The bisexual harassment exemption is thus a subset of an "equal opportunity" harassment exemption. The fact that "double for nothing" is not specific to the desire-based context should not be surprising, because the problem arises from the asymmetrical treatment of sex required by the "because of ... sex" language in the statute, rather than anything specific to desire.

But this means that the minatory statements made about "double for nothing" in Vinson lack subtlety. These judges argued that Title VII could not have been intended to reach the desire-based context because of "double for nothing." But the fact that the problem is not specific to desire means that it cannot - without further argument-be used by courts to sustain the proposition that Title VII covers nondesire-based harms but not desire-based harms.

470. Compare Vinson, 760 F.2d at 1333 n.7 (noting that a bisexual harassment exemption would entail a "bizarre result"), with Brief amicus curiae of Catharine A. MacKinnon, at 22 n.6, Oncale v. Sundowner Offshore Servs., Inc., 523 U.S. 75 (1998) (No. 96-568) (stating, in the course of a description of the bisexual harasser, that "equal discrimination is a clear oxymoron").

471. See text accompanying note 338 supra. 
could not defend against a same-sex sodomy charge by saying that he had also engaged in cross-sex sodomy. This means that there is no incentive for commentators to make bisexuals visible in the sodomy context-there is no privilege against which critics must inveigh.

The visibility of bisexuals in sexual harassment jurisprudence also suggests that bisexuals may in some instances be more visible in the law than in society in general. Courts noted the bisexual possibility in the late 1970s, 472 well in advance of a national bisexual movement. ${ }^{473}$ This is somewhat surprising, as legal knowledge of sexuality generally lags behind social knowledge of sexuality. 474 The exception to the general rule, however, may be explained by the formalism of the law. The logic of the "because of ... sex" formulation forced courts to hypothetically envision the bisexual harasser long before he ever made an actual appearance. Logic thus opened up imaginative spaces of possibility before such spaces were politically occupied in any robust way.

\section{2. (Incoherently) closing the bisexual harassment exemption- bisexual invisibility.}

One strategy for dealing with the bisexual harassment exemption-class erasure - could have been predicted from the previous discussion of bisexuality. When Vinson finally made its way to the Supreme Court, the Court stated that desire-based harassment was cognizable under Title VII. 475 In so stating, the Court implicitly rejected the argument made by then-judges Bork, Scalia, and Starr in that case. The basis for that rejection, however, was not clear; the Court evaded giving one by simply ignoring bisexuals. ${ }^{476}$ And when the Oncale Court reaffirmed that sexual harassment was cognizable insofar as it was discrimination "because of ... sex,"477 it once again sidestepped the problem of the bisexual harasser by erasing bisexuality. 478 The invisibility of bisexuality in Oncale was particularly ironic, given that Justice Scalia - who as a circuit judge had insisted on the visibility of bisexuality - wrote the opinion for the Court. 479

472. See, e.g., Barnes, 561 F.2d at 990 n.55.

473. See note 416 supra and accompanying text (dating inauguration of national bisexual movement to late $1980 \mathrm{~s})$.

474. See notes 431-432 supra and accompanying text.

475. Meritor Savings Bank v. Vinson, 477 U.S. 57, 64 (1986).

476. See id. (making no mention of the bisexual harassment exemption).

477. Oncale v. Sundowner Offshore Servs., Inc., 523 U.S. 75, 78-80 (1998).

478. See id. (making no mention of the bisexual harassment exemption).

479. Compare Vinson v. Taylor, 760 F.2d 1330, 1333 n.7 (D.C. Cir. 1985) (Bork, Scalia, Starr JJ., dissenting from denial of reh'g en banc) (raising the possibility of the bisexual harasser), with Oncale, 523 U.S. 75 (ignoring the possibility of bisexual harasser). 
As the contrast between Justice Scalia's positions in Oncale and in Vinson illustrates, elision is not a particularly persuasive strategy in this area of jurisprudence, as courts that have already confessed the existence of bisexuality in one case cannot logically deny it in another. Perhaps in recognition of this, other circuit courts have engaged in milder forms of class erasure, engaging not in elision but in explicit (and incomplete) denial of the existence of the class. Thus, in Henson v. City of Dundee, ${ }^{480}$ the Eleventh Circuit stated that "[e]xcept in the exceedingly atypical case of a bisexual supervisor, it should be clear that sexual harassment is discrimination based on sex." 481 That 1982 opinion's language about the "exceedingly atypical case of a bisexual supervisor" has become a boilerplate phrase in sexual harassment cases. ${ }^{482}$ But neither the Henson court nor any other court employing its phrase ever explains why bisexual supervision is so rare.

In fairness to these courts, actual defendants who deploy the bisexual harassment defense are rare. Such defendants appear more often in fiction ${ }^{483}$ or hypotheticals ${ }^{484}$ than actual litigation ${ }^{485}$; the defense has been raised in only two cases and has been rejected in both. ${ }^{486}$ Defendants may understand that the "double for nothing" reasoning underlying the defense violates equitable intuitions, ${ }^{487}$ and may fear that courts will privilege that intuition above the exemption. Alternatively, bisexual harassers who self-identify as straight may fear coming out as bisexual more than they fear potential liability. Such harassers could rationally assume that the potential stigma of being

480. 682 F.2d 897 (11th Cir. 1982).

481. Id. at 905 n.11.

482. See, e.g., Doe v. City of Belleville, 119 F.3d 563, 576 (7th Cir. 1997) (quoting Henson v. City of Dundee, 682 F.2d 897, 905 n.11 (11 th Cir. 1982)); Fredette v. BVP Management Assocs., 112 F.3d 1503, 1506 n.5 (11th Cir. 1997) (same); Jones v. Flagship Int'l, 793 F.2d 714, 720 n.5 (5th Cir. 1986) (same); McCoy v. Johnson Controls World Servs., Inc., 878 F. Supp. 229, 232 (S.D. Ga. 1995) (same); Demele v. Belle of Orleans, L.L.C., 1997 WL 411558 at *7 n.7 (E.D. La. July 21, 1997) (same).

483. See Miller, supra note 432, at 165.

484. See, e.g., Applebaum, supra note 432, at $601-02 \&$ n.1.

485. See Amicus Brief of Catharine MacKinnon, supra note 470, at 21-22 ("The so-called bisexual harasser, eluding equality snares by indiscriminately sexually harassing men and women alike, stalks the judicial imagination, cutting quite a figure in legal hypotheticals." (footnotes omitted)).

486. The bisexual harasser defense has been raised, but not accepted, in two cases. See Raney v. District of Columbia, 892 F. Supp. 283, $287-88$ (D.D.C. 1995); Ryczek v. Guest Servs., Inc., 877 F. Supp. 754, 762 (D.D.C. 1995) (granting summary judgment to defendant on other grounds). A similar "equal opportunity harasser" defense has been raised to no avail in two other cases. See Steiner v. Showboat Operating Co., 25 F.3d 1459, 1464 (9th Cir. 1994); Chiapuzio v. BLT Operating Corp., 826 F. Supp. 1334, 1336-38 (D. Wyo. 1993). In other cases, defendants have failed to raise the bisexual harasser defense where it might have been expected. See, e.g., Griswold v. Fresenius USA, Inc., 978 F. Supp. 718, 723 (N.D. Ohio 1997) (involving married man who allegedly sexually harassed other men and failed to raise bisexual harasser exemption); Hopkins v. Baltimore Gas \& Elec. Co., 871 F. Supp. 822, 824 n.2, 835 (D. Md. 1994) (same).

487. Cf. Saulpaugh v. Monroe Community Hosp., 4 F.3d 134, 144 (2d Cir. 1993) (noting, in § 1983 context, that it would take "audacity" for a defendant to raise a bisexual harassment defense). 
labeled harassers was less than the definite stigma of self-identifying as bisexuals. 488

The fortuity that not many bisexuals have pressed the defense, however, avoids rather than answers the problem of the bisexual harassment exemption. It also does not suffice in those situations in which the defense is actually raised. Perhaps in response to both points, some courts have proffered a different way of dealing with the problem of the bisexual harassment exemption. This approach, which is ultimately more coherent, trades on bisexual visibility, rather than invisibility.

\section{3. (Coherently) closing the bisexual harassment exemption- bisexual visibility (again).}

A more coherent way of closing (or at least significantly narrowing) the bisexual harassment exemption notes that while bisexuals may desire both men and women, they will not necessarily manifest that desire in a sexneutral way. This premise significantly mitigates the "double for nothing" problem, for if bisexuals treat men and women in sex-differentiated ways, they will still be liable under a "because of . . . sex" test. The courts, albeit in a haphazard and undertheorized way, have hypothesized a number of ways in which bisexual desire may have sex-differentiated manifestations. In so doing, they have significantly narrowed the bisexual harassment exemption by making the bisexual more, rather than less, visible.

First, some courts have stated that a bisexual harasser will not evade liability if he only harasses members of one sex. In other words, the harasser cannot escape liability simply by desiring both sexes, he must also express that desire in harassing ways toward both sexes. This requirement of actual harassment of both sexes distinguishes the bisexual harasser exemption from the bisexual harassment exemption. In Raney v. District of Columbia, ${ }^{489}$ the district court noted that Barnes v. Costle 490 could be read as providing for the former exemption, while the subsequent case of Bundy v. Jackson ${ }^{491}$ could be read as providing for the latter. The Raney court itself read Bundy as a clarification of Barnes, and thus required actual harassment of both sexes. ${ }^{492}$ It noted that while the defendant in that case had raised the defense that he was bisexual, he was alleged to have only harassed men, and the court therefore rejected his defense.

488. This is particularly true given that, as Colker has pointed out, an employee who selfidentifies as bisexual can be terminated on that basis without incurring Title VII liability for the employer. See Colker, Bisexual Jurisprudence, supra note 401, at 135-36.

489. 892 F. Supp. 283, 287-88 (D.D.C. 1995).

490. 561 F.2d 983,990 n.55 (D.C. Cir. 1977).

491. 641 F.2d 934, 942 n.7 (D.C. Cir. 1981).

492. See Raney, 892 F. Supp. at 288. 
Second, one court has stated in dicta that a sequential bisexual cannot deploy the exemption even if he harasses both men and women. In Tietgen v. Brown's Westminster Motors, Inc., 493 the court noted that the bisexual harassment exemption "may not prohibit sexual harassment by a bisexual harasser" insofar as one assumes that he or she "chooses whom to solicit for sex according to some criteria other than gender." 494 It went on, however, to contest this assumption, noting that "it may be that a bisexual solicits a person for sex based on the person's gender, which gender the bisexual prefers at that moment." 495 The court thus raised the possibility of, for example, an individual who directs his sexual attention solely to women for a period of time, then switches over to directing his attention solely to men for a period of time. 496 Even if he harassed the same numbers of men and women, one could still argue that at the time he was harassing any individual man, no woman was in danger, and vice versa. If one accepted this argument, his harassment would have occurred "because of . . . sex." 497

Finally, courts have implied that even if the harasser had concurrent sexual desire for both men and women and harassed them both, he could still be liable if he expressed that desire in different ways. In Chiapuzio v. BLT Operating Corp. ${ }^{498}$ a district court noted that the defendant's claim that its employee Eddie Bell harassed both men and women "raised the specter of the 'bisexual harasser."'499 The court exorcised that possibility by contending that although Bell harassed both men and women, he harassed them in different ways; specifically, by making remarks about sex acts he wanted to

493. 921 F. Supp. 1495 (E.D. Va. 1996).

494. Id. at 1501 n.10.

495. Id.

496. The Weinberg study documented the existence of bisexuals who were attracted to one sex or the other depending on their "mood" at a given time. See WEINBERG ET AL., supra note 113, at 55. One such bisexual stated: "I don't think it has much to do with pitting a good-looking man against a good-looking woman. I think it has more to do with my own feelings of whether I'm attracted to men or women more at a particular point." Id. than clear:

497. As Garber notes, the distinction between sequential and concurrent bisexuality is less

Clinicians these days tend to characterize bisexuality as either "sequential" or "concurrent," depending upon whether the same-sex/opposite-sex relationships are going on at the same time. But although this will at first seem useful in making gross distinctions, it is finally less clear than it appears. For one thing, what, precisely, is "the same time"? Alternate nights? The same night? The same bed?

GARBER, supra note 11, at 147. If one collapses the distinction between sequential and concurrent bisexuality in this way, one can completely close the bisexual harassment exemption, but only, perhaps, at the cost of absurdity.

498. 826 F. Supp. 1334 (D. Wyo. 1993).

499. Id. at 1336. 
perform with women but not with men.500 Therefore, the court concluded, Bell's harassment occurred "because of . . . sex." 501

Chiapuzio is not really an example of a court finding a defendant liable for concurrently harassing both sexes in a desire-based but sex-differentiated way. This is because the court determined that while Bell's harassment of women was sexual, his harassment of men was not. The court thus deemed that Bell was not a bisexual harasser, but rather an "equal opportunity" harasser-that is, someone who harassed both men and women, but who did not harass both in sexual ways. Indeed, the fact that Bell harassed one sex but not the other in a sexual way provided the sex-based distinction needed for Title VII liability.

The logic of Chiapuzio, however, may be easily extended to sexdifferentiated desire-based harassment of both sexes. To see this, consider that the court could have reasonably read Bell's comments towards men as being sexual in nature, and could still have found Bell liable. Bell's conduct is entirely consistent with what a man who had desire for both men and women might do in a society that stigmatized same-sex but not cross-sex desire - that is, express his desire for women openly, but find more closeted ways of expressing his desire for men. Even if the court had found this to be the case, however, Bell would still have been liable. If desire (even sexneutral desire) manifests itself in a systematically sex-differentiated way, that is logically sufficient to meet the "because of . . . sex" requirement.

These analytic moves do not completely close the bisexual harassment exemption - there might be a bisexual harasser who was genuinely "sexblind" such that the sex of the victim had no salience to him.502 In such a case, the bisexual harassment exemption would still obtain. Nonetheless, making the bisexual more visible has the effect of significantly narrowing the bisexual harassment exemption. By painting a subtler picture of the bisexual, we see that not all bisexuals are "sex-blind," and to the extent that they are not, they will be liable even under a "but for" test.

\section{Recognizing and Closing the Horseplay Exemption}

Bisexual visibility does not have much normative bite in the context of the bisexual harassment exemption. The exemption has already been closed as a practical matter; bisexual visibility only provides a more coherent justification for that closure. In contrast, bisexual visibility has significant nor-

500. See id. at $1337-38$.

501. See id. at 1338.

502. As noted above, however, I am dubious about the robustness of the "sex-blind" bisexual category. See notes 317-319 supra and accompanying text. 
mative consequences for another exemption in the sexual harassment jurisprudence: the horseplay exemption.

The horseplay exemption occurs in the same-sex sexual harassment context. The exemption arises when harassers (almost invariably males) defend against accusations of homosexual harassment by recasting the conduct as heterosexual horseplay. Because the jurisprudence emphasizes sexual over nonsexual harm, ${ }^{503}$ this re-characterization of the conduct, if successful, often absolves the harassers of liability.

Unlike the bisexual harassment exemption, the horseplay exemption is wide open as a matter of practice.504 This discrepancy can be explained by the relationship that each exemption has to judicial intuitions about fairness. The bisexual harassment exemption was closed because the "double for nothing" problem it raised violated a judicial intuition of equity. The horseplay exemption, in contrast, is consistent with such a judicial intuition. Specifically, the exemption reflects the intuition that the homosocial and the homoerotic are sufficiently intertwined that ambiguity should be resolved in favor of the former, lest heterosexuals be mistakenly re-characterized as nonheterosexuals. 505 The status quo in which the bisexual harassment exemption is closed while the horseplay exemption remains open thus is sociologically intelligible.

That status quo, however, also defies logic. This is because the recognition and closure of the bisexual harassment exemption relied on bisexual visibility. The horseplay exemption as it now stands, however, relies on bisexual invisibility. Closing the bisexual harassment exemption thus logically requires at least significantly narrowing the horseplay exemption.

In making this argument, I first examine the nature of the judicial intuition that keeps the horseplay exemption open. I then note the analytic moves the courts make to protect the horseplay exemption, pointing out that these moves rely on bisexual invisibility. Finally, I consider how the enhanced visibility of bisexuality would foreclose these moves, requiring a significant narrowing of the exemption.

503. Some may question whether this is still the case after Oncale v. Sundowner Offshore Servs., Inc., 523 U.S. 75 (1998). I address this question below. See notes 535-549 infra and accompanying text.

504. See, e.g., McWilliams v. Fairfax County Bd. Of Supervisors, 72 F.3d 1191 (4th Cir. 1996); Martin v. Norfolk S. Ry. Co., 926 F. Supp. 1044 (N.D. Ala. 1996); Tietgen v. Brown's Westminster Motors, Inc., 921 F. Supp. 1495 (E.D. Va. 1996).

505. This intuition is probably the impetus behind the various "queen-for-a-day" exemptions described above, in which adventitious homosexual conduct is not seen as damaging an otherwise heterosexual status. See notes 100-106 supra and accompanying text. 


\section{Understanding horseplay — the homosocial and the homoerotic.}

Intimate actions among men are ambiguous-they can be either homosocial or homoerotic. This ambiguity is peculiar insofar as the two ways in which it can be resolved are diametrical opposites. Usually when an ambiguity must be resolved, the two ways of resolving it are quite similar to each other; indeed, it is their similarity that leads to the confusion. Intimate acts among men, however, are not ambiguous in this way; the social meanings and consequences of homosociality are squarely opposed to those of homoeroticism.

One way of construing the opposition is to understand homosociality as a means of making men, and homoeroticism as a means of unmaking them. Homosociality is a means of making men insofar as the men who can take (and dish out) hazing, razzing, or horseplay are constituted as "real" men, while those who cannot (or who choose to opt out) are constituted as "failed" men. These rites are often explicitly formulated as initiations where the manhood of those hazed is tested and the manhood of those hazing is reaffirmed.506 Even when they are not so formulated, homosocial behaviors often perform that function. Over a course of homosocial conduct-however inchoate- a verdict is reached as to whether the new worker is "one of the guys" or not. 507

Homoeroticism, in sharp contrast, is a means of unmaking men. 508 As can be seen in the earliest formulations of homosexual men as "inverts"that is, as women trapped inside men's bodies ${ }^{509}$-a homosexual male was a man who would reveal himself to be a woman (and thus a failed man). That gay men are viewed as failed men can also be seen in the characterization of failed men as gay men. ${ }^{510}$ In case after case, the workplace outcast is cast

506. See HANK Nuwer, THE DEAdLY RITE OF HAZING 204-06 (1990) (describing highly sexualized hazing ritual through which Coast Guard initiates are inducted-or not-into the group).

507. See Michael S. Kimmel, Masculinity as Homophobia: Fear, Shame, and Silence in the Construction of Gender Identity, in THEORIZING MASCULINITIES 119, 128-29 (Harry Brod \& Michael Kaufman eds., 1994) ("Other men watch us, rank us, grant our acceptance into the realm of manhood. ... Masculinity is a homosocial enactment. We test ourselves, perform heroic feats, take enormous risks, all because we want other men to grant us our manhood.").

508. This is, of course, a culturally contingent claim. In other cultural contexts, homoeroticism could be seen as a means of initiating youths into manhood. See, e.g., EVA CANTARELLA, BISEXUALITY IN THE ANCIENT WORLD 6-8 (Cormac Ó Cuilleanáin trans., 1992) (describing such initiations in ancient Greek society).

509. See Edwards, supra note 342, at 112.

510. See Gary Kinsman, Men Loving Men: The Challenge of Gay Liberation, in BEYOND PATRIARChY: EsSAyS BY MEN ON PleAsURe, POWER, AND ChANGE 103, 104 (Michael Kaufman ed., 1987) (“'Real' men are intrinsically heterosexual; gay men, therefore, are not real men.”); Joseph H. Pleck, Men's Power with Women, Other Men, and Society: A Men's Movement Analysis, in THE AMERICAN MAN 417, 424 (Elizabeth H. Pleck \& Joseph H. Pleck eds., 1980) ("Our society uses the male heterosexual-homosexual dichotomy as a central symbol for all the rankings of masculinity, for the division on any grounds between men who are 'real men' and have power and 
"out" as a homosexual, regardless of whether there is evidence that he manifested any same-sex desire. 511

The fact that intimate intra-male acts can be interpreted in diametrically opposed ways makes that interpretive act extremely fraught.512 A misreading of homosociality as homoeroticism will have the devastating consequence of branding a real man as a failed man. In resolving that ambiguity, the riskaverse decisionmaker will err on the side of heterosexuality. This tendency could be defended on the grounds that we believe the majority of the population to be straight. That defense, however, may be insufficient, in that the courts are not dealing with the general population, but with the subset of that population whose same-sex conduct has given rise to a claim of harassment.

This suggests that the premise here may be less statistical than equitable; courts may believe that where any ambiguity exists, it is better to let the guilty homosexual go free than to convict the innocent heterosexual. That equitable premise, however, will create problems of its own when the costs

males who are not. Any kind of powerlessness or refusal to compete becomes imbued with the imagery of homosexuality.").

511. See, e.g., Johnson v. Hondo, Inc., 125 F.3d 408, 410 (7th Cir. 1997) (worker's masculinity impugned by allegations of homosexuality, despite lack of evidence of same-sex desire); Doe v. City of Belleville, 119 F.3d 563, 566-67 (7th Cir. 1997) (worker with earring called "queer" and "fag" despite lack of evidence of same-sex desire).

512. One might ask if it is just an unfortunate coincidence for real men that the modality through which real men constitute themselves and other real men looks awfully like the modality through which failed men constitute themselves and other failed men. I believe that it is no accident.

To see this, imagine a world in which same-sex horseplay did not exist-where men constituted themselves and others as real men by other existing methods-by work performance, say, or by salary. Real men never touch or engage in sexual banter. Thus, whenever a man touches another man or attempts sexual banter with him, the import is unambiguous-that man is gay. What do real men lose when they enter this imaginary world?

At least two things. First, they lose the ability to appropriate the signifier of the "private parts" to show how close they are to each other. Even if we assume the absence of desire, it still makes sense that many homosocial hazing activities involve male genitalia. This is because the genitalia are being deployed here as signifiers of the private, rather than as signifiers of sex (although of course their signification as the "private" stems in part from their use in sex). When someone's genitalia are used in a hazing ritual, the message is that the hazed man's most private parts are available to the men who haze him. Such hazing can be interpreted as a form of domination-of forcing the hazed man to admit that he is powerless to keep the hazers from violating any part of his body. Or it can be seen as a form of community-of forcing the hazed man to admit that the group is so tight that there is no realm of the "private" that he can withhold from the group. In either case, the hazed man's constitution as a "real" man will depend on his ability to demonstrate that he can survive this incident of powerlessness.

Second, they lose the ability to prove that they are so powerful that they can engage in taboo activities without suffering the consequences of that taboo. Straight men may be most able to constitute themselves as straight men when they engage in homosocial activity, because this permits them to demonstrate that even when they skate very close to the edge of homosexual ascription, they never fall over it. Another way of thinking about this is to consider how the closeted homosexual might be most afraid of engaging in "parodic" demonstrations of homosexuality, lest that ostensible parody be recognized as revealing his underlying homosexuality. 
of letting a bisexual or a homosexual go free as a heterosexual include the unredressed harms he has visited on others. This is the precise issue raised in the sexual harassment context.

\section{Recognizing the horseplay exemption-bisexual invisibility.}

In the same-sex sexual harassment context, courts are often confronted with male-on-male intimate conduct and asked to determine whether that conduct is homosocial or homoerotic. The priority of desire-based claims in the sexual harassment jurisprudence means that the harasser will be much more likely to be liable if the conduct is deemed sexual. Thus, the task of the courts is doubly fraught; they are not only determining sexual orientation, but also liability. To decide that the harassser is heterosexual is often simultaneously to decide that he is not liable; to decide that the harasser is homosexual is often simultaneously to decide that he is liable.

The courts' reluctance to interpret ambiguous conduct as homoerotic rather than as homosocial is often carried to extremes; so long as the harasser has not openly admitted his homosexuality or bisexuality, courts work furiously to assign him a heterosexual identity. For example, in McWilliams $v$. Fairfax County Board of Supervisors, ${ }^{513}$ the court noted that the harassers engaged in the following conduct:

On at least three occasions, coworkers tied McWilliams' hands together, blindfolded him, and forced him to his knees. On one of these occasions, a coworker placed his finger in McWilliams' mouth to simulate an oral sexual act. During another of these incidents, a coworker, Doug Witsman, and another placed a broomstick to McWilliams' anus while a third exposed his genitals to McWilliams. On yet another occasion, Witsman entered the bus on which McWilliams was working and fondled him. ${ }^{514}$

This conduct skates close to violating prohibitions on sodomy (a quintessentially sexual category) in some jurisdictions. ${ }^{515}$ Nonetheless, McWilliams's coworkers characterized it as "horseplay." 516 While the McWilliams court did not itself use this characterization, other courts have described the conduct in this case as "razzing and hazing"s17 or "mere locker room antics, joking, or horseplay." $\$ 18$

513. 72 F.3d 1191 (4th Cir. 1996).

514. Id. at 1193 .

515. Texas's sodomy statute, for example, prohibits same-sex "deviate sexual intercourse," TEX. PENAL CODE ANN. § 21.06(a) (West 1994), and defines "deviate sexual intercourse" to include "the penetration of ... the anus of another person with an object." TEX. PENAL CODE ANN. $\S$ 21.01(1)(B) (West 1994).

516. McWilliams v. Fairfax County Bd. of Supervisors, 72 F.3d 1191, 1194 (4th Cir. 1996).

517. Fredette v. BVP Management Assocs., 112 F.3d 1503, 1507 (11 th Cir. 1997).

518. Tietgen v. Brown's Westminster Motors, Inc., 921 F. Supp. 1495, 1501 (E.D. Va. 1996). 
Courts rationalize the resolution of ambiguity in favor of heterosexuality in two ways. First, courts reason from the premise that the harasser has manifested cross-sex desire to the conclusion that he therefore harbors no same-sex desire. Second, they state that they will not impute sexual desire to a harasser in the same-sex context unless the plaintiff has actually proven that the harasser is homosexual.519 To say that the courts do not mention bisexuality in making either of these analytic moves does not seem to be saying much. The damage that bisexuality could do to these moves is nonobvious. But when we examine these moves more closely, we see that both of them can be deeply problematized by bisexual visibility.

\section{Closing the horseplay exemption-bisexual visibility.}

Bisexual visibility significantly narrows the horseplay exemption by challenging the two analytic moves made to keep it open. Bisexual visibility disrupts the first move-the assertion of heterosexual status as pre-emptive of homoerotic conduct-because it makes this status impossible to prove conclusively. When the harasser is claiming heterosexual status, all he is really adducing is evidence that he manifests cross-sex desire-that he has a wife, that he is perceived as straight by colleagues, etc. When the plaintiff is claiming that homoerotic conduct occurred, he is imputing same-sex desire to the harasser. In finding these allegations to be in tension, the courts are really saying that allegations of cross-sex desire and allegations of same-sex desire conflict. But as noted above, 520 the premise that bisexuality exists means that the harasser's allegations of cross-sex desire and the plaintiff's allegations of same-sex desire are not necessarily in tension. If both the harasser's allegations of cross-sex desire and the plaintiff's allegations of samesex desire are plausible, the factfinder should not assume that either is lying or mistaken, but rather should entertain the possibility that they are both right, and that the harasser is therefore bisexual. This of course makes it more likely that courts will deem the conduct to be sexual, which in turn makes it more likely that they will deem it to be a Title VII violation.

One example of the first analytic move can be found in Johnson $v$. Hondo, Inc.521 Johnson and Hicks worked in an all-male environment for the Coca-Cola Company. ${ }^{222}$ Johnson's complaint alleged that Hicks subjected him to "homosexual advances," 523 including statements such as "I'm going

519. A third strategy that the courts use is simply to denominate the conduct in question as horseplay by repressing the homoerotic possibility. This strategy relies on fiat rather than argument-the difficult interpretive problem of whether the defendant is engaged in homosocial or homosexual behavior is wished away rather than confronted. I do not address it further here.

520. See notes 259-313 supra and accompanying text.

521. 125 F.3d 408 (7th Cir. 1997).

522. See id. at 410 .

523. Id. at 413. 
to make you suck my dick," "come down to the carwash and suck my dick," "come across the street and suck my dick," and actions such as simulated masturbation. 524

The court found that there had been no harassment because it found that Johnson's testimony belied his belief that Hicks had made a "homosexual advance" on him. ${ }^{525}$ The court maintained:

For example, Johnson testified that on one occasion, Hicks approached him and said: "I'm going to get my dick sucked," and then, apparently referring to Johnson's girlfriend, Hicks said "I think she's probably watching TV now. I'll go by and have that bitch suck my dick." Hicks also said, "that bitch ought to be getting in the shower right now .... [T] hat redhead bitch got a nice ass too. I ought to go get my dick sucked." It is extremely difficult to reconcile remarks such as these with Johnson's strained contention that Hicks was making "homosexual advances" toward him. ${ }^{526}$

The court thus used Hicks's expressions of cross-sex desire as negating the possibility that he harbored same-sex desire. This is logical only if the bisexual possibility is elided. If the bisexual possibility is recognized, the allegations of cross-sex desire are irrelevant. For while the allegations of crosssex desire arguably negate the inference that Hicks is homosexual, they do not negate the inference that he engaged in "homosexual advances." And it is the latter, rather than the former, which is relevant for the purpose of determining whether Johnson has a desire-based claim. Notwithstanding this problem, however, the logic of Johnson has been used in other cases. ${ }^{527}$

524. Id. at 410 n.1.

525. Id. at 413 .

526. $I d$.

527. In Bolt v. Norfolk S. Corp., 22 F. Supp.2d 512 (E.D. Va. 1997), the court denied a samesex sexual harassment claim because "the record provides no basis for an inference that Williams [the defendant] was homosexual other than his harassing conduct." Id. at 518. Evidence drawn from the record for the opposite conclusion included: (1) "Williams was married during most of the time in question"; (2) "Bolt [the plaintiff] saw Williams out with a woman socially"; (3) "Bolt never saw Williams on a date with a man"; (4) "Williams denie[d] that he is a homosexual and aver[red] that he has never held any sexual attraction for Bolt"; (5) "Bolt said he did not know if Williams was homosexual, or how to tell if someone was homosexual, and admitted that he did not know whether Williams subjectively intended to joke, engage in horseplay or was serious." Id. at 518-19. The court then noted that "[t]he only evidence other than the harassing conduct itself is a sworn affidavit by a co-worker who avers that he was told by co-workers shortly after joining Norfolk Southern that Williams was homosexual, despite the fact he was married." Id. at 519. It then noted that "[t]his statement, however, would be inadmissible at trial to prove Williams actually is homosexual." Id.

Similarly, in Gibson v. Tanks Inc., 930 F. Supp. 1107 (M.D.N.C. 1996), the court rejected a same-sex sexual harassment claim in part due to the absence of evidence that the defendant was homosexual, noting that "[i]n fact, [the plaintiff's] deposition indicates that [the defendant] was married during the time the alleged sexual harassment occurred." Id. at 1109.

And in Easton v. Crossland Mortgage Corp., 905 F. Supp. 1368 (C.D. Cal. 1995), rev'd and remanded on other grounds, 114 F.3d 979 (9th Cir. 1997), the court found no sexual harassment of the female plaintiffs by their female supervisors, noting the absence of "evidence that the defendants are lesbians," and pointing out that "[i]n fact, the record demonstrates just the opposite." Id. 
A second strategy the courts use to characterize the conduct as horseplay relies on the fact that the plaintiff has not proven that the harasser is homosexual. Thus, in McWilliams v. Fairfax County Board of Supervisors, 528 the court dismissed McWilliams's suit because "no claim is made that any [of the harassers] was homosexual." ${ }_{22}$ Other courts have approved its requirement that a plaintiff must generally plead and prove the homosexuality of the harasser in order to prevail in a same-sex harassment suit. 530

Even assuming a straight/gay binary, making liability turn on one's sexual orientation is a potential nightmare, raising issues of privacy and propriety. ${ }^{531}$ And once the bisexual possibility is introduced, the inquiry becomes even more complicated. In a simple straight/gay regime, the plaintiff's attempt to prove same-sex desire would be blocked by credible evidence of the harasser's cross-sex desire. But again, once the bisexual possibility is introduced, such evidence of cross-sex desire represents almost no obstacle to the plaintiff trying to make out a claim of same-sex desire. The plaintiff seeking to prove that the harasser harbored same-sex desire would thus be entitled to continue digging for that evidence no matter how much evidence of crosssex desire the harasser adduced.

To my knowledge, only one court has attached consequences to its own acknowledgement of the bisexual possibility. In that case, Griswold v. Fresenius USA, Inc., 532 the court observed that an alleged harasser who had adduced evidence of cross-sex desire could still have engaged in homoerotic conduct. 533 Based on this observation, the court permitted the plaintiff to continue searching for evidence of the alleged harasser's bisexuality. ${ }^{534}$

When the bisexual harassment exemption is read against the horseplay exemption, it becomes clear that we cannot close the first without significantly narrowing the second. Once courts admit in one context that bisexuals exist, they cannot then turn around in another context and presume that cross-sex desire ipso facto negates the existence of same-sex desire. If the

at 1380. Examples drawn from the record included (1) "the kinds of decorations chosen for [one supervisor's] birthday party"; (2) one supervisor's "flirtatious questioning of the outside services employee"; (3) "numerous discussions [the supervisors] participated in concerning their own and other employees' heterosexual sexual experiences"; (4) the plaintiffs' admission that "they do not know if [the supervisors] were even interested in having sex with the plaintiffs, with each other, or if they were lesbians"; and (5) the fact that both supervisors "were married during the relevant time period." Id. at $1374,1380$.

528. 72 F.3d 1191 (4th Cir. 1995).

529. Id. at 1195 .

530. See, e.g., Tietgen v. Brown's Westminster Motors, Inc., 921 F. Supp. 1495, 1502 (E.D. Va. 1996) (noting but waiving requirement).

531. See McWilliams, 72 F.3d at 1198 (Michael, J., dissenting) (describing pursuit of harasser's "'true' sexual orientation" as "complicated, far-ranging and elusive").

532. 978 F. Supp. 718 (N.D. Ohio 1997).

533. See id. at $727-28,730$.

534. See id. at 730. 
horseplay exemption were to be made consistent with the portrait of the bisexual painted in the context of the bisexual harassment exemption, many more putative straights would be liable. Whether conduct was nonsexual horseplay or sexual harassment would be an issue of fact. And in the resolution of that issue of fact, alleged harassers would no longer be permitted to categorically negate the possibility of homoerotic conduct simply by making plausible protestations of cross-sex desire.

\section{Sexual Harassment at a Crossroads}

I have demonstrated that closing the bisexual harassment exemption has implications for the horseplay exemption. Closing the horseplay exemption in turn has implications for the rest of sexual harassment jurisprudence. The jurisprudence is currently at a crossroads where courts must choose whether to continue privileging desire or to break from that tradition to embrace a "because of ... sex" standard that stops privileging desire. While the latter route clearly makes better sense, it is unclear even after Oncale that the courts will take it. Because it problematizes the regulation of desire, bisexuality could act as a goad that prompts the jurisprudence to depart from its historical fetishization of desire.

\section{The post-Oncale status quo.}

In her article, Schultz trenchantly argues against the pre-Oncale status quo, in which desire-based claims were seen as more valid than nondesire based claims. ${ }^{535}$ The crux of her argument is that Title VII prohibits discrimination on the basis of sex; that sex discrimination takes many forms that have nothing to do with desire; and therefore that interpretations of Title VII that fetishize desire will be underinclusive. 536 When a male welder sabotages a female welder's equipment because he believes that women should not be welders, for example, it seems clear that sex discrimination is occurring even though sexual desire is not obviously at issue. Schultz proposes that sexual harassment jurisprudence should return to the statutory language and protect against any discrimination - sexual or otherwise - that occurs "because of ... sex." 537

This proposal has important consequences for same-sex sexual harassment. In that context, a rule privileging desire has the pernicious consequence of assigning different sanctions for the same conduct based on the sexual orientation of the harasser. In considering the horseplay exemption, I demonstrated that the same conduct could be characterized either as hetero-

535. See Schultz, supra note 436.

536. See id. at 1796-1805.

537. See id. 
sexual horseplay or homosexual harassment, and that courts made that determination based on the sexual orientation of the harasser. We also saw that, under a desire-based paradigm, an individual was much more likely to be liable for so-called homosexual harassment than for so-called heterosexual horseplay. But this effectively means that the sexual orientation of the parties can be determinative of liability; a straight person and a gay person could do the same thing and be punished differently. ${ }^{538}$ Schutlz's proposal forecloses this inequitable result, encouraging courts to redirect their attention to conduct rather than simply relying on desire-based status.

As Schultz's article was going to press, 539 the Supreme Court handed down its decision in Oncale. 540 The Oncale Court's holding is completely consistent with Schultz's proposal. The Court not only stated that the plaintiff must "always prove that the conduct at issue ... constituted 'discrimina[tion] . . because of ... sex,"'541 but also clarified that "harassing conduct need not be motivated by sexual desire to support an inference of discrimination on the basis of sex." 542 Thus the Court held that sexual harassment subsumed all (sufficiently severe and pervasive) discrimination that occurs "because of . . . sex," including, but not limited to, desire-based harassment.

It would be naïve, however, to celebrate Oncale's holding too quickly as implementing Schultz's proposal. Prior courts have adopted rules analogous

538. It might fairly be asked whether the same actions undertaken by a nonheterosexual and a heterosexual are truly the "same" conduct. After all, desire could be characterized not as a status, but as an intent. And there are multiple circumstances in which the same action is treated as two different forms of conduct based on intent. If two men shoot their neighbors, but one does so intentionally and the other does not, the first is deemed to have committed murder, the second manslaughter. JOSHUA DRESSLER, UNDERSTANDING CRIMINAL LAW § 31.02 (1995) ("The common law definition of 'murder' is 'the killing of a human being with malice aforethought.' Manslaughter is 'an unlawful killing of a human being without malice aforethought."'). The same actshooting a human being-is deemed to be two legally distinguishable conducts-murder and manslaughter-based on something that is entirely within the individual mind.

This distinction is arguably deployed in the Court's hypothetical in Oncale, where the Court distinguishes between the coach smacking the buttocks of a male football player on the football field and smacking the buttocks of a male secretary back in the office. See Oncale v. Sundowner Offshore Servs., Inc., 523 U.S. 75, 81-82 (1998). The smacks are the same act, but are treated as two legally distinct forms of conduct. The first, in the Court's view, is clearly horseplay, the second is just as clearly harassment. See id. at 81 . The distinction between them, the Court says, is context. See id. at 81-82. But context here is shorthand for desire-in the first instance the conduct is read as not desirous, in the second it is read as the opposite.

The flaw in the analogy is that desire should not be equated with bad intent for at least two reasons. First, desire may not always be within individual control. Second, desire can be seen as having many positive aspects, such that adding desire to an otherwise acceptable act does not in itself make it worse.

539. See Schultz, supra note 436 , at 1683 n. $†$.

540. 523 U.S. 75 (1998).

541. Id. at 81 .

542. Id. at 80 . 
to Oncale's holding only to have them ignored or undermined in practice. As Schultz notes, ${ }^{543}$ the D.C. Circuit held in the 1985 case of McKinney $v$. Dole $e^{544}$ that harassment could be cognizable under Title VII even if it did not involve "sexual advances or ... other incidents with clearly sexual overtones." ${ }_{45}$ The McKinney court found that "any harassment or other unequal treatment ... that would not occur but for the sex of the employee or employees may, if sufficiently patterned or pervasive, comprise an illegal condition of employment under Title VII." ${ }^{446}$ Seven other circuits adopted analogues of this rule, ${ }^{547}$ which sounds remarkably like the rule adopted in Oncale.

The McKinney rule, however, has had little influence.548 Some subsequent courts have outright ignored it. Other courts have undermined it by recognizing both sexual harm and nonsexual harm, but by privileging the former over the latter. In other words, while the rule articulated in McKinney made it clear that both nonsexual and sexual harms were cognizable, it left open the question of the relative emphasis courts should place on each kind of harm. Courts were thus not constrained by the McKinney rule from continuing to privilege desire.

Although the authority of the Supreme Court makes it unlikely that the Oncale holding will be ignored, it could be undermined in exactly the way that the McKinney rule was undermined. Indeed, the norms articulated by the Oncale Court seem almost to invite a continued fetishization of desire. This can be seen in its discussions of the two requirements for a successful sexual harassment claim: the "because of . . . sex" requirement and the "severity and pervasiveness" requirement.

In enunciating its "because of ... sex" requirement, the Court began by stating that "[c]ourts and juries have found the inference of discrimination easy to draw in most male-female sexual harassment situations, because the challenged conduct typically involves explicit or implicit proposals of sexual activity; it is reasonable to assume those proposals would not have been made to someone of the same sex." ${ }_{449}$ The Court here privileged the desirebased route to proving sex discrimination by: (1) characterizing desire-based conduct as the "typical" form of male-female harassment (without noting that it may be typical only because of the historical fetishization of sexuality by the courts); and (2) noting that the inference of discrimination is "easy to draw" in contexts where desire is present.

543. See Schultz, supra note 436, at 1733.

544. 765 F.2d 1129 (D.C. Cir. 1985).

545. Id. at 1138 .

546. Id.

547. See Schultz, supra note 436 , at 1733 n. 250 .

548. See id. at 1732-38.

549. Oncale v. Sundowner Offshore Servs., Inc., 523 U.S. 75, 80 (1998). 
The Court also appeared to privilege desire-based claims in its discussion of the "severity and pervasiveness" requirement. It noted: "A professional football player's working environment is not severely or pervasively abusive ... if the coach smacks him on the buttocks as he heads onto the field-even if the same behavior would reasonably be experienced as abusive by the coach's secretary (male or female) back at the office." 550 But if the smack of a football's player's buttocks sounds different from the smack of a secretary's buttocks because the former smacks less of sexuality, this suggests that conduct is more likely to be deemed severe and pervasive if it is desirebased.

Thus, while the Supreme Court explicitly held that both desire-based harms and nondesire-based harms should be cognizable, it arguably continued to privilege desire-based harms over nondesire-based ones. What will stop lower courts from doing the same?

\section{Bisexuality as goad.}

Bisexuality may be deployed to help the courts down the right path after Oncale. I earlier noted that the tendency of bisexuality to confuse sexual orientation categories had pro-gay deployments. One such deployment was that bisexuality could threaten straights with falling into the stigmatized category of bisexuality. 551 The theory was that the more likely straights were to be threatened with homoerotic ascription, the less likely they would be to assign liability to that ascription.

One way to see how this works is to ask why the Court is so sure that the coach smacking the football player on the buttocks as he heads out onto the field is engaged in horseplay. The answer seems to be that this is football; that some homosocial acts are so transparently homosocial that they cannot be read any other way. But this, as we have already seen, is simply untruethe homosocial and the homosexual are inextricably intertwined. Anyone who thinks that football is always homosocial needs to review his Tennessee Williams. 552 The bisexual possibility powerfully exposes the illogic of this conclusory defense.

When that defense is stripped away, it becomes clear that the reason football cannot be homoerotic is that some homosocial acts are so valued that they cannot afford to be tainted with homosexuality. ${ }^{553}$ Thus, even if ambi-

550. Id. at 81 .

551. See notes 303-304 supra and accompanying text.

552. See generally TENNESSEE WILLIAMS, CAT ON A HOT TIN ROOF (1955) (play turning on the homoerotic undertones of "homosocial" interactions between football players).

553. Another example of this dynamic might be the National Organization of Women's hostility toward lesbians in the 1970s. See BARRY D. ADAM, THE RISE OF A GAY AND LESBIAN MOVEMENT 97 (rev. ed. 1995) (noting then-President Betty Friedan's description of lesbians as a 
guity between the homosocial and the homosexual is recognized at one level, it must be repressed on another.

But this answer-that while the homosocial/homosexual binary is intrinsically unstable, straights desperately try to preserve its stability-should serve as a clue for those arguing against the regulation of desire. For if that binary can be shown to be so unstable that self-identified heterosexuals themselves become threatened with potential homoerotic ascription, they too will have an investment in not having liability turn on orientation. 554

This is bisexuality's final and most tentative critique of sexual harassment law. By destabilizing the homosocial/homoerotic binary, bisexuality reveals that sexuality is so fluid that heterosexuality is impossible to prove. Historically, the reaction to the bisexual threat has been repression, but bisexual visibility has become sufficiently great that this repression has become more difficult. Increased bisexual visibility makes the deployment of a desire-based paradigm more risky for straights, who will encounter challenges not only to their conduct (horseplay) but also to their status (heterosexual). To the extent that self-identified straights have investments in keeping those statuses immured from scrutiny, a different form of repression is in order. It is now not the bisexual, but desire itself, that must be abjured. In sexual harassment jurisprudence, this means that the courts may wish to leave the path they have been on, shifting from a desire-based paradigm of sexual harassment to a broader "because of . . . sex" paradigm.

\section{E. Other Applications}

Although bisexuals are most visible in sexual harassment jurisprudence, bisexuality's potential to effect changes in doctrine is not limited to that area. I do no more than touch on two other areas in which it might make a difference-the "don't ask, don't tell" policy and same-sex marriage.

The "don't ask, don't tell" policy raises issues analogous to those in the sexual harassment context in that individual liability turns on sexual orientation. An individual deemed homosexual will be evicted from the military if he engages in homosexual conduct, such as same-sex sodomy.555 An individual deemed heterosexual, however, can engage in the exact same conduct,

\footnotetext{
"lavender menace" to the feminist movement); ROSALIND ROSENBERG, DIVIDED LIVES: AMERICAN WOMEN IN THE TWENTIETH CENTURY 208 (1992) (describing Friedan's view that "NOW could not survive ... if feminism was identified with lesbianism").

554. While this strategy is admittedly speculative, it has parallels in the race context in the ante-bellum era. As Ariela Gross observes, abolitionists and fugitive slaves writing in the North used cases in which individuals who appeared "white" were enslaved to bring home the horror of slavery to white audiences. See Ariela Gross, Litigating Whiteness, 108 YALE L.J. 109, 127 (1998). Such accounts were meant to encourage "white readers to imagine themselves in the enslaved [person's] shoes." Id.
}

555. See 10 U.S.C.A. $\S 654(b)(1)$ (West 1994). 
and not be so evicted under the "queen for a day" exemption.556 Here, the heterosexual ascription performs an even more powerful role because it protects individuals even from the consequences of their concededly homoerotic (rather than homosocial) acts. No one is arguing that same-sex sodomy is simply heterosexual horseplay, but sodomy will not have consequences for the individual who can prove that he is "heterosexual." Again, sexual orientation status defines liability. Again, there is no reason why bisexuality could not destabilize those statuses in such a way as to force straights to interrogate such a desire-based paradigm.

At this point, a bisexual activist might comment on the fact that the two examples I have thus far adduced-sexual harassment and "don't ask, don't tell"- link increased bisexual visibility to increased bisexual liability. How should bisexuals feel about the fact that they are being rendered more visible simply to be held more accountable? Is this deployment of bisexual visibility truly pro-bisexual? Or is it pro-gay and anti-bisexual? Insofar as these examples are concerned, it would certainly seem that bisexuals are being deployed either to out self-identified straights as bisexuals or to threaten them with being outed. Of course, as can be seen from the gay context, outing is not necessarily against the interests of the group into which the individual is outed: even when costly to the individuals involved, it has been viewed by many as beneficial to the community at large. 557 It might be helpful, however, to think of a legal instance in which bisexual visibility might actually redound to the benefit of the individual bisexual litigant.

Marriage may be such an example. Both gays and bisexuals can argue that the cross-sex requirement of marriage violates sex discrimination norms because it permits one sex but not the other from marrying members of a given sex. The bisexual, however, might express an additional harm. This harm is that the state is contributing to sex-consciousness in society by distinguishing in this way between men and women. For the sex-blind bisexual, this consciousness is in itself a harm, because it impedes her from seeing "through" sex to other traits that she may find more important. Because the homosexual, just as much as the heterosexual, does not purport to be blind to sex in this way, this is not a harm that he will adduce. 558

The claim that the state harms the bisexual by forcing her to view the world through the lens of sex is, of course, a rather utopian one. This is es-

556. See 10 U.S.C.A. § 654(b)(1)(A)-(E) (West 1994).

557. See, e.g., Warren Johansson \& William A. Percy, Outing: Shattering the CONSPIRACY OF SILENCE 229 (1994) (noting that while outing impinges on an individual's privacy, its net effects can be beneficial for the group).

558. There is another distinction between sexual harassment and "don't ask, don' $t$ tell" on the one hand and marriage on the other. While sexual harassment and "don't ask, don't tell" primarily implicate bisexuality's influence on norms of sexual orientation, the marriage context primarily implicates bisexuality's influence on norms of sex. This is because the marriage context is one that technically discriminates on the basis of sex rather than on sexual orientation. 
pecially true given my expressed doubt as to whether any bisexual truly is sex-blind.559 Yet a bisexual could respond by noting that even if she is not completely sex-blind, she has a right to aspire to lowering the salience of sex in her life. She could also attempt an analogy to race, noting that the Supreme Court has owned the American judiciary's obligation not to increase race-consciousness in society. 560

\section{CONCLUSION}

"We have not yet reached a point," Garber notes, "though nothing is unimaginable, at which monosexuals, hetero- and homo-, band together to stave off the advancement of bisexuals." 561 This article has argued that we have actually never left that point. It has maintained that bisexuality is erased because self-identified straights and self-identified gays have entered into an epistemic contract of bisexual erasure. And it has suggested that the rising visibility of bisexuality might have transformative consequences for how we think about sexual orientation politics and law.

The strength of this hypothesis will depend in part on its ability to explain the erasure of bisexuality in daily life. I thus end where I began, with the anecdote of my own erasure of bisexuals in my seminar on sexual orientation. Do the explanations I provide intuitively explain why that erasure occurred? In one sense, the answer must be no. I do not think that I erased bisexuals because of a fear of not being able to prove my orientation, or out of a fear of failing to retain sex as an important diacritical axis, or out of a fear of nonmonogamy. Rather, my erasure can be most easily explained by the fact that bisexuality is not part of our cultural or semantic stock: it is difficult constantly to read cases, articles, or popular accounts that erase bisexuals without following suit. But this just displaces the question from the individual level to the cultural level, for it is ultimately not that interesting simply to point out that individuals erase bisexuals because they belong to cultures that do. And when the question arises of what cultural investments

559. See notes 317-318 supra and accompanying text.

560. See, e.g., Adarand Constructors, Inc. v. Pena, 515 U.S. 200, 228-29 (1995) (approving prior opinion that criticized affirmative action program for delaying "'the time when race will become a truly irrelevant, or at least insignificant, factor"') (quoting Fullilove v. Klutznik, 448 U.S. 448, 545 (1980) (Stevens, J., dissenting)); Shaw v. Reno, 509 U.S. 630, 657 (1993) (warning that "[r]adical gerrymandering, even for remedial purposes ... threatens to carry us further from the goal of a political system in which race no longer matters-a goal that the Fourteenth and Fifteenth Amendments embody, and to which the Nation continues to aspire"); City of Richmond v. J.A. Croson Co., 488 U.S. 469, 495 (1989) (criticizing "[t]he dissent's watered-down version of equal protection review" for ensuring "that race will always be relevant in American life, and that the ultimate goal of eliminat[ing] entirely from governmental decisionmaking such irrelevant factor's as a human being's race, will never be achieved" (citation omitted)).

561. GARBER, supra note 11 , at 80. 
might lead to the erasure of bisexuals, I believe the investments I have described gain in plausibility.

The degree to which the hypothesis of this article is held accountable to lived experience deserves more global comment. Colleagues have repeatedly noted this article's obsession with logic-its insistence on analyzing bisexuality in strictly Cartesian terms. That observation has often been accompanied by the exhortation to give less to the reader's head and more to her experience. The implication of the exhortation is that the logical account of bisexuality leaves something important about bisexuality unconsidered.

This is doubtless true. The logical approach of the article may be read as compensation for the often parlously imprecise terms in which debates about sexuality in general and bisexuality in particular are conducted. Yet the fact that it may also be read as overcompensation is important. Sexual identity has always struck me as a kind of illogic, given that sexuality is such a powerful solvent of identity, a modality that expands the consciousness through shock and surprise. If this is right, then bisexuality may be the sexual identity that best reflects the oxymoronic nature of all sexual identity, insofar as bisexuality, too, is a contradiction, a class and its own dissolution. This may explain why explanations of bisexuality that seek to tame bisexuality within the bounds of Cartesian reason will always feel anxiously incomplete.

But this has consequences for the law, which is often a project that privileges such reason. It may mean that if we are concerned about the "logical" regulation of sexuality as failing to respect sexuality's fluid and narrative nature, we might do worse than to begin by looking at the sexual identity - bisexuality-that best represents that nature. Properly harnessed, bisexuality's destabilizing force may be a powerful means of contesting that regulation. 